University of Rhode Island

DigitalCommons@URI

Open Access Dissertations

1980

\title{
An Investigation of Grief and Adaptation in Parents Whose Children Have Died from Cancer
}

Therese Ann Rando

University of Rhode Island

Follow this and additional works at: https://digitalcommons.uri.edu/oa_diss

\section{Recommended Citation}

Rando, Therese Ann, "An Investigation of Grief and Adaptation in Parents Whose Children Have Died from Cancer" (1980). Open Access Dissertations. Paper 1126.

https://digitalcommons.uri.edu/oa_diss/1126

This Dissertation is brought to you for free and open access by DigitalCommons@URI. It has been accepted for inclusion in Open Access Dissertations by an authorized administrator of DigitalCommons@URI. For more information, please contact digitalcommons-group@uri.edu. 


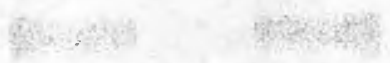

AN INVESTIGATION OF GRIEF AND ADAPTATION

IN PARENTS WHOSE CHILDREN

HAVE DIED FROM CANCER

BY

THERESE ANN RANDO

A DISSERTATION SUBMITTED IN PARTIAL FULFILLMENT OF THE REQUIREMENTS FOR THE DEGREE OF

DOCTOR OF PHILOSOPHY

IN

PSYCHOLOGY

UNIVERSITY OF RHODE ISLAND 


\section{ABSTRACT}

In an effort to investigate parental experience and adaptation, to a child's terminal illness, fifty-four parents (twentyseven married couples) were administered a structured interview and two objective instruments: the Grief Experience Inventory (Sanders et al. 1978) and the Parental Experience Assessment Form (Rando 1979) from two months to three years following the death of their child from cancer. The parental grief experience was analyzed with respect to the variables of: support received during the illness, the influence of previous loss, the length of the child's illness, the length of time since the death, the sex of the parent, the parent's satisfaction with the child's treatment experiences, parental anticipatory grief, and the amount of parental participation during the child's hospitalizations. Chief among the results are the findings that there appears to be a phenomenon in the third year of bereavement which is associated with an intensification of the grief experience and suggests that parental bereavement may actually worsen with time. Other findings indicate that there are "optimum" amounts of anticipatory grief, participation with the hospitalized child, and lengths of illness, below and above which parental adjustment is compromised. Mothers appeared to sustain grief experiences reflective of higher degrees of intensity and poorer adjustment as compared to fathers, although only 
to a statistically significant, level on the variables of somatization and number of participation behaviors during the child's hospitalizations. Parents appeared overwhelmingly satisfied with their child's treatment experiences. The amount of support received during the illness of the child had a mixed effect upon the parents' grief and adjustment. Previous loss tended to be associated with poorer bereavement outcomes, although not to a statistically significant level. 


\section{DEDICATION}

This dissertation is dedicated to PARENTS:

the fifty-four who participated

in this investigation and shared

their grief in order that others may be helped

and

the two who gave me

life and love 


\section{ACKNOWLEDGMENTS}

The author owes a debt of gratitude to a number of people who have contributed to making this dissertation, and the graduate school experience it culminates, possible. Mere mention of their names would be unacceptable to her and therefore the following personal acknowledgements are made. With the exception of the first and last groups of individuals, those mentioned are in alphabetical order since prioritization was impossible.

This entire investigation would have been impossible in most medical centers and therefore the support received from the staff of the Pediatric Hematology-Oncology Department at Rainbow Babies and Childrens Hospital deserves not only gratitude but admiration in their endorsement of the study. Dr. Samuel Gross, chairman, and Drs. Elizabeth Kurczynski, John Graham-Pole, and Susan Shurin gave not only advice, verbal support and encouragement, but participated in the enlisting of subjects for the study. Dr. Gross voluntarily secured the financial assistance necessary in order to enlist the assistance of the pediatric nurse whose participation was so vital to the study. These physicians clearly destroy the stereotypical myth of the oncologist who forgets about the "failures" once they die. The highest accolade that can be paid to them is that this author would be secure in trusting her own children to this excellent and unparalleled team.

Other individuals related to the Pediatric Hematology-Oncology 
Department include most notably Ms. Susan Holland, R.N. Ms. Holland contacted the vast majority of parents in the study and coped with the attendant pain when she recontacted these parents whose children she had come to know and love. It was quite a stressful experience for her emotionally, yet her dedication to the purpose of this study caused her to continue. She gave of herself and her technical knowledge to the author and the study in measures which are indescribable, and were, indispensable.

The secretaries in the Department deserve great appreciation for their assistance, patience, and support. This appreciation goes to Ms. Marge Bruch, Ms. Sandy Hartman, and Ms. Kathy Donner.

Heartfelt appreciation and thanks must go to:

Dennis Drotar, Ph.D., who not only helped organize the study and secure its approval, but served as a model for the author of the "clinician-researcher." The investigation could never have taken place if not for him.

Bettine Fitzgerald-Costa, ACSW, who enabled the author to have "a good ending," survive her own griefs, and learn the art of therapy from a master.

Lawrence Grebstein, Ph.D., who, as advisor and major professor, not only guided the author with her research, but was there to assist with the numerous trials and tribulations occurring within the five years of graduate school. Special thanks necessarily go to him.

Louis Hafken, M.D., who psychologically supported the author's writing during times that had been committed to his employ and who understood that naive researchers may be unrealistic in their judgments of how long it will take to complete a dissertation. 
Karen Heise, who, with unexpected and extraordinary concern, set in format and typed the final draft of the manuscript.

Pamela Hoose, who not only typed the original drafts of the manuscript, but tolerated the moaning and groaning that accompanied that phase. She has been a very special and caring friend.

Lee Ann Johnston, R.N., who always lent an ear when the pressure was intense and who had the faith to endorse the hiring at Providence Psychiatric Associates, Ltd.

J. Eugene Knott, Ph.D., who, as both mentor and friend, has given this author invaluable support, knowledge, and encouragement in both the personal and professional realms. Words cannot express his influence upon the author who has found him to be the most significant individual and source impacting upon her pursuits in the area of loss. For his tutelage and friendship she is forever grateful.

Albert J. Lott, Ph.D., who, more than anyone else, has continued to urge the promulgation of this data for the lay public and, hence, supports the author's basic desire. For continued support during undergraduate and graduate school, Dr. Lott and Dr. Bernice Lott both stand out.

James L. Mack, Ph.D., who assisted with the initial formulation of the study, critiqued the instrument, provided a model for the "clinician-academician" role of the psychologist, taught the author to "think," and provided one of the best-timed clinical interventions ever in the life of the author.

Peter F. Merenda, Ph.D., who struggled to teach this author statistics on both the undergraduate and graduate levels and who had the infinite patience required to do it. Special thanks for the extra 
time given and guidance provided. It was above and beyond any expected responsibility of a committee member.

A. J. Nookie, friend and companion, who served the very important function of "being there" during the writing of the dissertation.

Catherine M. Sanders, Ph.D., who shared with the writer crucial information on the research of bereavement and whose personal support and encouragement was unwavering during times of dissertation despair. Dr. Sanders served as a model which assured that such a thing as studying grief could actually be done.

John F. Stevenson, Ph.D., who had the author sit down and look at her data common-sensically, which resulted in a major finding theretofore unnoticed. "His continued support and friendship of the last seven years is gratefully appreciated.

Family have been important in their support of this writer. Therefore, for significantly "being there" at some very crucial times, the author extends her appreciation and love to: Ms. Mary Rando Mancini; Mr. and Mrs. Joseph D. Morris, Sr.; Miss Rita Rando; Mr. and Mrs. Samue1 Rando; Mr. and Mrs. Joseph Franco; and Mr. and Mrs. Robert Tesoro. Special mention must be made of Thomas A. Rando, Jr., who has been uniquely supportive and helpful and who alone can answer the burning question of "Who's we?" Thanks for keeping, "being a TAR" alive.

And finally, for the three single individuals most responsible directly or indirectly for this dissertation:

Mr. Philip Maini, Jr., who alone was most responsible for the author's entering into the field of psychology, who was one of the three biggest supports during her own intense period of grief, and 
whose death leaves her with an irreplaceable loss. "Tenna Bahooda!" Ricky, with whom the author "grew up," who was most significantly involved during the crises of parental loss, who as "brother," lover, and friend shared in relationship such that to this day is a viable and meaningful force in the life of the writer and who, with "the little people," belongs forever in her heart.

And Anthony, my best friend. 
TABLE OF CONTENTS

ABSTRACT . . . . . . . . . . . . . . . . . .

DEDICATION . . . . . . . . . . . . . . . . . . . iv

ACKNOWLEDGMENTS . . . . . . . . . . . . . . . . . . . v v

LIST OF TABLES . . . . . . . . . . . . . . . . . . xii

LIST OF FIGURES . . . . . . . . . . . . . . . . . . . $\quad x i v$

Chapter.

I. JUSTIFICATION FOR AND SIGNIFICANCE OF THE STUDY . . . . 1

II. REVIEW OF LITERATURE . . . . . . . . . . . . 8

III. METHODOLOGY . . . . . . . . . . . . . . . 48

Subjects

Setting

Procedure

Instruments

IV. RESULTS . . . . . . . . . . . . . . . . . 65

Obtaining Results

General Analysis of the Data

Scoring of the Data

Hypotheses

V. DISCUSSION .......................

Personal Characteristics Influencing Parental

Experience and Adaptation

Time Factors Influencing Parental Experience

and Adaptation

Parental Experience During the Illness

Limitations of the Study

Emotional Reactions of the Investigator

VI. SUMMARY . . . . . . . . . . . . . . . . .

Implications for Future Research 


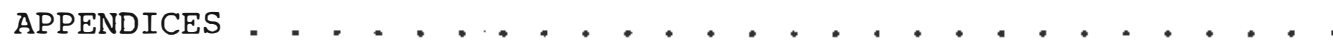

1. Grief Experience Inventory

2. Parental Experience Assessment Form

3. Structured Interview Topics

4. Parental Consent Form for Participation in Investigation

5. Original Version of Parental Experience Assessment Form

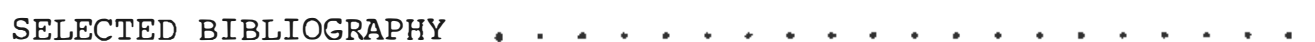




\section{LIST OF TABLES}

1. Parental Socioeconomic Profiles... . . . . . . . . 54

2. Medical Profiles for Deceased Children . . . . . . . . 57

3. Support Received by Parents and Perceived Subsequent

Adjustment .. . . . . . . . . . . . . 69

4. Support Received by Parents and Atypical Responses

Subscale Scores ................. 70

5. Number of Losses Previously Coped With Successfully and

Parental Ratings of Subsequent Adjustment . . . . . . . 71

6. Number of Losses Previously Coped With Successfully and

Numbers of Anticipatory Grief Behaviors . . . . . . . 72

7. Pre-Morbid Coping and Subsequent Adjustment . . . . . . 73

8. Length of Illness and Preparedness at Death . . . . . . 74

9. Length of Illness and Anger/Hostility Scores . . . . . . 75

10. Length of Illness and Atypical Responses Scores . . . . . . 76

11. Length of Time Since Death and Loss of Control Scores . . . . 77

12. Length of Time Since Death and Despair Scores . . . . . . 79

13. Length of Time Since Death and Depersonalization Scores . . 80

14. Length of Time Since Death and Somatization Scores ..... 81

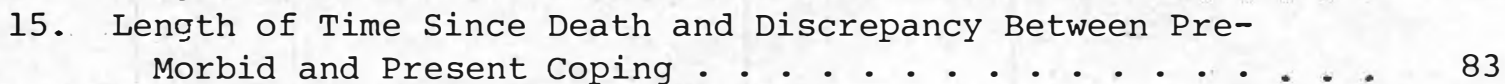

16. Length of Time Since Death and Anger/Hostility Scores . . . . 84

17. Length of Time Since Death and Atypical Responses Scores . . 85

18. Length of Time Since Death and Rumination Scores . . . . 87

19. Length of Time Since Death and Ratings of Subsequent
Adjustment . . . . . . . . . . . . . . . 88

20. $t$-Values for Differences Between Males and Females and
Means for Subscales of the Grief Experience Inventory . . . 92

21. Parental General Overall Satisfaction with Child's
Treatment Experiences and Anger/Hostility Scores . . . 93

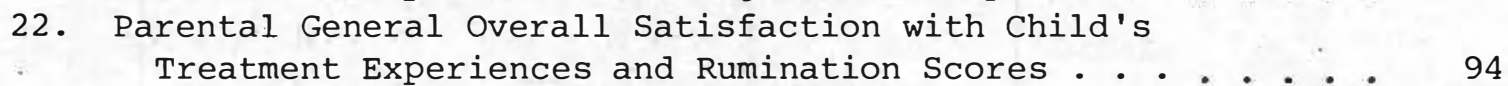

23. Number of Anticipatory Grief Behaviors and Ratings of
Preparation at Death . . . . . . . . . . . . . 9 95

24. Number of Anticipatory Grief Behaviors and Ratings of
Subsequent Adjustment . . . . . . . . . . . . 9 96

25. Number of Anticipatory Grief Behaviors and Support
Received During Illness . . . . . . . . . . . . . 97

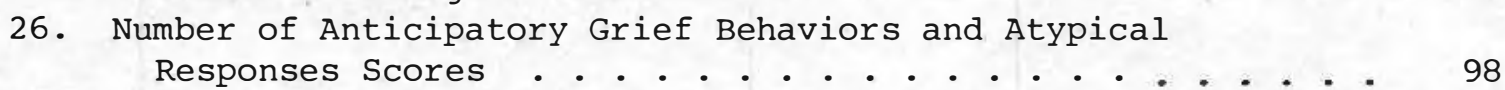

27. Number of Anticipatory Grief Behaviors and Anger/
Hostility Scores . . . . . . . . . . . . . . 9 99

28. - Number of Anticipatory Grief Behaviors and Loss of
Control Scores 
29. Number of Behaviors Participated in by Parents During the Child's Hospitalizations and Parents' Ratings of Subsequent Adjustment . . . . . . . . . . . . 101

30. Number of Participation Behaviors and Anticipatory Grief Behaviors Engaged in by Parents . . . . . . . . . 102

31. Number of Participation Behaviors and Rating of Satisfaction with Child's Treatment Experiences . . . . 103

32. Number of Participation Behaviors and Ratings of

Satisfaction with Involvement with Child . . . . . . . 104

33. Number of Participation Behaviors and Rumination Scores . . 105 


\section{LIST OF FIGURES}

\section{Figure}

1. Mean GEI Subscale, Subsequent Adjustment, and Discrepancy Scores for Parents in Three Time Periods 


\section{CHAPTER I}

\section{JUSTIFICATION FOR AND SIGNIFICANCE OF THE STUDY}

The major justification for this study lies in the crucial need for systematic study of the processes and sequelae of parental grief. Although the grief of children who lose their parents has been relatively well researched, little attention has been paid to parental grief. Objective data concerning parental grief is particularly needed in view of the deleterious and malignant effects that can result from unresolved and inappropriate grief. These sequelae of inappropriately resolved grief have been well documented in clinical observations (Cain and Cain 1964; Gorer 1965; Wallace 1967; Binger et al. 1969; Alby and Alby 1970; Townes, Wold and Holmes 1974). Recently Heller and Schneider (1978, p. 321) delineated some of the disturbing statistics:

A terminal illness has a devastating impact on both individual family members and on the family unit itself. David Kaplan, in a recent three-year study of forty families at Stanford Medical School, found that thirtysix out of the families (90\%) were seriously disrupted by the critical illness of a child in the family. For example, twenty-eight of the families (70\%) reported serious marital problems. Moreover, since the end of the study, nine of the couples have been divorced (23\%). Approximately half the siblings (43 of 97 surviving children=44\%) experienced adjustment problems, parent-child problems, and school problems. In eighteen families (45\%), at least one parent had a serious drinking problem. There were fifteen families (38\%) with at least one member under psychiatric treatment (although no one had been in therapy prior to the diagnosis) and families (16\%) reported new medical problems such as ulcers, high blood pressure, and asthma. 
The most common difficulty, which occurred in 88 per cent of the families, was extreme grief, which took such forms as enshrining the room of the deceased child, building locked cabinets to house the child's effects, making daily visits to the cemetary, or prohibiting any mention of the child (Kaplan, 1973; 1974). Other studies have produced similar findings (Solnit and Green, 1959; Binger et al., 1969).

Although they are relatively few in number, there have been some studies examining the experience of parents whose children are dying, although little has been written on parental bereavement after the death. However, the previous studies that have been conducted have led to results that are often inconsistent in findings and emphasis, and often based upon subjective clinical observation without objective, valid or reliable measures of adjustment. Moreover, these investigations were generally conducted prior to the advances in the treatment of cancer, which has become more of a chronic, life-threatening illness in recent years. Recent developments in treatment are reflected in altered familial lifestyles, treatment regimens, life expectancies, and disease process. In addition, these studies have tended to slight the investigation of the experiences of fathers. For these reasons, the results of the initial pioneering studies are less applicable to present clinical reality. Their neglect of research on parental bereavement subsequent to the death leaves a lack of information about the post-death grief experiences and adaptations of parents. It is in response to the aforementioned deficits that the present investigation was conducted. It provides empirical data in a field which presently lacks empirical justification for the psycho-therapeutic interventions proposed and utilized. It is 
anticipated that this data will generate further hypotheses for future experimental manipulation in studies with families of terminally ill children. The ultimate hope is to learn what will provide the maximum support for the children, their parents, families, and caregivers.

The eight hypotheses to be tested and the thirty-one predictions they generated are as follows:

(1) The amount of support received during the terminal illness is related to the post-death grief experience: Prediction 1A: There will be an association between the support reported by parents and their own ratings of subsequent adjustment to the death. Prediction 1B: The more support received by each parent, the less will be the number of Atypical Responses on the Grief Experience Inventory of that parent.

(2) Previous loss influences grief:

Prediction 2A: There will be an association between parental losses previously coped with successfully and parental ratings of subsequent adjustment. Prediction 2B: There will be an association between previous losses successfully coped with and the number of anticipatory grief behaviors engaged in by the parent. Prediction 2C: There will be an association between the pre-morbid coping style of each parent and their ratings of their subsequent adjustment following the death. 
(3) Length of illness influences parental grief:

Prediction 3A: There will be an association between the length of time from diagnosis until death and the parental ratings of preparedness at the time of death. Prediction 3B: The longer the interval between diagnosis and death, the lower will be the subscale score of Anger/ Hostility on the Grief Experience Inventory profile. Prediction 3C: The longer the interval between diagnosis and death, the lower will be the subscale score of Atypical Responses on the parents' Grief Experience Inventory profiles.

(4) The length of time since the death affects the intensity of parental grief:

Prediction 4A: The longer the length of time since the death, the lower will be the parental subscale score of Loss of Control on the Grief Experience Inventory. Prediction 4B: The longer the length of time since the death, the lower will be the parental subscale score of Despair from the Grief Experience Inventory. Prediction 4C: The longer the length of time since the death, the lower will be the parental subscale score of Depersonalization on the Grief Experience Inventory. Prediction 4D: The longer the length of time since death, the lower will be the parental subscale score of Somatization on the Grief Experience Inventory. Prediction 4E: The longer the length of time since the death, the more discrepant will be the parental comparisons 
between pre-morbid coping.

Prediction 4F: The longer the length of time since the death, the lower will be the parental subscale score of Anger/Hostility on the Grief Experience Inventory. Prediction 4G: The longer the length of time since the death, the lower will be the parental subscale score of Atypical Responses on the Grief Experience Inventory. Prediction 4H: The longer the length of time since the death, the lower will be the parental subscale score of Rumination on the Grief Experience Inventory. Prediction 4I: The longer the length of time since the death, the higher will be the parental ratings of subsequent adjustment.

(5) The sex of parents is related to their grief experience: Prediction 5A: There will be a significant difference between the mean subscale scores of mothers and fathers on the Grief Experience Inventory.

(6) Parental evaluation of the child's treatment experience is related to parental grief experiences:

Prediction 6A: The more positively the parents evaluated their general overall satisfaction with their child's treatment experiences, the lower will be their subscale score of Anger/Hostility on the Grief Experience Inventory.

Prediction 6B: The more positively the parents evaluated their general overall satisfaction with their child's treatment experiences, the lower will be their subscale 
scores of Rumination from the Grief Experience Inventory .

(7) Anticipatory grief is related to post-death grief experience:

Prediction 7A: There will be an association between the number of anticipatory grief behaviors engaged in by the parent prior to the death and their ratings of preparedness at the time of death.

Prediction 7B: There will be an association between the number of the anticipatory grief behaviors engaged in by the parent prior to the death and their ratings of subsequent adjustment since the death.

Prediction 7C: There will be an association between the number of anticipatory grief behaviors engaged in by the parent prior to the death and the support they received during the terminal illness.

Prediction 7D: The greater the amount of anticipatory grief behaviors, the less will be the subscale score of Atypical Responses from the Grief Experience Inventory. Prediction 7E: The greater the amount of anticipatory grief behaviors, the less will be the subscale score of Anger/Hostility from the Grief Experience Inventory. Prediction 7F: The greater the amount of anticipatory grief behaviors, the less will be the subscale score of Loss of Control from the Grief Experience Inventory.

(8) Parental participation in the care of the dying child is related to post-death grief experience: 
Prediction 8A: There will be an association between the amount of behaviors involving the care of the hospitalized child which the parents participated in and the parental ratings of subsequent adjustment.

Prediction 8B: There will be an association between the amount of behaviors involving the care of the hospitalized child which the parents participated in and the amount of anticipatory grief behaviors engaged in. Prediction 8C: There will be an association between the amount of behaviors involving the care of the hospitalized child which the parents participated in and the positive ratings of parental satisfaction with the child's treatment experiences (evaluation of child's treatment experiences).

Prediction 8D: There will be an association between the amount of behaviors involving the care of the hospitalized child which the parents participated in and the parent's ratings of satisfaction with their own involvement with their child.

Prediction 8E: The more the parents participated in the care of the hospitalized child, the lower will be the Grief Experience Inventory subscale score of Rumination. 
CHAPTER II

REVIEW OF LITERATURE

Although in recent years there has been a burgeoning of interest in the topics of dying, death, and bereavement, and there has been an astronomical increase in the number of studies and investigations of these topics, there has been a strange reluctance to address the topic of childhood terminal illness with the same vigor. There has been even less investigation of the reactions and experiences of the parents of the terminally ill child. There is, however, no lack of agreement that such studies are warranted and it is far from uncommon to see such research advocated in the conclusions of other investigations and descriptions of reactions to loss and/or childhood terminal illness.

One might hypothesize about the reason for most of the research falling within the realms of grief and childhood to be devoted to the study of the child whose parent dies, and not to the reverse. Perhaps the "magical thinking" of childhood, wherein there is the fear that if one thinks or says something it will come to pass in reality, is not restricted solely to the young child. The relatively conspicuous lack of investigation in the area of parental response to childhood terminal illness may attest to this possibility. 
Furman (1976, pp. 233-234) addressed the particular diffi-

culties inherent in the processes of mourning for one's child.

Although written to describe the grief of parents over the death of

a newborn, the same issues are salient in a parent's grief over

the loss of an older child. (See below)

Mourning, a silent intrapsychic process, consists on the one hand of detaching ones emotional ties from the image of the deceased loved one and on the other hand of changing one's own image, to an extent, so as to become like the deceased, that is, identifying with some aspects of his personality. . . In mourning an infant a parent faces a particularly difficult task because (1) he can only utilize the painful long process of detachment, since identification would not prove adaptive (how can a parent become part child again?) and (2) he deals not only with the loss of a loved one but also with a loss of a part of himself (parental attachment consists of a mixture of object love and self-love).

Schwartz (1977, p. 196) continues the psychoanalytic

description of the dynamics of the parent-child relationship and concludes:

- . with the death of a child in the family the blow is felt narcissistically, and as a threat to the sense of our immortality. . . . The bereavement for the child is intimately connected with, and related to, the libidinal investments. The child serves as a tie with the traditional past, but also, and perhaps more importantly, with the future and with our sense of immortality.

Jackson (1977, p. 187) provides further discussion of the reason for the unique difficulties inherent in the loss of a child:

Physiologically, psychologically, and socially, the relationship that exists between parents and their children may well be the most intense that life can generate. Obviously, then, vulnerability to loss through death is most acute when one's child dies.

Not only is the death of a child inappropriate in the context of living, but its tragic and untimely nature is a basic threat to the function of parenthood--to preserve some dimension of the self, the family, and the social group. 
Kliman (1977, p. 191) discusses the "victimization" of the parent

who loses a child:

Parents who lose a child are multiply victimized. We are victimized by the realistic loss of the child we loved, we are victimized by the loss of the dreams and hopes we had invested in. that child, and we are victimized by the loss of our own self-esteem. Not unlike the survivors of the concentration camps, we cannot comprehend why we did not die instead.

Previously, in 1967, Wallace had keyed into the same experience of victimization, noting in his description of bereaved parents that they were "victims of an overwhelming assault on their parental identities as protectors and providers." And Stephens (1977, p. 211) puts the process in physical terms:

The sense of mutilation (for bereaved parents), the feeling of being disabled is very strong. It is no exaggeration when parents compare this phase in their bereavement to the imagined pain accompanying the loss of a limb (Murray Parkes, 1972).

And lest the parents' pain is believed to be exclusively experienced by themselves, Cain and Cain (1964) describe parental grief rippling out toward the young and unprotected siblings of the dead child, as well as those yet unborn, i.e., the "replacement child."

There is great social concern over the death of a child. Kalish (1969, p. 102) discusses several reasons why the death of the young child seems to cause so much additional stress as compared to that of an older individual. He notes that:

The life of a child has great social value. He has not had a chance to live, and we feel he is entitled to this. Also, his general helplessness moves us. . . Another factor is that we do not attribute the death of a child to "his own fault," to inevitability, or to a 
style of living of which we disapprove. . . The child who dies in contemporary American society is not considered mature enough to be responsible for behavior leading to his death, and, unlike the elderly man, he cannot be considered to have died inevitably.

Glaser and Strauss (1964) also point out the greater loss of a child, since the child has not had the opportunity to live a full life as compared with the adult or aged individual. They note that such an evaluation may be responsible for the better quality of care and personal treatment given to children by nurses.

There is controversy over whether age of the child is an important determinant in the parent's grief. Schiff (1977, p. 4) disagrees that it is an important variable:

Bereaved parents come in all ages. It does not appear to make a difference whether one's child is three, thirteen, or thirty if he dies. The emotion in each of us is the same. How could it be that a parent outlives a child?

Thus, the "unnaturalness" is not determined by the age of the child, but by the role of this person who dies "out of turn" with the parent.

However, the writing that is done about the age of the child appears to form a concensus that the older child's death poses the most difficult situation for the survivors.

In 1965 (pp. 121-122), Gorer wrote about the universal experience of parents, while articulating his finding that the loss of a grown child was the most difficult:

The most distressing and long-lasting of all griefs, it would seem, is that for the loss of a grown child. In such a case it seems to be literally true, and not a figure of speech, that the parents never get over it. I can only speculate as to why this should be so, for most of my informants were not very articulate. First, it would appear that, at least in time of peace, it is "against the order of nature" that a child should die before his or her 
parents. . . Second, although a person's social status is in no way modified by the death of a grown child, it seems as though their self-image may be destroyed. . . Perhaps a reliance on the orderliness of the universe has been undermined.

In 1977, three authors wrote about the difficulty of losing

a teen-aged child. Delineating how psychoanalytic issues predispose the parent to have an additional burden of guilt, Schwartz (p. 195) noted that "It appears that the effects of the death of an adolescent child or young adult is exceptionally intense." Schneidman (p. 75) asserted, "To die of cancer in one's teens or twenties, in college, seems a particular 'unfair' and tragic thing." Kalish (pp. 219-220) wrote:

In our society, the death of young adults is viewed as the most tragic of all (Kalish and Reynolds, 1976). They have not yet been able to.make use of the lengthy schooling they undertook; their deaths are often sudden and unexpected; they are seen as having been deprived of their birthright. And since they are often younger than the rest of us, their death brings our own finitude painfully close to home.

However, as if to reflect the fact that the death of a child, no matter what age, is crucial, Kalish (p. 220) adds the following:

Infants or young children have a small network of social interactions, have no one dependent on them (except as someone to love and to give to, which is certainly a very significant role), and--if young enough--do not comprehend the process of dying. On the other hand, the love given to them, the vulnerability that they display, and the seeming meaninglessness of their death cause many people to view such an event as the most tragic of all.

Therefore, although researchers may argue as to the critical ages, the question is academic and most probably meaningless to the parent who has lost their child, parts of their self and their future. Studies comparing parents with other bereaved individuals in a different relationship to the deceased, e.g., spouse, child, etc., find that the grief of parents is particularly intense. 
Clayton, Desmarais, and Winokur (1968) found that parents of deceased children appeared to respond most severely when compared to other bereaved individuals and that they report considerably more irritability and self-condemnation. Schwab et al. (1975) found in their study that significantly more parents and spouses were rated as grieving intensely. In 1977, Sanders interviewed one hundred and two bereaved individuals and found that the death of a child produced the highest intensities of bereavement as well as the widest range of reactions. Parental grief resulted in more somatic reactions and greater depression, anger, guilt, and despair than did the mourning of those subjects who had lost either a spouse or a parent.

In reviewing the literature on the quasi-experimental and descriptive studies that have been undertaken to research the experience of parents of terminally ill children there is consistent repetition of eleven investigations which form the backbone of the research on the topic. These studies and their major findings will be summarized here. Following this there will be a survey of literature pertinent to the eight major independent variables, commencing with a general literature review and concluding with a survey of that literature specific to parents of terminally ill children.

\section{Major Investigations of Parents of Terminally Ill Children}

In 1955, Bozeman, Orbach, and Sutherland chronicled the adaptation of twenty mothers of children with acute leukemia. Information was derived from interviews with and observations of the mothers. Subsequent to the interviews nine mothers were able to be tested on the Thematic Apperception Test (see Orbach 1955). 
Among their major findings Bozeman et al. reported that the initial diagnosis of leukemia was so devastating that the mothers could only describe their reactions in terms of a physical injury to themselves, e.g., a "blow." Following this was a period of overactivity with frantic attempts to prove the doctor and the diagnosis incorrect. Denial occurred in two ways: through screening out of the reality of the situation and compulsive efforts to reverse it. The nature of adaptation to the diagnosis was modified by the manner in which the doctor delivered the diagnosis. It was especially helpful if hope was offered and they participated in the treatment planning. Many of the mothers expressed feelings of guilt and personal responsibility for the illness of their children. After the diagnosis mothers tended to want their child hospitalized immediately in order to receive better treatment and to demonstrate the fallacy of the diagnosis. However, as the time of hospitalization grew near, mothers tended to experience increasing separation anxiety. This hospitalization implied probable later permanent separation. Separation anxiety for the mother varied with the meaning of the child in her life and her resources for integrating the experience. The mother's fearfulness would tend to increase her child's anxiety which in turn would exacerbate her own fear. Once treatment was started many mothers attempted to cope by intellectual mastery of the disease. After the initial period of urgency this striving to learn as much about the disease as possible ceased, with the mother shifting concern to the child's immediate medical condition and treatment. As time progressed there was a rejection of hope on an intellectual basis. Affectively, some degree of hope continued until the end stage. 
They describe parts of the mourning process in the normal person as including: withdrawal, feelings of unworthiness, preoccupation with thoughts of earlier experiences with the loved one for a period of time (usually several weeks), guilt over parental responsibilities for the development of the illness, and emptiness. Separation and its irreversibility is a major concern of the parents. Depression or marked anxiety may accompany the initial impact of the diagnosis, yet the authors note that the period of illness prior to the death may be one of re-integration "of parental feelings in which the mourning process takes place substantially prior to the death of the child," i.e., anticipatory grief. Richmond and Waisman (p. 45) also found that parental involvement in the physical care of the child was:
- . extremely important in facilitating parental adapta- tion. First, this permits the parents to have a feeling that they personally have done everything possible for this child; second, feelings of guilt are somewhat relieved by the expendi- ture of personal effort in the care of the child; third, in retrospect parents are very grateful for having had the op- portunity to spend as much time with the child as was possible; and fourth, an opportunity to observe and to participate in measures directed to relieve pain and discomfort as much as possible is comforting to parents.

In this study the authors also document the development of parental capacities to care for other children on the ward. Initially they were involved solely with their own child. After a period of time they developed a desire to help other children as effectively as they could. The authors interpret this as marking a turning point for parents in their adjustment which reflected an acceptance of their child's illness and ultimate death. This conversion of energy from mourning to more constructive endeavors is viewed by them as signalling the end of mourning, in accordance with Freud's (1917) criteria for the termination of mourning. The authors take the 
opportunity at the end of the study to enjoin parents from participation in the care of the sick child at the expense of the emotional and physical well-being of the remainder of the family. They also report in conclusion that the hospital staff accepted and understood the need for parental participation in the care of the terminally ill child.

Solnit and Green (1959) discuss psychologic assistance for the family of the terminally ill child at various points within the terminal illness. The physician is advised to repeat the diagnosis as often as warranted by the admixture of denial and shock present in the parents. The physician is admonished against stating definite time trajectories and cautioned against censure of the parental reactions. Parents are expected to be offered the opportunity to be at hand when death is imminent and to be promptly informed by the physician when it has occurred. Methods of dealing therapeutically with the parents and siblings post-death are discussed with emphasis upon the unique feelings of those family members generated by their specific roles and ages.

Thirty-three children with leukemia were studied by Natterson and Knudson (1960) as were their mothers. Observations of the mothers indicated that as a result of the nature of the maternal-child relationship, the threat of death of the child posed a symbolic threat of death to the mother. Consequently, the authors hypothesize, the mother faces death, experiences it, and survives it. The reactions elicited in the mother, by the symbolic threat of death, will be influenced by the mother's acute contact with death and her knowledge that she herself will survive 
it. The Natterson and Knudson study is an attempt to isolate and examine the mother's reactions to this death threat. The findings revealed that, when the disease lasted four months or more, the mothers reacted to the illness with a tri-phasic response. The situations where the interval between diagnosis and death was less than four months resulted in more disturbed reactions on the part of the mothers. The tri-phasic process consisted of an initial phase, wherein denial was the characteristic emotion and there was a tendency towards irrational initial reactions; the intermediate phase, where there was manifested a tendency to more readily accept reality and to direct energy toward realistic measures that offered hope of prolonging the child's life, while emotionally starting to separate themselves from the child; and the terminal phase, in which increased sublimation is noticed and the mother's interests expand and suggest the development of socializing tendencies, with interests less focused upon her child. A calm acceptance of the death of the child accompanied by improved integration also characterized the terminal phase.

These same authors (Knudson and Natterson 1960) also wrote on the participation of parents in the hospital care of their fatally ill children. In this paper they again describe the aforementioned process of adjustment to the child's illness. They then argue that the mother's participation in the care of her hospitalized child "facilitates the resolution of her guilt and denial, which are so characteristic at the outset of the "child's illness." In addition they are enabled to cope with their own separation anxiety. Not summarized in this review is the observations on the child's adjustment and the description of the program at the City of Hope Medical 
Medical Center in Duarte, California, wherein both investigations took place, with both topics having been addressed in each study.

An investigation using behavioral observations of parents anticipating the death of a child was funded by the National Institute of Mental Health and reported by Friedman, Chodoff, Mason, and Hamburg in 1963. They observed forty-six parents of twenty-seven children and conducted a series of interviews. Further information was garnered from the parents through a brief daily questionnaire and from weekly parent meetings. Findings indicated that although a number of parents stated they suspected the diagnosis prior to discussion with the physician, they nevertheless were "stunned" and felt that it came as a shock to receive the diagnosis. In this study, as contrasted to some others, the subjects initially accepted the diagnosis intellectually and it was only later that they consciously hoped that the diagnosis was in error. They did not manifest the disbelief and marked denial of other populations. Subsequent to the diagnosis most of the parents experienced transient guilt over their child's illness which was assuaged, for the majority of them, by the reassurances of the physician. During the early stages following the diagnosis this group too attempted to attain mastery over the threat through an insatiable thirst for knowledge about the disease and attendant concerns. Most of the parents in this study attempted to shield their child from information about his condition. Some of the younger children openly rejected their parents who they seemed to blame for being negligent in protecting them. This resulted in guilt and feelings of failure on the part of these parents. Major coping mechanisms of the parents included: isolation of affect, 
intellectualization, denial, motor activity, and participation in the care of the child. Relatives and friends tended to hinder the adaptations of the parents in this study. Their denial, disbelief, and expectations which they placed upon the parents served to increase rather than decrease the stress. Most parents felt that their strongest support came from other parents of terminally ill children. In the terminal phase these parents commenced grieving more intensively, became more resigned to their child's imminent death, and became more actively involved in the care of other children. Chodoff, Friedman, and Hamburg (1963) authored another article about results from this same study. In this there was much overlapping information with the aforementioned article. However, in this second article (p. 743) they more strongly assert that most parents - . were able to function effectively during the period of the illness, carrying out whatever tasks were necessary without being overwhelmed with despair or anxiety, at the same time preserving their own personalities, maintaining key relationships and a measure of self-esteem.

Another important process that occurred during this time was the parents' "search for meaning." These parents had an urgent need to make sense out of the tragedy and this would take various forms such as seeking out some personal agency to be blamed for the disease or placing it within the realm of "God's Will."

In 1964 Hamovitch demonstrated the results of parental participation in the Pediatrics Department of the City of Hope Medical Center in Duarte, California. His sample consisted of eighty-two children with diagnoses of cancer and their parents. The major sources of information were ongoing social work interviews with parents, weekly interviews with staff members to elicit observations on the 
children and their parents, transcriptions of weekly staff meetings in which social and emotional problems of the families were discussed, follow-up interviews with parents after the death of their child, and individual interviews with staff members regarding their reactions to working in such a setting which included a Parent Participation Program. Results indicated that the Parent Participation Program was an effective means of helping families and children with terminal illness cope in an adequately constructive manner. Data revealed that the marital status of the parents is a significant clue to the ability of the families to cope with their problems and to benefit from parent participation. Differential medical diagnosis had an influence on coping adequacy, with non-operable sarcomas associated with difficulties in adaptation and with relative ineffectiveness of the Parent Participation Program to deal with the anxieties engendered. The age of the child was identified as another important variable, with children beyond the age of ten, and their parents, displaying more difficulties than the younger age groups. In terms of parental reactions to the illness, initially there were feelings of shock and self-pity. They tended to be angry at the referring physicians as well as at fate. This group also displayed guilt over the child's illness, and this was capable of being dissipated by discussion with physicians. During the early phase there was a quest for medical information and a considerable preoccupation with the death. Later this was modified to a concern with more immediate routines and emphasis on having as much time as possible with the child. At the terminal phase came a wish that the child's suffering and the waiting "in limbo" would end. In followup it was noted that the longer the interval between death and 
follow-up interview, the more successfully the family had worked through its grief reactions, thus illustrating the importance of time in mourning. It was found that the first three months were the critical time period, for both positive and negative influences. A close correlation was found between the adjustment pattern of the families during the hospitalization of the child and the family's adjustment pattern subsequent to the death.

Binger et al. (1969) interviewed twenty sets of parents regarding the emotional impact of childhood leukemia on both patient and family. In this retrospective study they found that for many the news of the diagnosis was the hardest blow they had to bear. Their subjects reported a variety of reactions ranging from loss of control to an appearance of composure and resignation. Immediately following the news there was a tendency for parents to express a number of symptoms in the succeeding days and weeks. These gradually subsided and were replaced by acceptance and resolution to meet all the special needs of the child. An interesting finding was that parents with the most negative attitudes toward professional staff were those whose children had the shortest illnesses, thereby indicating the role of time in coming to grips with the crisis. In this study, too, it was found that parents particularly appreciated being allowed to participate in the care of their child and being granted freedom of visiting privileges. Interestingly, although fourteen out of the twenty sets of parents attempted to shield their child from knowledge of his diagnosis, eleven of the children indicated that they had a sense of their impending death. The parents manifested all aspects of anticipatory grief as well as reactive grief following the death. The 
authors were impressed over the amount of silent worry and fear that was generated in the contemplations of some parents of the actual circumstances of their child's death. For this reason they maintain that it is important to discuss with the parents the circumstances of the death in order to offset the cruel parental fantasies which they found to be much worse than actual fact. In terms of support for the parents the authors discovered that the parents supporting of each other depended upon their earlier relationship with one another. Parents of other terminally ill children were viewed as a major source of support:

Easson (1970) compiled the research and outlined the preadult phases of human growth in terms of understanding of personal death and the experiences of dying. He addressed the major issues in the dying process for each age group, as well as discussing the implications of terminal illness for families and treating personnel.

\section{Review of Literature on Variables Investigated}

The eight major hypotheses and the variables they test fall into three main categories: personal characteristics influencing parental experience and adaptation; time factors influencing parental experience and adaptation; and parental experience during the illness. A literature review on each of the eight specific variables within these categories is presented below. A general survey of the literature written on the variable is presented first and is subsequently followed by a review of the literature specific to parents of terminally ill children. 
During the illness the mothers frequently expressed the needs for: (1) tangible services, (2) temporary escape, and (3) emotional support. Burdens most frequently expressed included: (1) financial problems, (2) care of the other children, and (3) transportation difficulties. Parents of other children afflicted with leukemia were cited as the most important source of support. Relatives provided little emotional support to the mothers, in fact, difficulties with maternal grandmothers were common in this sample and contributed to more problems with adaptation for the mothers. Problems relating to the discipline of the terminally ill child were frequently at issue during remission.

Orbach, Sutherland, and Bozeman (1955) in Part II of the previous paper, present a theoretical discussion of the implications of the investigative findings, mostly in terms of psychoanalytic principles. Recommendations for management of mothers of terminally ill children are delineated for the physician, nurse, clinical case worker, and hospital administrator.

In 1955 Richmond and Waisman investigated the psychologic aspects of management of children with malignant diseases. In the study of these forty-eight children they describe the clinical impressions they received about the parents of such children. The authors note that one of the physician's most important roles is to assist the parents with the integration of the tragic event of their child's terminal illness into their life experience (p. 44). They state:

Perhaps at no other time does the previous integration of the personality and of the family unit reflect itself so clearly as it does during the severe emotional stress associated with mourning. 


\section{Personal Characteristics Influencing Parental \\ Experience and Adaptation}

Personal characteristics of the parents were addressed in Hypotheses 2 (Previous Loss Influences Grief) and 5 (The Sex of Parents Is Related to Their Grief Experience).

Numerous writers have suggested that previous loss experience is a determinant of the individual's bereavement and grief. With regard to widows, Parkes (1975, 1972) and Maddison (1968) report that previous life crises (including loss experiences), especially when occurring within a two-year period prior to the bereavement, are significantly related to poorer outcome. It has long been held that early parental loss by death, divorce, or separation will seriously impede the consequent socioemotional development of the child and his/her capacity to handle future losses effectively as well as pave the way for anxiety, the need for defences, and psychopathology (Freud 1926; Bowlby 1973).

Friedman (1967) spoke specifically about parents of dying children and noted that parental adjustment to the illness of their child reflects to varying degrees the parents' previous experiences with illness and death (constituting both "real" and "symbolic" losses), their previous modes of coping with past crises, and the idiosyncratic meaning the child has for the parent. Kennell, slyter, and Klaus (1970) researched the mourning of mothers after the loss of a newborn. They found that high mourning was associated with the previous loss of a baby.

The research in sexual differences as determinants of bereavement has been mixed. Much of the descriptive literature reports 
that the social role of the male and the increased maternal-child involvement during the illness predispose the father to less participation during the child's illness; more suppression of overt grief expression; decreased self-esteem; and feelings of guilt, rejection, and exclusion (Volkart and Michael 1957; Nolfi 1967; Binger et al. 1969; McCollum and Schwartz 1972; Burton 1974b; and Travis 1976). Generally the literature has described the father in less-thandesirable terms.

The more empirical research that is available is mixed in results. In an overview of bereavement research vachon (1976) notes that most of the research has been conducted with women as subjects. Yet she finds that what evidence that is available on males suggests that the risks of bereavement may well be greater for the widower. This finding is similar to that of Glick, Weiss, and Parkes (1974) who discovered that although men appear to move more rapidly toward social recovery following a bereavement (spouse) than do women, they actually move relatively slower toward emotional recovery. They also report that the "proper" male reaction centers around realism and control, hence the findings that compared to women men are more unable/unwilling to display grief; ended any emotional display of grief quicker in terms of length of time after the death; were initially higher in guilt which then decreased; and were more realistic and quicker to accept the death. However, other studies suggest that women usually come out of bereavement worse than men (cited in Parkes 1972) and that sex is not found to be a significant determinant of the outcome of bereavement (Parkes 1975). Clayton, 
Desmarais, and Winokur (1968) Comnl losulls similal lo dianler:s (1977) which indicate that most bereavement symptoms occur more frequently in women, although not usually at statistical levels of significance. The exception to this was the clayton et al. finding that there was a statistically significant difference between males and fomales in the females' greater use of medications and more frequent crying behavior. The empirical research on sexual aifferences among parents of dying children is minimal. Hamovitch (1964) found that fathers evidenced worse subsequent adjustment after the child's death than did the mother. He related this to the mothers' intense participation with the child which he believed facilitated anticipatory grief. In addition he felt that the stereotypical role of the male inhibited appropriate grief expression and grief work. Kennell, Slyter, and Klaus (1970) reported mixed results with fathers at times higher as well as lower than mothers on certain bereavement indicators. Townes, Wold, and Holmes (1974) discovered that fathers were more accepting of the death than were the mothers and that they felt less life change for them subsequent to it as compared to their spouses. Benfield, Leib, and Vollman (1978) found that the mean of the grief experience was significantly higher for mothers than for fathers after the death of a newborn.

\section{Time Factors Influencing parental \\ Experience and Adaptation}

There are two time dimensions which were examined in this investigation. The first time dimension is the Length of the child's Illness (Hypothesis 3) and the second concerns the Length of Time 
Since the Death (Hypothesis 4).

Much of the writing about the length of illness as a deter-

minant in bereavement is enmeshed in discussion about anticipatory grief in the bereavement literature ffor citations see section on Anticipatory Grief). The findings have been mixed. In studying one hundred and two bereaved individuals, Sanders (1977) found no relationship between length of illness and outcome. Clayton, Desmarais, and Winokur (1968) observed that with the exception of anorexia and weight loss there was no significant relationship between the duration of the illness and the prevalence of bereavement symptoms. In studying the widowed, Vachon et al. (1976) found sudden death to result in worse post-death adjustment. Similar findings were reported by Silverman (1972); Glick, Weiss, and Parkes (1974); and Parkes (1975). Maddison (1968) found that sudden death, or death with minimal warning did not necessarily lead to a worse outcome. He also found that a protracted death associated with severe suffering and disfigurement maximized pre-existing ambivalence and lead to feelings of guilt and inadequacy. It appeared to create a greater intrapsychic and physical strain than did sudden death. In the same vein, Gerber et al. (1975) discovered that in a sample of the elderly, chronic fatal illnesses of more than a six-month duration predisposed the bereaved to poorer medical adjustment. Schwab et al. (1975) reported similar results and found that extended illnesses past one year were related to more intense grief reactions subsequent to the death.

With specific regard to the experience of parents of terminally ill children significant changes have occurred in the last two decades. 
Townes and Wold (1977) report that within this time the life span of a child diagnosed with leukemia (the most prevalent of all childhood cancers and the one most represented in this study) has increased from an average of three months to a current median of over twentyone months. They note that this increase subjects the parents to an intensified and prolonged period of anxiety with significant lifechange and family reorganization demanded.

Investigators of parents of terminally ill children are split in their beliefs about the impact of the length of the child's illness. Wolff et al. (1964) measuring the mean urinary 17-hydroxycorticosteroid excretion rate of parents; Kennell, Slyter, and Klaus (1970) investigating parental response to the loss of a newborn; and Benfield et al. (1976) also investigating the grief of parents subsequent to the death of a neonate; all found that the length of the illness (or, in the case of the neonates, the length of life) was unrelated to the parents' experience of grief.

In possible contrast to this, Hamovitch (1964) found that the longest illnesses were associated with the most serious familial problems. Natterson and Knudson (1960); Knudson and Natterson (1960); and Chodoff, Friedman, and Hamburg (1964) found that there was a crucial time period of approximately four months which was required for therapeutic adjustment to the illness and death. If the child died before this optimum four-month period, greater disorganization and poorer adjustment was evidenced by the survivors, in these cases, most usually the mothers. The typical tri-phasic response of initial denial and disturbance; followed by acceptance of the diagnosis but not the prognosis with concomitant initiation of 
anticipatory grief; and finally a "calm" acceptance of the death, was rarely observed in less than a four-month duration of illness. All three investigations generated findings identifying such a process and length of time as necessary for good subsequent adjustment. Related to this were the findings of Binger et al. (1969) which revealed that those parents with the most negative attitudes toward the professional staff were those whose children had the shortest illnesses.

Relatively few studies have investigated the effects of time since the death on the severity of the grief reaction. Many studies have been descriptive in nature in their assessment of the time required for adequate resolution of grief. Lindemann (1944) felt that the majority of grief work could be accomplished in four to six weeks. Contrasting this is Marris' (1958) contention, based on his research with widows, that two or more years are required in order to become reconciled with the death. Glick, Weiss, and Parkes (1974) criticized Lindemann's time period as being far too short and asserted that reaction to grief must be measured in years rather than weeks or months. Relevant statements have been offered by Clayton, Desmarais, and Winokur (1968) who noted that eighty-one percent of their sample were improved in their bereavement symptoms within two to four months after the death; and Gorer (1965) who observed that nineteen percent of his sample felt that the adage about time healing was inappropriate and that they would never get over the death. In general, Gorer felt that the middle stage of grief, which he viewed as comprised of a period of violent grief and disorganization, usually required six to twelve weeks for abatement. Schwab et al. (1975) found that there was no statistical 
differences for intensities of grief reaction over three intervals of time since the death (one to six months, seven to eleven months, and over twelve months). As is readily apparent, there is little consistency among the findings and much to preclude their generalizability since they are clearly not all talking about the same phenomenon at the same time, e.g., some speak in terms of acute grief while others discuss complete reconciliation.

There are only two quasi-experimental studies which address the impact of time on the grief of bereaved parents. Hamovitch (1964) writes that there is a relationship between the length of time since the death and the parents' current adjustment. He finds that the shorter the interval between the death and the interview, the more problems of adjustment are reported by the parents at the interview. Stehbens and Lascari (1974) found that thixty-seven of forty parents were fully recovered from their bereavement symptoms within six months' time.

Paxental Experience During the Illness Aspects of the parental experience during the illness were addressed in Hypotheses 7 (Anticipatory Grief Is Related to PostDeath Grief Experience); Hypothesis 8 (Parental Participation in the Care of the Dying Child Is Related to the Post-Death Grief Experience); Hypothesis 6 (Parental Evaluation of Their Child's Treatment Experiences Are Related to Parental Grief Experience); and Hypothesis 1 (The Amount of Support Received During the Terminal Illness Is Related to the Post-Death Grief Experience). Anticipatory grief was first addressed by Lindemann (1944) 
as a phenomenon which arose in response to separation and accompanying threat of death. The individual is so concerned about their adjustment after the potential death that he/she undergoes the process of grief prior to any actual loss. The result of such a process, while forming a safeguard against the impact of a sudden death notice, could be disadvantageous in allowing the individual to effectively emancipate themselves from the relationship with the separated individual so that, should this person not die, the griever is unable to resume the relationship due to their having effectively decathected themselves.

Rosenbaum (1944) worte about the problems associated with this type of anticipatory grief with the families of individuals in the military service and noted how the survivors were victimized by the unforeseen consequences of anticipatory grief when they returned to families who had established new role relationships that no longer included them.

In 1971 Fulton and Fulton discussed the process of anticipatory grief as a psychosocial aspect of the terminal experience for the patient, the family, and the staff. (For the remainder of this paper discussion of this process will be limited to the experience of the family.) Writing about the family's experience they report (p. 93): . . the family members are so concerned with their adjustment in the face of the potential loss that they slowly experience all the phases of normal grief as they cope with the illness or endure the separation prior to the death. Over an extended period of time, therefore, the family members may experience depression, feel a heightened concern for the ill member, rehearse his death, and attempt to adjust to the various consequences of it. 
After this important article anticipatory grief became a subject greatly addressed in the literature. Both the salutory and detrimental effects of anticipatory grief were debated. For example, Goldberg (1973), in looking at the family tasks and reactions in the crises of death, perceived anticipatory grief as being mourning that was longer in duration but less intense compared to post-death mourning. He noted ( $p$. 405) the positive aspects of anticipatory grief as providing "a powerful family-affective experience" enabling the . family to begin to cope with the necessary tasks of mourning, i.e., allowing mourning to occur, relinquishing the memory of the deceased, and realigning of intrafamilial and extrafamilial roles. The result is that "For the family, mourning becomes a gradual, extended, and less intense process."

This notion coincides with that espoused by Herter in 1969. Herter noted (p. 200) that when grief finds its fullest expression prior to the death it is gradually replaced by a resigned acceptance of the facts.

Death, under these circumstances, comes anticlimatically, without drama. A transient resurgence of grief may ensue, but it is dulled by long months of anticipation. More often, the end is marked by a sense of relief. . . . It is not unnatural that this surpressed relief should be accompanied by feelings of confusion and guilt.

In this, however, are the implications for difficulties arising from the process of anticipatory grief. Herter's description was echoed by the Fultons (1971) in their delineation of the critical judgments from self and others as an unanticipated consequence of anticipatory grief. The Fultons write that by . the time of death the family will, ". . to the extent that they 
have 'anticipated' the death or dissipated their grief, display little or no emotion." Both grievers and medical staff are surprised when reactions are less-than-expected. The bereaved are described as feeling guilt and shame when their reactions are inconsistent with their own and social expectations. Hence, the Fultons note (p. 98), ". . a two-edged effect. It (anticipatory grief) possesses the capacity to enhance our lives and secure our well-being, while possessing at the same time the power to undermine our fragile existence and rupture our tenuous social bonds."

Other concerns about anticipatory grief harken back to those noted by Lindemann (1944) and Rosenbaum (1944) regarding emotional detachment from those not yet dead. Peretz (1970, p. 26) in discussing the nature of anticipatory grief, warns "Anticipatory grief may deprive both the dying patient and the bereaved-to-be of the possibilities still remaining in their relationship."

Aldrich (1974) asserts that there are significant differences between anticipatory grief and post-death grief, which he terms "conventional grief." He feels that the contradictory findings of Maddison and Viola (1968), Clayton et al. (1968), and Parkes (1970) who all found that the duration of the period of anticipation is not significantly related to the severity of the grief reaction, and Parkes' (1972) finding that more emotional disturbance occurred in widows following deaths for which they had little time to prepare, may be accounted for by the fact that a long period of anticipation increases both the duration of the destructive potential of the hostile component of ambivalence, as well as the opportunity for working through the loss. Aldrich feels that this impact of 
ambivalence on anticipatory grief is significantly different than that felt in conventional grief. This is due to the fact that the target of the ambivalent feelings is not only still alive but potentially vulnerable, balanced between life and death. This vulnerability makes the death wish appear particularly potent and dangerous and may contribute to the clinical impression that anticipatory grief appears to be more readily denied than conventional grief. Other differences between anticipatory and conventional grief are in aspects of endpoint, acceleration, and hope. (In other ways they are very similar.)

Aldrich also raises a provocative point when wondering whether a period of anticipation could actually prolong conventional grief. He points to Parkes' (1970) observation that Lindemann's (1944) writings caused workers to underestimate the probable duration of uncomplicated grief. Parkes' sample (1970) all had time for anticipatory grief yet their conventional grief lasted longer. Aldrich suggests that perhaps such disasters as the Cocoanut Grove Fire (the subject of Lindemann's study) may have group factors, e.g., shared mourning and evidence of national sympathy, that facilitate early working-through.

There have been other writers and investigations suggesting a fundamental difference between anticipatory and conventional grief despite many similarities. Urinary 17-hydroxycorticosteroid excretion rates for parents during and subsequent to their child's terminal illness revealed a difference in the two experiences (Wolff et al. 1964). Glick, Weiss, and Parkes (1974) feel that anticipatory grief is not merely conventional grief begun earlier. They found (p. 32) 
that there was a positive correlation between longer advance warning and eventual satisfactory adjustment to widowhood.

The value of advance warning seemed to be that it allowed emotional preparation for the loss. Loss without preparation almost seemed to overwhelm the adaptative capacities of the individual. Grief might not be augmented, but capacity to cope seemed diminished.

Thus, it was not the intensity of the grief that was affected by the anticipation, but the adaptative capacities. Further evidence for this is seen in the accompanying finding that those whose loss was not anticipated had less likelihood of regaining full capacity for functioning and happiness. Glick et al. found that widows without time for anticipatory grief did not move toward remarriage as did those with anticipated deaths. They appeared to be unwilling to risk future unanticipated loss for themselves or their children. Nevertheless, the grief was as deep among those who anticipated the death of their husbands as among those who did not. It was in form and duration that it differed.

Glick et al. did note that when there was a long period of illness the wives tended to accept the inevitability of the loss, and began to wish that death would release both their husbands and themselves from their suffering. These subjects reported that although they grieved prior to the actual death, this did not reduce subsequent grieving. Although there might be relief at the end of a long, debilitating illness, there was still shock and desolation at the time of the death. This illustrated that the experience of feelings of depression, etc., prior to death is not associated with diminished grief after. This corroborates the findings of Clayton, Halikas, 
Maurice, and Robbins (1973) who reported that widows who were depressed prior to the death and evidenced grief before bereavement were no less grief-stricken afterwards than those who showed no such evidence.

Conversely, many investigators have found that anticipatory grief possesses adaptational value (Rees and Lutkin 1967; Parkes 1975). The reader is referred to the previous section on length of illness as a factor influencing grief. Many of the writings on length of illness or anticipatory grief are synonomous in concept and content.

There has been a significant amount of writing about anticipatory grief in the literature on dying children and their parents. The detailed studies presented earlier in the Review of Literature section describe much of the anticipatory grief experience for parents. A brief review of the most pertinent ones follows.

In 1955 Richmond and Waisman described depression and anxiety as often accompanying the initial impact at diagnosis, with the period of illness prior to the death being one of reintegration of parental feelings in which the mourning process occurred substantially prior to the death of the child. Natterson and Knudson (1960) described a similar process for mothers whose children survived more than four months. They manifested a disturbed initial reaction in which they tended to deny the reality, followed by the second phase in which they tended to accept the reality and to direct their energy toward those realistic measures that could afford the hope of saving their child. The final reaction was one in which the mothers' interests 
were less sharply focused upon the child and their energy was diverted away from their children. The authors believed that these changes and the accompanying acceptance of the death of the child suggested increases in sublimation and may be interpreted presently as manifestations of the anticipatory grief.

Friedman et al. (1963) wrote that the grief process was usually quite apparent by the fourth month of the illness. It evolved as the disease progressed and any death on the child's ward had a potentiating effect upon it. They reported that it began with symptoms of somatic problems, apathy, weakness, and preoccupation with thoughts of the child and continued with a process of resigning oneself to the inevitable, a narrowing of hope, and an increased involvement with other children on the ward, sometimes to the neglect of their own child. The death was generally taken calmly but with "appropriate expression of affect" (not defined in article). They observed that the absence of anticipatory grief resulted in a more prolonged and distressing grief reaction subsequent to the death of the child.

Chodoff et al. (1964) wrote that it was possible to observe anticipatory grief if the illness lasted at least from three to four months (a "magic" time span in these studies). The process entailed the parents changing from a purely intellectual to an emotional acceptance of the fatal nature of the disease with a gradual curtailment and constriction of hope. The expressions of grief evident in the somatic symptoms and the preoccupation with thoughts of the ill child gave way to gradual detachment of investment from the child who became less a real object than a memory while still alive, leading to an attitude of "philosophic resignation." This 
attitude enabled the parents to react to the acute phase and death in a more muted fashion than if death had occurred without a period of anticipatory grief. They reported a reciprocal relationship with anticipatory grief and denial, illustrating with cases where anticipatory grief was absent an immense amount of denial was present. Such situations were found to bode poorly for subsequent adjustment.

Friedman (1967) discussed anticipatory grief as being similar to conventional grief except that it was diluted over time. He saw it as reflected by some degree of emotional detachment from the child, with renewed interest in other family matters, hope becoming more limited, and a decrease in questions being asked about anything but the immediate future. He noted that parents spent more time with other children on the ward. Friedman conceptualized anticipatory grief as self-preparation for the death and a rehearsal of how to act afterwards. Unlike parents whose loss was sudden, these parents usually had control of their grief. The exception to this were those who denied until the end and subsequently experienced the loss all at once. This often resulted in prolonged grief afterwards.

Binger et al. (1969) found that parents manifested anticipatory grief from the initial moment of diagnosis. He was impressed by the amount of silent, intense worry of some of the parents over the circumstances under which their child would die.

In discussing the reaction of the family to the fatal illness of a child, wiener (1970, p. 95) writes that the symptoms of anticipatory grief are not as dramatic or condensed as in an acute grief reaction. He asserts that the importance of anticipatory grief is as "a further step in adaptation to the child's illness, making 
possible a return to more normal functioning and attention to other responsibilities during the illness, and serving to cushion parents against the massive and disorganizing impact of their child's death." He also notes that a paucity of anticipatory grief or denial consistently maintained will result in parents being ill-prepared and unable to mobilize their resources with consequent intensification of the grief reaction after the death.

Further concerns over the absence of anticipatory grief, its unsatisfactory progress, or parental discrepancies in the degree of mourning have prompted Burton (1974a) to note the possible need for long-term care and guidance after the death.

Dangers of parental anticipatory grief have been described by Travis (1976) who is concerned that it will result in a premature emotional separation from the child and end in his actual or emotional abandonment. Often aggravating this danger of premature bereavement is the child's altered appearance and behavior secondary to the illness and its medications. She is also worried about the emotional exhaustion from rising hope during remissions and despair during relapses, which lead to parental wishes for the end. In consort with these are the numerous practical matters, e.g., finances, other family members, etc., which contribute. to decreasing involvement with the dying child. In agreement is Levitz (1977) who quotes Easson and warns against the dangers of the child becoming "emotionally dead" with the consequent experience of having to endure a tragic sense of isolation and aloneness.

In 1974, Futterman, Hoffman, and Sabshin studied the phenomenon of parental anticipatory grief exclusively. They found ( $p \cdot 243$ ) 
that "despite the wishes of parents to thwart the inevitable course of the disease and to maintain their investment in the cherished child, mourning invariably begins before death." They conceptualized anticipatory grief or "anticipatory mourning" as is their chosen term, as a series of five functionally related aspects or "part processes": Acknowledgment--becoming progressively convinced that the child's death is inevitable; Grieving--experiencing and expressing the emotional impact of the anticipated loss and the physical, psychological, and interpersonal turmoil associated with it; Reconciliation--developing perspectives on the child's expected death which preserve a sense of confidence in the worth of the child's life and the worth of life in general; Detachment--withdrawing emotional investment from the child as a growing being with a real future; and Memoralization--developing a relatively fixed conscious mental representation of the dying child which will endure beyond his death.

Futterman et al. (1972) report that the quality of the grief becomes more differentiated and focused: acute emotional pain characteristic of the early reactions becomes more tempered melancholy accompanied by active articulation and evaluation of the loss that is impending. This mellowing of grief occurs in conjunction with rising reconciliation, detachment, and memoralization. At the time of actual death there is a deepened sense of the acknowledgment of loss with a concomitant brief upsurge of acute grief. This is followed by further reconciliation. The authors write (p. 267): Presence of grieving at this time testified to the significant emotional investment in the child that had been maintained through the entire illness, while the limited intensity and duration of post-bereavement turmoil testified to the work accomplished in anticipatory mourning. 
They maintain, however, that although the task of mourning was well advanced, the mourning was rarely completed and that significant work remained to be accomplished after the death. In retrospect they also report that although behavioral signs of detachment were evident, parents maintained care of the child's physical and emotional needs, thus integrating both anticipatory grief and the care of their child.

This lengthy review of the literature (both general and specific to parents of terminally ill children) has been undertaken due to the importance of the process and the mixture of consistent and inconsistent findings that have been generated in its investigation. Theoretically, anticipatory grief commences at the moment of perception of potential loss, and hence, the entire experience of their child's terminal illness is comprised within the anticipatory grief rubric for the parents. For this reason, this author has chosen to analyze at length the previous work in the field.

Synthesizing the previous findings one is left with the conclusions that: it is, unclear whether anticipatory grief is or is not the same process as conventional post-bereavement grief; unless there is persistent denial anticipatory grief is experienced in some manner during a terminal illness; the lack of anticipatory grief appears more often than not to adversely influence the post-death grief experience; anticipatory grief contains aspects of emotional detachment and resignation (although the extent of these is variable); and that the experience of the grief prior to the death may contribute to a premature decathexis which leaves the patient abandoned while facilitating acceptance of the death on the part of the family. 
Hypothesis 8 addressed participation behaviors (Parental

Participation in the Care of the Dying Child Is Related to the

Post-Death Grief Experience).

In 1955 (p. 45) Richmond and waisman related the parents' participation in the care of their dying child to their adaptation psychologically:

We have found that the involvement of parents in the physical care of the child is extremely important in facilitating parental adaptation. First, this permits the parents to have a feeling that they personally have done everything possible for the child; second, feelings of guilt are somewhat relieved by the expenditure of personal effort in the care of the child; third, in retrospect parents are very grateful for having had the opportunity to spend as much time with the child as was possible; and fourth, an opportunity to observe and to participate in measures directed to relieve pain and discomfort as much as possible is comforting to parents.

Knudson and Natterson (1960, p. 486) appear to have agreed:

For most mothers important psychologic changes occur through their experiences in the parent participation program. The pain and anxiety that accompany separation from a sick child are reduced for the mothers. Parents are enabled to vent the guilty and hostile feelings so commonly held by those with fatally ill children. They are also better able in this setting to identify with rational attempts to deal with a desperate situation and to maintain hope in a less neurotic way. They are much less suspicious of staff members, and, in fact, often become quite friendly with them.

They further note that such participation facilitates the resolution of guilt and denial which are so characteristic of the initial parental reactions and point out that after approximately four months the mother's mental health improves and consequently her extreme need for the parental participation program diminishes. Further assertion of the therapeutic nature of parental participation is made by Friedman et al. (1963), who also note that participation appeared most supportive to the mothers who found, in contrast to their husbands that the nursing role was consistent with their past experiences 
and self-image; and Burton (1974b), who also wrote about its salutory effects in necessitating activity which assisted parents in forgetting their otherwise overwhelming anxiety. Wiener (1970) asserts that physicians and hospital staff must allow wide latitude for the degree to which parents participate in their child's care and willis (1974) cautions against staff discouragement of parent participation important for the reduction of guilt.

Prugh (1963) writes that parents can make vital contributions to the hospital program through participation in the care of their own children, while Morrissey (1963), echoing the sentiments of numerous other writers, reports that parental participation (in a qualitative versus quantitative spectrum) is quite therapeutic for the dying child. And Hamovitch (1964), who wrote on the effectiveness of the Parental Participation Program at the City of Hope, reports that those parents who participated moderately seemed to have fewer problems. The highest proportion of cases with serious problems were found in those who limited their participation solely to visiting the dying child. Full participation was at the expense of other members of the family and reflected an insensitivity to the importance of continuing to shoulder their other responsibilities. He writes in summary (pp. 116-117):

When participation was moderate, that is, where the parents visited to some extent with the child and spent a considerable amount of time with him, but also spent some time handling their affairs and being with siblings at home, the course was more even and contained fewer problems. This tended to be reflective of the parents' ability to recognize other reality demands and to fulfill them, especially the needs of other children. Those parents who participated maximally seemed to be more volatile; they were more optimistic at remissions and more despairing at relapses. Those parents who participated minimally were obsessed with more external problems that impinged on their adaptation and which might account for the lesser degree of participation. 
In Hypothesis 6 (Parental Evaluation of Their Child's Treatment Experiences Are Related to Parental Grief Experience) the effect of the parents' evaluations were studied with respect to their Anger/ Hostility and Rumination scores on the Grief Experience Inventory. Previous writings had indicated the association of the level of parental satisfaction with the grief experience.

In 1975 (p. 43) Schwab et al. reported that in their study of forty-five bereaved individuals "dissatisfaction with medical care seemed to be related to feelings of guilt or frustration, possibly influencing the intensity of grief." Twenty-nine percent of their poulation reported some level of dissatisfaction with the treatment care.

Geis (1965) in an interview of twenty-six bereaved mothers reported that nearly half the mothers commented on their satisfaction with nursing care and that there were as many positive as negative remarks about the physical and technical care received by the children. A majority of the mothers stated they appreciated "the kindness, understanding, patience, or sweet manner the nurses had toward their children." The mothers were overwhelmingly concerned about the interpersonal relationships between themselves and the staff, as well as between the children and the staff. It was in this area that they offered the most suggestions for improvement.

Binger et al. (1969) noted that in general most parents were well satisfied with the clinic and the professional team. When complaints were articulated they were usually in regard to inpatient experiences and most often were in regard to specific situations as opposed to recurrent or basic shortcomings in care. Consistent with 
other research findings there were some parents who felt that as the death approached the professional staff became more remote. It was also reported that those parents with the most negative attitudes toward the staff were those whose children had the shortest course of illness. These children were usually the sickest and did not have remissions; they were a constant source of distress to both parents and staff.

Corroborating the premise that parental satisfaction with care is related to the parents' grief experience were Townes, Wold, and Holmes (1974, p. 12) who described parental adjustment to childhood leukemia. They wrote that "parental acceptance was related to attitudes toward the doctor, the staff, and the hospital where the child was being treated." They detailed the interface between parental satisfaction with treatment and the grief experience:

During the illness of the child, fathers who reported more negative feelings viewed the circumstances surrounding the care of their child as being more potent, active and close. These attitudes may reflect an acceptance of the reality of the disease and the fact that everything possible was being done to save the child. While fathers' acceptance of this reality may be more painful, such attitudes may facilitate transition into the final phase of the mourning process. Fathers who are less successful in completing the triphasic mourning process following the death of the child were those who experienced alienation from the family.

During the initial stages of the child's treatment, highly distressed mothers felt close to the nurse and to the hospital. Toward the middle stages of treatment such mothers continued to feel close to the treatment process, however, they began to assess doctors in general negatively. Negative attitudes toward the doctors persisted in highly distressed mothers following the death of the child and generalized to nursing personnel and to death. Negative attitudes toward medical personnel during the middle stages of the disease may be an indication of denial of the reality of the disease with subsequent difficulties in accepting death as the child's release from suffering. Such negative attitudes may be a warning of mothers' difficulty in successfully completing the mourning process. An alternative explanation may be that mothers of children with leukemia require a longer, though 
unknown, length of time to complete the mourning process successfully due to their greater involvement in the treatment process.

Although their findings and rationale are open to criticism, the authors' positing of the implications of parental evaluations and attitudes towards health care personnel are quite important.

Further, Hamovitch (1964, p. 119) describes the psychological tendency frequently in operation when he discusses a major finding in the Parental Participation Program as being the "almost universally positive quality of feelings parents held about their experience with the hospital." He writes about the importance of these feelings in the sense of what appears to be cognitive dissonance theory:

- . the key to their positive reactions probably (is) related to the psychological need to feel that they had done everything that they possibly could for the benefit of the child, and, therefore, the hospital to which they had brought the patient retrospectively had to be recalled in the most positive terms.

Therefore, by implication, there would be more psychological need to "distort" or make more palatable the child's treatment since the parents had more of a hand in choosing it and thus were more culpable for this variable (treatment experiences) than they might have been with regard to other variables, e.g., type and length of illness over which they had even less control.

There are numerous writers who discuss the various types of support of parents of terminally ill children (Friedman et al. 1963; Geis 1965; Lang and Oppenheimer 1968; Binger et al. 1969; Burton 1974a; and Kennell and Klaus 1976; to name but a few). The focus of this review, however, is on support as a solitary variable, and not on the individual sources of support for parents. The sole study to have a similar focus was that conducted by Spinetta, Swarner, Kard, 
and Sheposh (1978) who identified a "viable and ongoing support" system" as one of the three best variables predicting the postdeath adaptation of parents whose child had died from cancer. 
CHAPTER III

METHODOLOGY

This investigation is retrospective in nature. Given the field of study there is ample support and precedent for an investigation of this type.

The first consideration in deliberating the merits of a retrospective study is to critically examine the experience of the subjects to be investigated. In the case of parents of terminally ill children there are strong reasons why an intervention study or one which requires some restructuring of their time and availability to their child would not be received favorably. Bozeman et al. (1955) write about the impossibility of engaging mothers in on-going studies during their child's terminal illness because of their preoccupation with the child. In fact, they report on their inability to secure the information they had needed in order to satisfy their original research requirements. They were forced to utilize retrospective data: "In place of direct observation of behavior and reports of feeling during the phase of treatment in which they occurred, it was necessary to rely on recall to a considerable extent."

A number of researchers take the position that it is almost immoral to subject these parents to investigation in such a period of crisis. Orbach et al. (1955) enjoin "The small amount of visiting time should never be infringed upon for administrative purposes, such 
as conferences with clinic adjustors and interviews with social service workers, or indeed by the routine of the ward itself." And others raise ethical questions about the researcher who changes the experience for the dying patient and the family through the investigatory process.

A number of studies in the area of parental experience during childhood terminal illness have utilized a retrospective design as part or the whole of their study design (e.g., Bozeman 1955; Binger et al. 1969; Stehbens and Lascari 1974; and Benfield et al. 1978). Nearly all other studies which investigate parental experience in other than a retrospective sense have reported difficulties with continued participation of the subjects due to their preoccupation with the care and needs of the child. Therefore, even when investigations eliminate the problem of retrospection, equal numbers of repeated measures and amounts of data gathered for the subjects within the studies are very rare occurrences.

Given the problems with systematically collecting data while the child is dying and the parents are preoccupied and given the questionable ethics of intruding at that time, a well controlled retrospective study was warranted. Cannell and Kahn (1968) have delineated a number of procedures to guard against problems with memory in interview investigations. This study was designed to accommodate these safeguards: (I) They advocate the consulting and usage of documents and records. In this vein the present study entailed the collection of verifying data from hospital medical charts; (2) Providing a context and sequence of questions geared to assist the respondent in reconstructing the past had been built into the structured 
Interview; (3) It is advisable to alert the subject to the problem of bias in recall. This was done periodically throughout the structured Interview by such comments as "There is that tendency to want to just remember the good things about your dead child and to forget that he/she was a normal child with normal irritabilities . . ." etc.; (4) A very effective method of formulating questions to assist memory is to ask for recognition rather than recall. Therefore some of the Structured Interview questions were geared to provide the respondent with a list of possible alternatives to the question. This was done in conjunction with open-ended questions since both generate important kinds of data. The Parental Experience Assessment Form had been designed in accordance with a recognition format. The fifth safeguard involves the use of indirect questions which were not applicable to this investigation.

The design of this study was quasi-experimental given the fact that there was no direct manipulation of variables and no control group per se. The purpose of this study was descriptive and associational. No control group was mandated since the author was not attempting to test for the effect of death or any other variable upon the subjects. Instead, the purpose was to critically examine variables of the parents' experiences and to do so with regard to quantitative measures of the grief experiences as measured by the Grief Experience Inventory and the Parental Experience Assessment Form.

Justification for the use of non-experimental research is becoming more prominent in the social sciences, in order to obtain a more comprehensive view of a smaller number of subjects (Goldman 1977; Frey 1978; Sue 1978; and Thoreson 1978). This increased usage 
of non-experimental research is not advocated to the exclusion of using experimental methods, but rather had been offered as a valuable companion to the experimental endeavor. This present study has attempted to integrate these two types of research.

Further justification for the quasi-experimental design of this study is provided by sue $(1978$, p. 260) in promoting the value of non-experimental studies when: (1) investigating rare and unusual phenomena; (2) challenging universal assumptions; (3) demonstrating novel procedures in diagnosis and treatment; (4) generating future hypotheses for controlled research; and (5) evaluating the effectiveness of an intervention strategy. It is clear that these five instances legitimizing the use of non-experimental procedures are partaspects of this investigation and hence warranted this study's implementation of non-experimental design.

\section{Subjects}

The subjects were fifty-four parents (twenty-seven married couples) whose children had died from cancer following treatment at Rainbow Babies and Childrens Hospital in Cleveland, Ohio. Criteria for selection were that the parents were still married and living together; that they resided in a location within three-hours' drive of Cleveland; and that their child had died from a form of cancer between six months and three years before. (However there were two sets of parents whose child had died less than six months ago; one set was included in the pilot sample, which comprised the first three couples and was not subject to the time criteria, and the second set of parents were just shy of the six-month mark and were contacted and 
accepted before it was discovered.) All of the parents, except three fathers, were the biological parents of the children. In these three cases the stepfathers had been intimately involved with the children and the families (they had already married into the families prior to diagnosis of the illness) and were judged to be emotionally and physically as involved with the child as a biological parent would have been.

Although the restrictions that the parents still had to be married and living together, and that their children had to have been treated at Rainbow Babies and Childrens Hospital, might limit somewhat the generalizability of the findings, it was deemed that such restrictions minimized the amount of confounding variables in the study .

The age range for the parents was from twenty-six to fiftyeight years. The mean parental age was forty years old. The majority of the couples were in the upper middle class. Family income ranged from eleven thousand dollars to seventy thousand, three hundred and thirty-three dollars a year. This reflected the fact that in fortyone percent of the couples both parents were employed. Educationally, all save two of the parents had completed high school (or in one case, trade school), with fifty-six percent of the parents having gone on to training or education past the high school level. Sixty-one percent of the parents were of a Protestant denomination. Thirty percent of them were Catholic and nine percent reported they had no religion. Racial background was overwhelmingly white, with only two of the fifty-four parents being Black. There was a mixture of ethnic back: grounds with Slovak and German nationalities predominant. Most other 
nationalities were at least represented, with the exception of the Jewish nationality for which there were no representatives. Table 1 summarizes the socio-economic information on the parents while Table 2 summarizes the medical profiles of the deceased children.

In total, there were thirty-nine couples who were definitely contacted to participate in the study. (Five couples were mailed letters due to changes in addresses and telephone numbers. Of these two consented to participate, the letter to one was returned, and nothing was ever heard of the other two--prohibiting knowledge of whether it would have been feasible for them to participate or whether the lack of response reflected an unwillingness to participate. These last three are not included in those that are known for sure to have been definitely contacted.) of these, thirty-one initially agreed to participate. However, only twenty-seven couples fully completed the study. Of the other four couples; one failed to return the objective measurements which had had to be left with them to complete due to time constraints; one couple, which would have ended up having to be eliminated from the study anyway due to the death being slightly over three years old, had had only the father willing to participate once the investigator reached the house and, even with this, would have had to be excluded due to his failure to return the forms which had been left him to complete due to time constraints also; one couple called to cancel on the day of the interview stating that they were "not able to do it yet"; and one couple was not at home when the investigator arrived for the pre-determined interview.

OnIy two couples directly refused. In one couple the mother was interested in participating, but the father, a chronic alcoholic, 
TABLE 1

PARENTAL SOCIOECONOMIC PROFILES

\begin{tabular}{|c|c|c|c|c|c|c|c|c|c|}
\hline $\begin{array}{c}\text { Case } \\
\#\end{array}$ & Sex & Age & Occupation & $\begin{array}{l}\text { Year } \\
\text { Incon }\end{array}$ & & $\begin{array}{l}\text { Highest Level } \\
\text { of Education }\end{array}$ & $\begin{array}{c}\text { Ethnic } \\
\text { Background }\end{array}$ & Rellgion & \\
\hline 1 & father & 31 & executive & 27.0 & $\mathbf{K}$ & B.s. & Polligh & Lutheran & \\
\hline 2 & mother & 26 & housewife & NA & & 1 yr. college & Czech & Lutheran & \\
\hline 3 & mother & 29 & cook & 3.12 & $\mathrm{k}^{\star}$ & $12+$ & American & Pentecostal & \\
\hline 4 & father & 29 & teacher & 8. 0 & $\mathbf{k}$ & B.A.+ & Irish/Dutch & Pentacostal & \\
\hline 5 & father & 41 & $\begin{array}{l}\text { executive V.P. } \\
\text { of company }\end{array}$ & 50.0 & $\mathbf{K}$ & Ph.D. & German & Protestant & \\
\hline 6 & mother & 37. & housewife & NA & & B.A. & German & Protestant & \\
\hline 7 & mother & 32 & office work & 3.9 & $\mathbf{K}$ & $2+y x \cdot$ college & Slovak & Lutheran & \\
\hline 8 & s/father & 29 & $\begin{array}{l}\text { Fed. Inspector } \\
\text { U.S. Treasury }\end{array}$ & $20.0+$ & $\mathbf{K}$ & l yr. college & slovak & Catholic & $\underset{D}{M}$ \\
\hline 9 & mother & 51 & former secy. & NA & & H.S. & llungarian & Lutheran & \\
\hline 10 & 8/father & 48 & $\begin{array}{l}\text { electric co. } \\
\text { supervisor }\end{array}$ & 20.0 & $\mathbf{R}$ & H.S.t & English & Lutheran & \\
\hline 11 & father & 30 & laborer & $30-35$ & K & H.S. & slovak & Catholic & \\
\hline 12 & mother & 29 & hougew ife & NA & & I yr. college & Dutch/English & Catholic & \\
\hline 13 & mother & 31 & nurse & 6.0 & K & nursing diploma & Irish/German & Catholic & \\
\hline 14 & father & 28 & meat cutter & 17.0 & $\mathbf{K}$ & H.S. & English & Baptist & \\
\hline 15 & - father & 38 & traffic mgr. & $20-25$ & $\mathbf{K}$ & $2+$ yr. college & Polish & Eplscopal & \\
\hline 16 & mother & 37 & housew Ife & NA & & LPN training & Pollah & Eplscopal & \\
\hline 17 & father & 55 & $\begin{array}{l}\text { private } \\
\text { investigator }\end{array}$ & 20.8 & $\mathbf{k}$ & 1 yr. H.S. & Slovak & Cathoilic & \\
\hline 18 & mother & 49 & clerk & 5.2 & $\mathbf{k}$ & H.S. & Slovak/Russian & Catholic & \\
\hline 19 & mother & 32 & former nurse & NA & & B.s. & English/American & Methodist & \\
\hline 20 & father & omltted & physician & $40-45$ & $\mathbf{k}$ & M.D. & French/English & Methodist & \\
\hline
\end{tabular}


TABLE 1--Continued

\begin{tabular}{|c|c|c|c|c|c|c|c|c|}
\hline Case & Sex & Age & Occupation & $\begin{array}{l}\text { Year } \\
\text { Incor }\end{array}$ & & $\begin{array}{l}\text { Highest Level } \\
\text { of Education }\end{array}$ & $\begin{array}{c}\text { Ethnic } \\
\text { Background }\end{array}$ & Rellgion \\
\hline 21 & mother & 43 & housewife & NA & & 11 & $\begin{array}{l}\text { Lebonese/Italian } \\
\text { Bohemian }\end{array}$ & Catholic \\
\hline 22 & father & 46 & dock hand & 24.0 & $\mathbf{k}$ & H.S. & Irish/Dutch & Catholic \\
\hline 23 & father & 34 & maintenance & $15-20$ & $\mathrm{k}$ & H.S. & German & Lutheran \\
\hline 24 & mother & 31 & housewife & NA & & H.S. & Polish & Lutheran \\
\hline 25 & father & 36 & $\begin{array}{l}\text { management } \\
\text { consul tant }\end{array}$ & 70.0 & $\mathbf{x}$ & M.S. & Italian & None \\
\hline 26 & mother & 35 & housewife & NA & & B.s. & Scotch/German & None \\
\hline 27 & father & 45 & plumber & 28.0 & $\mathbf{x}$ & H.S. & German & Lutheran \\
\hline 28 & mother & 43 & housewife & NA & & H.S. & $\begin{array}{l}\text { French/Scotch } \\
\text { Penn. Dutch }\end{array}$ & Lutheran \\
\hline 31 & mothex & 40 & secretary & $9.0+$ & $\mathbf{k}$ & H.S. & $\begin{array}{l}\text { Irish/Indian } \\
\text { Dutch }\end{array}$ & Cathollc \\
\hline 32 & $8 /$ father & 41 & $\begin{array}{l}\text { plant } \\
\text { supervisor }\end{array}$ & 18.5 & $\mathbf{k}$ & trade school & Hungarlan/Slovak & Catholic \\
\hline 33 & father & 35 & bailiff & 17.0 & $\mathbf{x}$ & B.s. & German/Itallan & Catholic \\
\hline 34 & mother & 35 & nurse & 3.12 & $\mathrm{~K}^{*}$ & nursing diploma & German & Cathollc \\
\hline 35 & mother & 43 & housewife & NA & & $12+$ & $\begin{array}{l}\text { Irlsh/German } \\
\text { English/Indian }\end{array}$ & None \\
\hline 36 & father & 58 & $\begin{array}{l}\text { master } \\
\text { mechanic }\end{array}$ & $20-25$ & $\mathrm{k}$ & 2 yrs. pre-med. & $\begin{array}{l}\text { Irish/German } \\
\text { Hungarian }\end{array}$ & None \\
\hline 37 & mothex & 57 & housew Ife & NA & & H.s. & Austrian & Protestant \\
\hline 38 & father & 49 & of $f$ fce work & 14.0 & k & $12+$ & English/German & None \\
\hline 39 & mother & 39 & billing clerk & 10.0 & $\mathrm{k}$ & H.S. & Italian & Catholic \\
\hline 40 & father & 42 & set-up man & 20.0 & $\mathrm{x}$ & н.s. & Croatlan & Cathollc \\
\hline 41 & father & 49 & plumber & 20.0 & $\mathbf{x}$ & H.S. & German & Method1st \\
\hline
\end{tabular}


TABLE 1--Continued

\begin{tabular}{|c|c|c|c|c|c|c|c|c|c|}
\hline $\begin{array}{c}\text { Case } \\
\#\end{array}$ & Sex & Age & Occupation & $\begin{array}{l}\text { Year } \\
\text { Incor }\end{array}$ & & $\begin{array}{l}\text { Highest Level } \\
\text { of Education }\end{array}$ & $\begin{array}{c}\text { Ethnic } \\
\text { Background }\end{array}$ & \multicolumn{2}{|l|}{ Religion } \\
\hline 42 & mother & 49 & housewife & NA & & H.S. & $\begin{array}{l}\text { English/Irish } \\
\text { Scotch/Welsh }\end{array}$ & Protestant & \\
\hline 43 & father & 49 & $\begin{array}{l}\text { insurance } \\
\text { salesman }\end{array}$ & 65.0 & $\mathbf{K}$ & B.s. & $\begin{array}{l}\text { English/Irish } \\
\text { French }\end{array}$ & Protestant & \\
\hline 44 & mother & 47 & $\begin{array}{l}\text { former music } \\
\text { teacher }\end{array}$ & NA & & B.s. & American & Lutheran & \\
\hline 45 & father & 33 & $\begin{array}{l}\text { financial } \\
\text { analyst }\end{array}$ & $20-24$ & $\mathbf{x}$ & M.S. & German/English & Protestant & \\
\hline 46 & mother & 31 & housewife & NA & & 1 Yr. college & Scotch & Protestant & \\
\hline 47 & mother & 42 & postal clerk & 16.0 & $\mathbf{x}$ & H.S. & Afro-American & Presbyterian & \\
\hline 48 & Eather & 45 & postal clerk & 19.0 & $\mathbf{x}$ & 1 yr. college & Afro-American & Presbytertan & \\
\hline 49 & father & 51 & $\begin{array}{l}\text { electric co. } \\
\text { operations mgr. }\end{array}$ & 21.0 & $x$ & H.S. & German & Catholic & ज \\
\hline 50 & mother & 49 & housewife & NA & & H.S. & German & Catholic & \\
\hline 51 & mother & 34 & nurse & 12.58 & & nursing diploma & $\begin{array}{l}\text { English/Irish } \\
\text { Scotch }\end{array}$ & Presbyterian & \\
\hline 52 & father & 36 & die setter & $12-15$ & $\mathbf{R}$ & H.S. & Omitted & Christian & \\
\hline 53 & father & 43 & teacher & 16.0 & $\mathbf{K}$ & B.A.t & German & Lutheran & \\
\hline 54 & mother & 38 & factory worker & 12.0 & $\mathbf{x}$ & H.S. & English & Lutheran & \\
\hline 55 & father & 44 & assembly worker & 8.0 & $\mathrm{x}$ & H.S. & $\begin{array}{l}\text { Scotch/English } \\
\text { Indian }\end{array}$ & Protestant & \\
\hline 56 & mother & $4 n$ & sales assistant & 5.2 & $\mathbf{x}^{\star}$ & H.S. & $\begin{array}{l}\text { Scotch/English } \\
\text { Iriah }\end{array}$ & Protestant & \\
\hline
\end{tabular}

LEGEND:

s/Eather = stepfather

$+=$ some in addition, but not enough for new category

* = part-time work, salary averaged

$K=$ thousand dollars
NA $=$ not applicable

B.S./B.A. - Bachelor's degree

H.s. = high school

M.S. = Master's degree 
TABLE 2

MEDICAL PROFILES FOR DECEASED CHILDREN

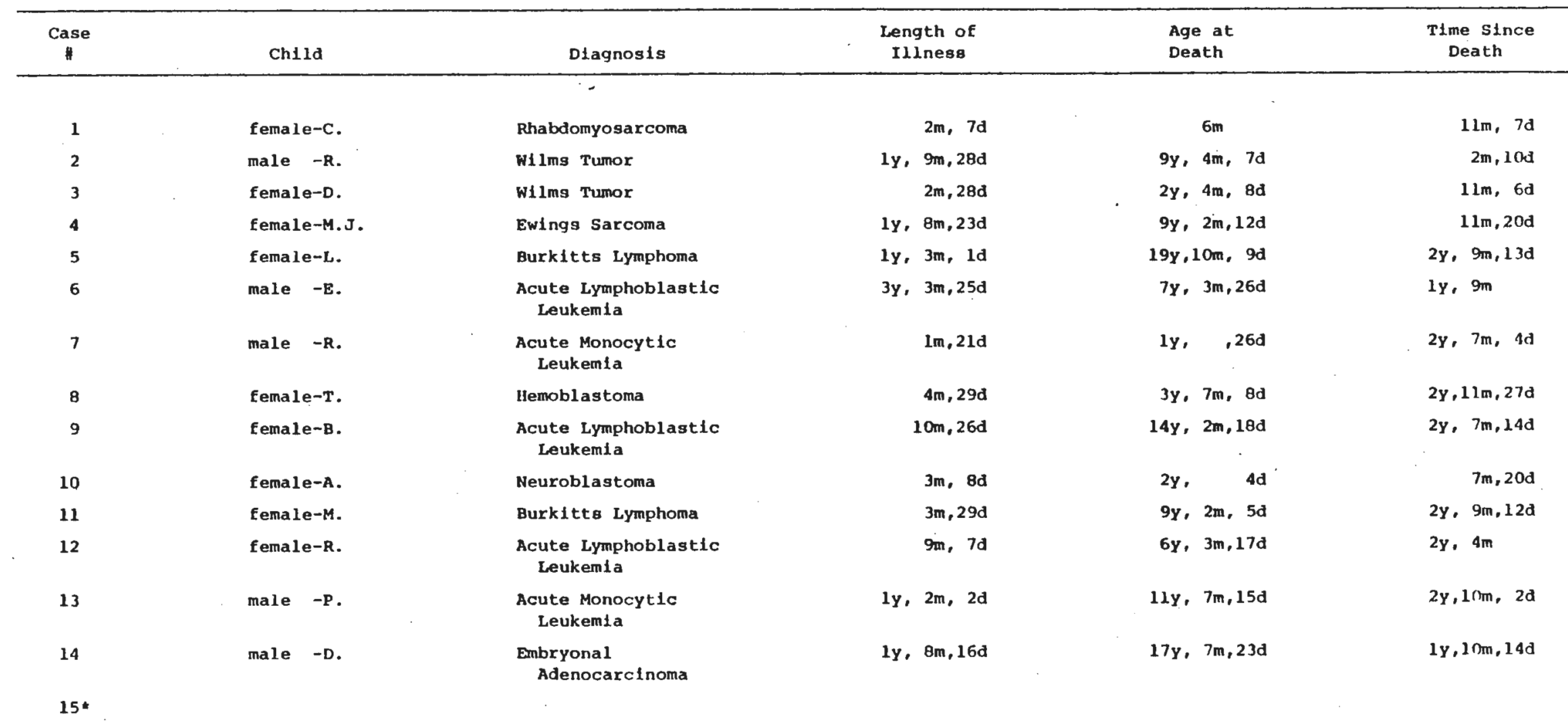

'case dropped due to parents' fallure to complete measurements 
TABLE 2--Continued

\begin{tabular}{|c|c|c|c|c|c|}
\hline $\begin{array}{c}\text { Case } \\
\#\end{array}$ & Child & Dlagnosis & $\begin{array}{l}\text { Length of } \\
\text { I1lness }\end{array}$ & $\begin{array}{l}\text { Age at } \\
\text { Death }\end{array}$ & $\begin{array}{l}\text { Time Since } \\
\text { Death }\end{array}$ \\
\hline 16 & male $-J$ & Ewings Sarcoma & $3 \mathrm{~m}, 3 \mathrm{~d}$ & $16 y$, & $1 y, 4 m, 5 d$ \\
\hline 17 & male $-\mathrm{J}$. & $\begin{array}{l}\text { Acute Monocytic } \\
\text { Leukemía }\end{array}$ & $7 m$ & $10 \mathrm{y}, 11 \mathrm{~m}, 20 \mathrm{~d}$ & $9 \mathrm{~m}, 23 \mathrm{~d}$ \\
\hline 18 & male $-P$. & $\begin{array}{l}\text { Congenital } \\
\text { Erythroleukemia }\end{array}$ & $6 d$ & $7 d$ & $1 y$ \\
\hline 19 & male $-P$ & $\begin{array}{l}\text { Acute Lymphoblastic } \\
\text { Leukemia and } \\
\text { Burkitts Lymphoma }\end{array}$ & $5 y, 3 m, 6 d$ & $10 y, 3 \mathrm{~m}, 3 \mathrm{~d}$ & $2 y, 9 m, 27 d$ \\
\hline 20 & female-M. & Ewings Sarcoma & $1 y, 10 m, 5 d$ & $13 \mathrm{y}, 4 \mathrm{~m}, 2 \mathrm{~d}$ & $2 y, \quad 5 d$ \\
\hline 21 & female-G. & $\begin{array}{l}\text { Acute Lymphoblastic } \\
\text { Leukemia }\end{array}$ & $3 y, 8 m, 5 d$ & $19 y, 5 m, 8 d$ & $2 y, 5 m, 7 d$ \\
\hline 22 & male $-k$ & Osteogenic Sarcoma & $1 y, 3 m, 5 d$ & $18 y, 9 m, 25 d$ & $2 y, 3 m, 15 d$ \\
\hline 23 & male $-M$. & $\begin{array}{l}\text { Acute Lymphoblastic } \\
\text { Leukemia }\end{array}$ & $2 m, 25 d$ & $5 y, 8 m, 21 d$ & $1 y, 10 \mathrm{~m}, 1 \mathrm{~d}$ \\
\hline 24 & male $-R$. & $\begin{array}{l}\text { Acute Lymphoblastic } \\
\text { Leukemia }\end{array}$ & $2 y, 4 m, 23 d$ & $9 y, 8 m, 29 d$ & $1 y, 3 \mathrm{~m}, 19 \mathrm{~d}$ \\
\hline 25 & male $-J$ & Synovial Cell Sarcoma & $2 y$ & $20 \mathrm{y}, 3 \mathrm{~m}, 18 \mathrm{~d}$ & $6 \pi, 26 d$ \\
\hline 26 & male $-R$. & Burkitts Lymphoma & $9 m, 28 d$ & $5 y, 5 m, 29 d$ & $2 \mathrm{y}, 10 \mathrm{~m}, 27 \mathrm{~d}$ \\
\hline 27 & male $-M$ & Ewings Sarcoma & $7 \mathrm{y}, 7 \mathrm{~m}, 2 \mathrm{~d}$ & $18 y, 8 m, 21 d$ & $5 m, 14 d$ \\
\hline 28 & female-J. & $\begin{array}{l}\text { Acute Lymphoblastic } \\
\text { Leukemia }\end{array}$ & $2 m, 7 d$ & $3 y, 1 m, 16 d$ & $2 y, 8 m, 4 d$ \\
\hline
\end{tabular}

NOTE: Letter following sex of chfld denotes first infital of child's name.

LEGEND: $y=$ year

m $=$ month

d $=$ day 
refused to participate. In the other couple (which later was realized to have fallen just short of the six-month criteria for inclusion) the mother declined immediately upon contact saying that it was "too hard," "too close," and that they were "having a hard time." Six other couples were informed of the study and said they would call back to discuss it or if they could persuade their spouse (in several cases one of the spouses was willing where the other one was not and this would have precluded their being accepted into the study). These six were the ones who, for whatever reason, never recontacted the investigator. These individualș were not called back by the investigator in an effort to appreciate their non-verbal decision.

Clearly; the main reason for the parents' participation in a study which was intesely painful at times was their desire to provide information that would be helpful to parents and children in similar situations in the future.

\section{Setting}

Although all of the interviews took place in the private homes of the subjects, they had all had their children treated at Rainbow Babies and Childrens Hospital and it is this setting. which is to be described.

Rainbow Babies and Childrens Hospital is a two hundred and twenty bed.hospital devoted exclusively to the care of infants, children, and adolescents. It provides primary and specialty care for children in urban and suburban cleveland, as. well as serving as a special children's referral center for northern ohio with a population of more than one million children. Approximately one half of 
the patients referred are from other parts of the state, country, and, in some instances, from foreign countries. Over nine thousand children are admitted to Rainbow Babies and Childrens Hospital each year and approximately seventy thousand visits are made to the ambulatory clinics and the emergency care center. The hospital has over thirty major divisions and services for the children and thirty-nine special children's diagnostic and treatment centers.

Rainbow Babies and Childrens Hospital is one of a small group of national centers for children with cancers and the results of the investigations there are shared with similar institutions in the United States and Canada to establish treatment protocols using chemotherapy, transplantation, and radiotherapy for the treatment of cancer. The treaters of the child are cognizant of approaching the child as a whole person and thus parental involvement is strongly fostered and families are encouraged to participate in the care of their children, and children are allowed to enjoy as much freedom as their illnesses will permit. The prevailing attitude in the Hematology-oncology Department is to be as completely candid and honest with both parents and child as is possible. The same physicians staff both the inpatient service and the out-patient clinics and a primary care physician is assigned. These procedures foster continuity of care as well as facilitate the benefits of on-going communication with an identified primary care physician.

\section{$\underline{\text { Procedure }}$}

In several cases the pediatric hematologist-oncologist who had attended the child during his/her illness contacted the parents 
initially by phone. In a couple of instances this contact was made by another physician in the same office. By far, the vast majority of the contacts were made by a pediatric oncology nurse who had worked with both the parents and the children both during and after the illness. The parents were given a description of the study and its purpose. When consent for participation was obtained the parents were informed that this investigator would be contacting them to arrange an interview with them at a time convenient to them within the privacy of their own homes. At the interview both parents were initially seen together in order to describe to them in more detail the nature and objectives of the study as well as to address any questions or concerns they may have had. Each parent was requested to sign a consent form indicating his/her willingness to participate and his/her understanding of the content and purpose of the investigation (Appendix 4). Parents were then separated, with one parent being interviewed individually while the other completed the Grief Experience Inventory (Appendix 1). When each had finished they reversed roles. After the Structured Interview (Appendix 3) was administered to each parent, the Parental Experience Assessment Form (Appendix 2) was completed by each parent in which they rated their responses to specific questions addressed during the interview. (The first ten parents in this study were administered an earlier version of this form. The differences are slight, only reflected in several new ratings on the PEAF. This original form is included in Appendix 5.) All interviews were audio taped for future analysis outside of the scope of this study. 


\section{Instruments}

There were four sources of data in this investigation: the Grief Experience Inventory, the Structured Interview, the Parental Experience Inventory, and hospital charts.

The Grief Experience Inventory (Sanders et al. 1978; Appendix 1) is a self-report, objective instrument to assess an individual's grief experience through an eleven-scale profile of parental grief. It is the sole instrument of its kind in existence at the present time. The instrument has received norming on various populations including a sample of parents whose children died from various causes. For purposes of this investigation the following scales have been chosen as most valid and will be used accordingly: Atypical Responses, Despair, Anger/Hostility, Loss of Control, Rumination, Depersonalization, and Somatization. These subscales were chosen since they met or exceeded the criterion (imposed by this author to assure reliability) of an Alpha coefficient of .68. The sole exception to this was the Atypical Responses scale which has been included since it is an empirically-derived scale from the other clinical scales which precludes it having a higher Alpha coefficient than the .52 it has. Those subscales not meeting this criterion were not employed in this investigation due to their questionable reliability.

Atypical Responses is an empirically-derived scale indicating the tendency to endorse items which less than twenty-five percent of the normative sample endorsed. It spans a variety of content areas and, in this study, is taken as an index of abnormality of the grief experience. Despair is a rationally-derived scale measuring the mood state of the respondent, characterized generally by pessimism 
of outlook on life, feelings of. hopelessness or worthlessness, slowing of thoughts or actions, and low self-esteem. It is the longest and most reliable of the bereavement scales on the GEI. It measures the most pervasive psychological expression of grief. Anger/Hostility is a rationally-derived scale which indicates the individual's level of irritation, anger, and feelings of unjustice. Loss of Control is also a rationally-derived scale. It indicates a person's inability to. control his/her overt emotional experiences. Rumination is a scale that has been rationally-derived and measures the amount of time spent with thoughts concerning the deceased or preoccupation with thoughts of the deceased. Depersonalization is a rationally-derived scale measuring the numbness, shock, and confusion of grief. Factor analytic studies of the Grief Experience Inventory suggest that this scale measures a deeper, more intense form of bereavement. Somatization is a rationally-derived scale which measures the extent of somatic problems which take place under the stress experience.

The topics addressed in the Structured Interview (Appendix 3) were taken from prior research on grief, with special emphasis on the parental loss of children. The format had been designed to assist the parents in describing their experiences from the time of diagnosis to the period of readjustment subsequent to death. The questions were all open-ended.

There was a discrete series of questions in areas that had been addressed in the Structured Interview for which the parents provided objective ratings. This Parental Experience Assessment Form (Rando 1979; Appendix 2 and Appendix 5 for the earlier version) provided more objective quantification of the parents' perceptions and judgments, 
and gave a formal comparative basis for such data.

Hospital and outpatient charts were utilized to provide such information as dates of diagnosis, number of hospitalizations, treatment regimens, numbers of remissions and relapses, and other information relating to the course of the child's illness. 
CHAPTER IV

RESULTS

Independent and Dependent Variables

Independent variables were obtained through parental self-report on the PEAF, through medical records, or determined by the sex of the parent. Those independent variables obtained through the PEAF included parental ratings of support, previous loss, participation behaviors during child's hospitalizations, extent and satisfaction with personal involvement with child during hospitalizations, satisfaction with health care and treatment given to child, anticipatory grief behaviors, preparation at death, and pre-morbid coping ability. The duration of the illness and the length of time since the death were variables determined through information in the medical records. The sex of the parent provided the final independent variable.

The dependent variables of parental grief were operationalized by ratings and scores derived from the Grief Experience Inventory (GEI) and the Parental Experience Assessment Form (PEAF). The dependent variables from the GEI were the subscale scores of Atypical Responses, Despair, Anger/Hostility, Loss of Control, Rumination, Depersonalization, and Somatization. These were selected from the instrument because they possessed an acceptable Alpha coefficient of .68 or above. The dependent variables from the PEAF were two ratings of coping. The first rating provided information on the parents' coping in relation to their pre-morbid coping: "Compared to how I was coping in life prior 
to my child's illness, I feel that right now I am coping: (1) much worse; (2) a little worse; (3) at the same level; (4) a little better; (5) much better." The second rating provided information on the parents' evaluation of their overall subsequent adjustment to their child's death: "I feel that I have coped with my child's death: (1) not well at all, with major difficulty; (2) not too badly, but with a number of problems; (3) adequately, without too many problems; (4) very well, without very many problems at all; (5) excellently, without any problems."

\section{General Analysis of the Data}

There were three primary statistical analyses performed on the data. A chi-square analysis of the data was performed in order to test the significance of an association between two variables when the expected frequency was greater than five. When the expected frequency was less than five in any one of the cells in the four-fold table, the Exact Probabilities Method for calculating "p" directly was used. The statistic could only be employed when the calculations allowed for one degree of freedom solely. On several predictions the degrees of freedom precluded the exact probabilities method of analysis and thus on these specific predictions the level of significance was doubled to test for a 2-tailed test and, if this was not significant, their results were described in the form of trends. The third major statistical procedure involved student's t-test of significance of difference between means.

\section{Scoring of the Data}

Due to the fact that statistical analysis of the data was largely confined to testing for significance of association, the data needed to be categorized. This procedure was completed in the following 
manner. All GEI subscales were divided into low/high ranges based upon the raw score which most evenly divided the subject population. On the PEAF parents provided ratings for specific behaviors, experiences, and evaluations. Two ratings have been used quite frequently in this study and will be discussed here. All other ratings and the determinations for their categorizations will be discussed in line with the appropriate hypothesis.

Parental evaluation of their subsequent adjustment following their child's death was obtained from their ratings in response to the following statement: "I feel that I have coped with my child's death: (1) not well at all, with major difficulty; (2) not too badly, but with a number of problems; (3) adequately, without too many problems; (4) very well, without very many problems at all; (5) excellently, without any problems." Those who rated their coping with their child's death as (1) or (2) were viewed as having low subsequent adjustment; those with ratings of (3), (4), or (5) were seen as having high adjustment.

Anticipatory grief has been operationalized by a series of behaviors for which the parents indicated "yes" or "no" depending on their engaging in the behavior. The parents were asked: "Prior to your child's death did you ever: Discuss your child's dying with your child?; Discuss with someone outside of your family the possibility that your child would die?; Think what the future would be without your child?; Plan the type of death you wanted for your child?; Acknowledge the fact that your child was going to die?; Grieve in anticipation of the loss of your child?; Start to partially disengage yourself from your child?; Make funeral preparations?" The anticipatory 
grief behaviors reported engaged in by each parent were summed to generate a total anticipatory grief behaviors score. A total score of 0-3 constituted low involvement in anticipatory grief. A score of 4 was viewed as a moderate level of anticipatory grief and scores 5-8 were viewed as revealing high anticipatory grief. Wherever multiple answers had been provided to a particular question, the average of them was taken to constitute the response.

\section{Hypotheses}

Hypothesis 1: The Amount of Support Received During the Terminal Illness is Related to the Post-Death Grief Experience

The amount of support received by each parent was determined by their rating of twenty discrete sources. Each parent was asked to: "Please indicate the source, quality, and frequency of support you received during your child's terminal illness." In the categories of Family, Friends, Organizations, Other Parents of Terminally Ill Children, Hospital Staff, and Personal Sense of Religion/Philosophy of Life, the ratings were made according to the following criteria: "(0) no support; (1) not helpful, actually harmful; (2) not helpful, but didn't hurt; (3) helped a little; (4) significant help; (5) couldn't have managed without it." For each parent, the sum of those sources rated from 3-5 was computed to generate a single number indicative of the amount of support received. The range of numbers of behaviors was from 26 to 76. A median split was done in order to differentiate into low and high categories of support.

Prediction 1A: There will be an association between the support reported by parents and their own ratings of subsequent adjustment to the death 
Table 3 shows the association between support received during the terminal illness and parental ratings of subsequent adjustment since the death.

TABLE 3

SUPPORT RECEIVED BY PARENTS AND

PERCEIVED SUBSEQUENT ADJUSTMENT

Support

Lo $\quad \mathrm{Hi}$

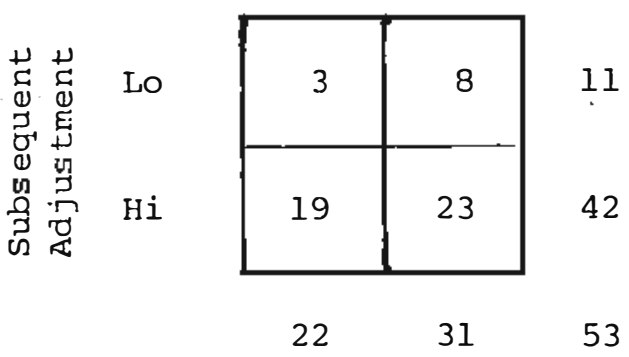

The exact probabilities method yielded $p=.1594$. The association was not significant and the prediction was not supported. Seventynine percent of the parents perceived themselves as having high subsequent adjustment following their child's death.

Prediction 1B: The more support received by each parent the less will be the number of Atypical Responses on the Grief Experience Inventory of that parent

The range of responses for this subscale was $0-13$ out of a possible 28. Table 4 indicates the association between support received by parents and the number of Atypical Responses endorsed on the GEI. 
TABLE 4

SUPPORT RECEIVED BY PARENTS AND ATYPICAL
RESPONSES SUBSCALE SCORES

Support

Lo $\mathrm{Hi}$

\begin{tabular}{|c|c|c|}
\hline Øn LO & 8 & 14 \\
\hline 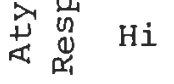 & 15 & 17 \\
\hline
\end{tabular}

22

$23 \quad 31$

54

A chi-square analysis yielded $x^{2}=.2376(p>.05)$. The association was not significant and the prediction was not supported. There was a greater percentage of parents having low Atypical Responses scores among those parents who had reported receiving more support.

Hypothesis 2: Previous Loss Influences Grief

The number of previous losses (i.e., losses occurring before the death of the child) rated by the parents as having been successfully coped with were used as the sum of previous loss experience. The degree of successful coping was measured by the following items from the Parental Experience Assessment Form (PEAF) in which parents indicated which of the listed experiences they had had by rating how they felt they coped with them. There were four ratings of coping: "(1) didn't cope at all; (2) coped only minimally; (3) coped fairly well; (4) coped very well." The sum of the previous losses which had been rated either a (3) or (4) was used to give an index of previous loss successfully coped with. The range of previous losses successfully coped with was 0-10. A median split was done to separate low 
and high number of losses. Three predictions were tested.

Prediction 2A: There will be an association between parental losses previously coped with successfully and parental ratings of subsequent adjustment

Table 5 shows the association between the numbers of losses successfully coped with previously by the parents and their ratings of subsequent adjustment following the death.

TABLE 5

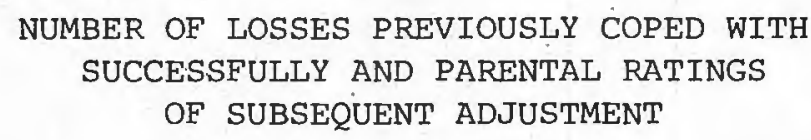

Subsequent Adjustment

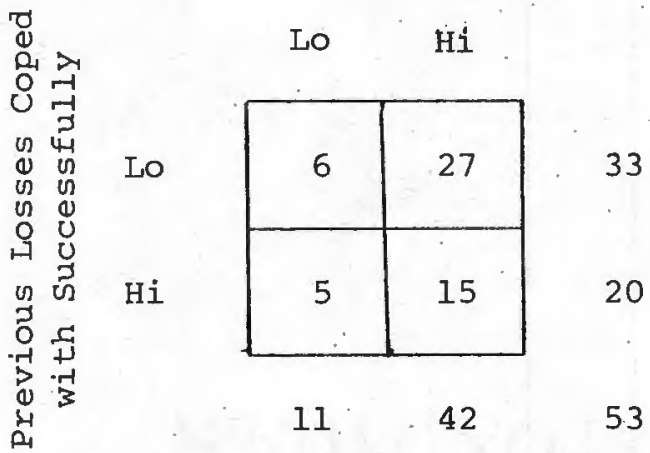

The exact probabilities method yielded $p=.2250$. There was no significant association between the variables. The prediction was not supported. Seventy-nine percent of the parents rated themselves as having high adjustment. Of those who had high subsequent adjustment sixty-four percent had low previous loss scores. Although the low subsequent adjustment subjects were split almost evenly on previous losses, those with high subsequent adjustment were almost two times more likely to have low previous loss than high previous loss. 
Prediction 2B: There will be an

association between previous losses

successfully coped with and the

number of anticipatory grief behaviors

engaged in by the parent

Table 6 illustrates the association between losses successfully coped with prior to the child's death and the amount of anticipatory grief behaviors in which the parents engaged.

TABLE 6

NUMBER OF LOSSES PREVIOUSLY COPED WITH SUCCESSFULLY AND NUMBERS OF ANTICIPATORY GRIEF BEHAVIORS

Number of Anticipatory Grief Behaviors
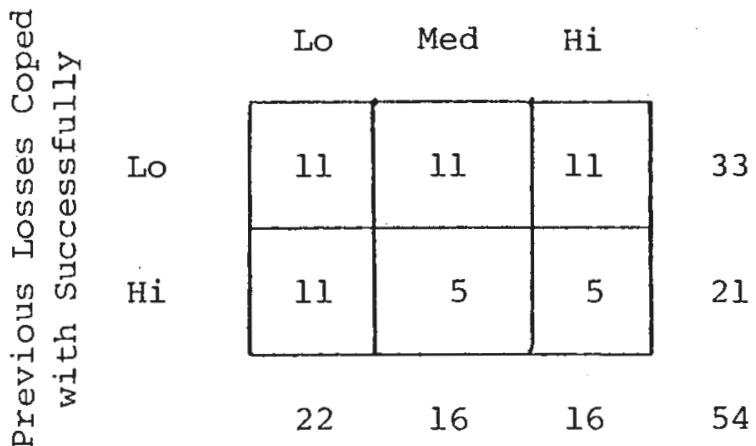

A chi-square analysis yielded a $x^{2}=1.9215$ (p>.05). No significant association was indicated. The prediction was not supported. A greater percentage of parents in the low anticipatory grief group reported having more previous losses than those parents in the medium. and high grief groups.

Prediction 2C: There will be an association between the pre-morbid coping style of each parent and their ratings of their subsequent adjustment following the death

Each parent rated their pre-morbid coping on the following item on the PEAF: "Before my child's illness. I managed to cope with life: (1) not well at all, with major difficulty; (2) not too badly, but with 
a number of problems; (3) adequately, without too many problems;

(4) very well, without very many problems at all; (5) excellently, without any problems." Those who indicated they coped with life with a rating of (1) or (2) were perceived as being low pre-morbid copers. Those who rated their coping as (3), (4), or (5) were seen as being high pre-morbid copers. Table 7 shows the association between premorbid coping and subsequent adjustment.

TABLE 7

PRE-MORBID COPING AND SUBSEQUENT

ADJUSTMENT

Pre-Morbid Coping

Lo $\quad \mathrm{Hi}$

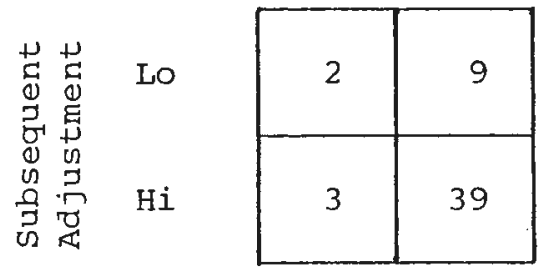

11

$5 \quad 48 \quad 53$

The exact probabilities method yielded $p=.2200$ indicating no significant association. The prediction was not supported. Seventyfour percent of all parents rated themselves as both high pre-morbid copers and high subsequent adjusters.

\section{Hypothesis 3: Length of Illness \\ Influences Parental Grief}

Length of illness refers to the amount of time elapsed from diagnosis until death. The length of illness times were divided into three categories: those with illnesses of less than 6 months; those with illnesses greater than 6 months and less than 18 months; and 
those with illnesses greater than 18 months in duration. The range of times represented in the sample was from 6 days to 7 years, 7 months, 2 days.

Prediction 3A: There will be an association between the length of time from diagnosis until death and the parental ratings of preparedness at the time of death

Preparedness was rated on the following item from the PEAF: "How prepared did you feel when your child died?: (1) not prepared at all; (2) a little prepared, but not enough; (3) adequately prepared for me; (4) totally prepared." Those who rated (1) or (2) were seen as low prepared people; those who rated (3) or (4) were seen as high prepared people. Table 8 illustrates the association between length of illness and ratings of preparedness at actual time of death.

TABLE 8

LENGTH OF ILLNESS AND PREPAREDNESS AT DEATH

Length of Illness

$0<6 \quad 6<18 \quad 18+$

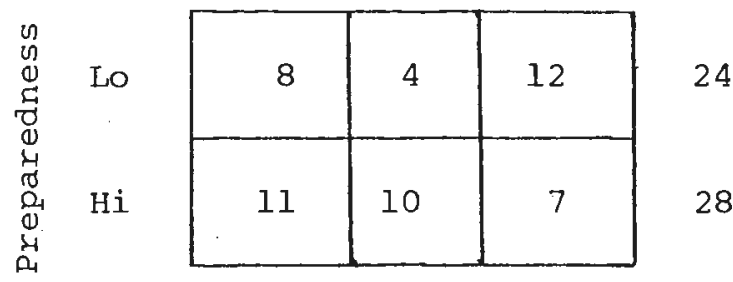

$\begin{array}{llll}19 & 14 & 19 & 52\end{array}$

A chi-square analysis rendered a $x^{2}=4.0740$ ( $\left.p>.05\right)$. The results indicated there was no significant association. The prediction was not supported. Of note is the observation that the majority of 
those who had the least preparation as defined by length of illness ( $0<6$ months) were high on preparedness as contrasted to those with a longer period of preparation (over 18 months) for whom the majority were low prepared. The period of $6<18$ months contained the greatest percentage of parents who were high on preparedness suggesting that this period may be an optimum one for the interaction of these variables.

Prediction 3B: The longer the interval between diagnosis and death, the lower will be the subscale score of Anger/ Hostility on the Grief Experience Inventory profile

The range of scores for this subscale was 0-9 out of a possible 9. Table 9 indicates the association between length of illness and Anger/Hostility scores.

TABLE 9

LENGTH OF ILLNESS AND ANGER/ HOSTILITY SCORES Length of Illness

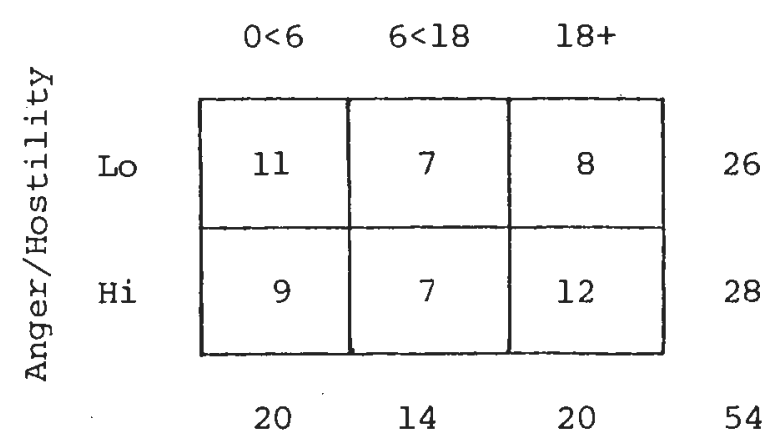

The chi-square method generated $x^{2}=.9363$ (p>.05) indicating a lack of significant association. The prediction was not supported. 
High Anger/Hostility scores increased in percentage in each succeeding time category.

Prediction 3C: The longer the interval between diagnosis and death, the lower will be the subscale score of Atypical Responses on the parents' Grief Experience Inventory profiles

Table 10 shows the association between length of illness and Atypical Responses scores.

TABLE 10

LENGTH OF ILLNESS AND ATYPICAL RESPONSES SCORES

Length of Illness

$0<6 \quad 6<18 \quad 18+$

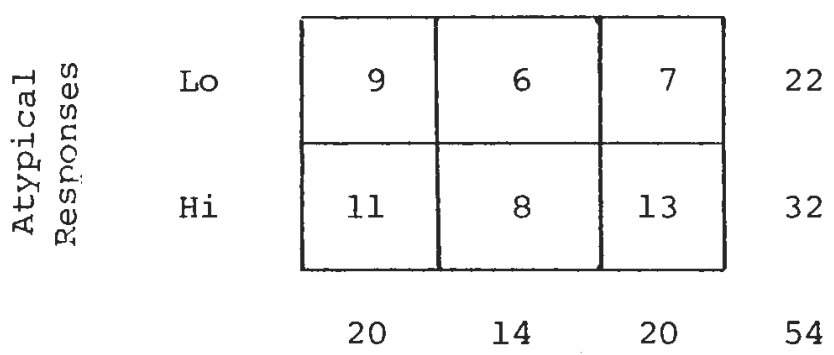

The chi-square method yielded $x^{2}=.4502(p>.05)$ and revealed no significant association. The prediction was not supported. Parents whose child had a longer illness (18 months or longer) were almost twice as likely to have high rather than low Atypical Responses scores.

Hypothesis 4: The Length of Time Since the Death Affects the Intensity of

Parental Grief

Subjects were divided into three categories based on the length of time since their child's death. Time Period I includes those whose child died less than 12 months ago; Time Period II includes those whose 
child died more than 12 but less than 24 months ago; and Time Period III includes those whose child died more than 24 but less than 36 months ago. The time since the death ranged from 2 months and 10 days to 2 years, 11 months, and 27 days. Each time period was divided in half (into six-month periods) and the predictions were tested within each twelve-month period. The results of all the predictions are presented first and are then followed by an analysis of the mean raw scores of the GEI subscales according to time periods. Under each table is the p-value derived from the Exact Probabilities Method or the $x^{2}$ value from the chi-square method of analysis.

Prediction 4A: The longer the length of time since the death, the lower will be the parental subscale score of Loss of Control on the Grief Experience Inventory

The range of scores for this subscale was $1-9$ out of a possible 9. Table 11 shows the association between length of time since the death and Loss of Control scores.

TABLE 11

LENGTH OF TIME SINCE DEATH AND LOSS OF CONTROL SCORES

Time Period I Months Since Death

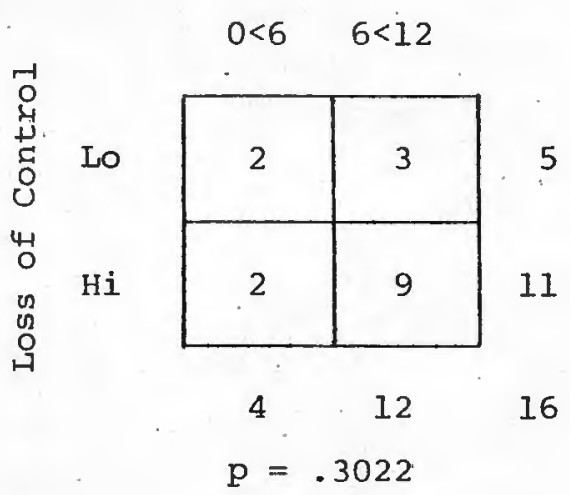

Time Period II Months Since Death

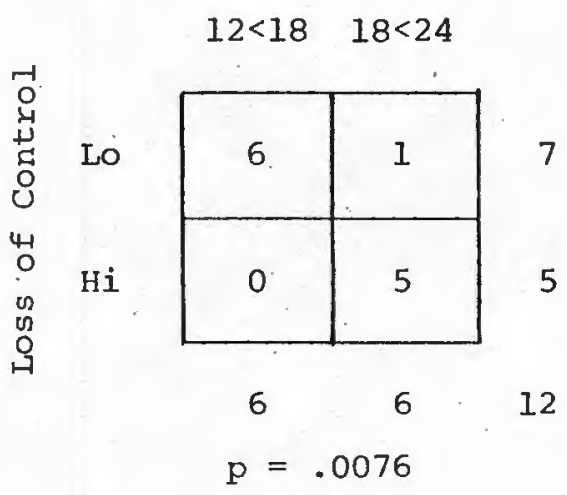


TABLE 11--Continued

Time Period III

Months Since Death

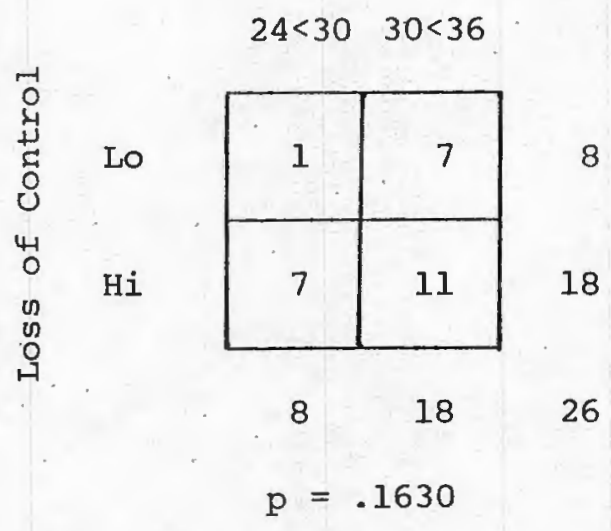

There was a significant association within Time Period II $(p=.0076)$. Parents whose child died from $12<18$ months ago evidenced a low level of Loss of Control while those whose child died from $18<24$ months ago evidenced a high amount of Loss of Control. Thus, there appears to be a positive association between Loss of Control and length of time since death for parents in their second year of bereavement. There was no significant association in either Time Periods I or III, however in Time Period I seventy-five percent of those who had lost a child from $6<12$ months prior to the study were high on Loss of Control as compared to a 50-50 split found for those whose child had died less than 6 months prior to the study and 2 times more than those who scored low within the same time period, suggesting an increase in Loss of Control experienced within the second half of the first year.

Prediction $4 \mathrm{~B}$ : The longer the length of time since. the death, the lower will be the parental subscale score of Despair from the Grief Experience Inventory 
The range of scores for this subscale was 0-14 out of a possible 18. Table 12 shows the association between length of time since the death and Despair scores.

TABLE 12

LENGTH OF TIME SINCE DEATH

AND DESPAIR SCORES

Time Period I

Months Since Death

$0<6 \quad 6<12$

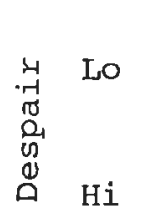

\begin{tabular}{|l|l|}
\hline 1 & 6 \\
\hline 3 & 6 \\
\hline
\end{tabular}

$4 \quad 12$

16

$p=.3231$
Time Period II

Months Since Death

$12<18 \quad 18<24$

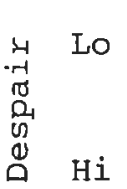

\begin{tabular}{|l|l|}
\hline 5 & 3 \\
\hline 1 & 3 \\
\hline
\end{tabular}

6

$6 \quad 12$

$p=.2424$

Time Period III

Months Since Death

$24<30 \quad 30<36$

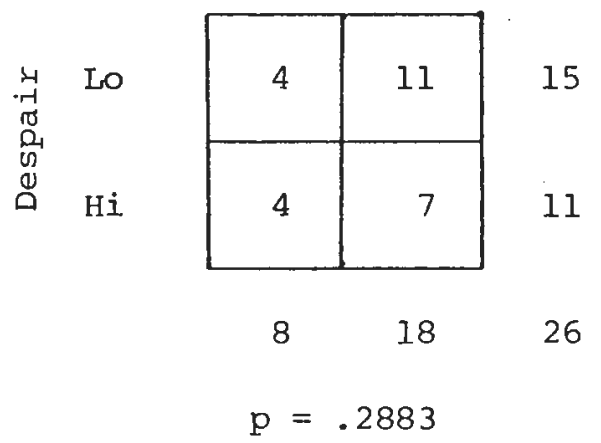

There were no significant associations found within any of the three time periods. 
Prediction 4C: The longer the length

of time since the death, the lower

will be the parental subscale score

of Depersonalization on the Grief

Experience Inventory

The range of scores for this subscale was 0-7 out of a possible 8. Table 13 indicates the association between length of time since the death and Depersonalization scores.

TABLE 13

LENGTH OF TIME SINCE DEATH AND DEPERSONALIZATION SCORES

Time Period.I

Months Since Death

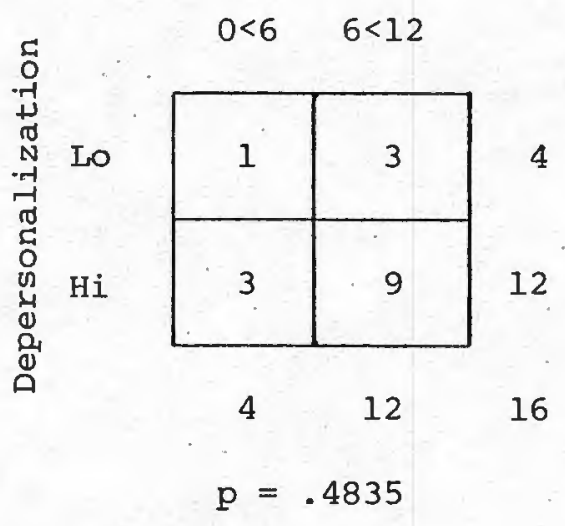

Time Period II

Months Since Death

5
0
-1
4
0
$N$
-1
-1
$\pi$
5
0
0
0
0
0
0
0
0

$\mathrm{Hi}$

$12<18 \quad 18<24$

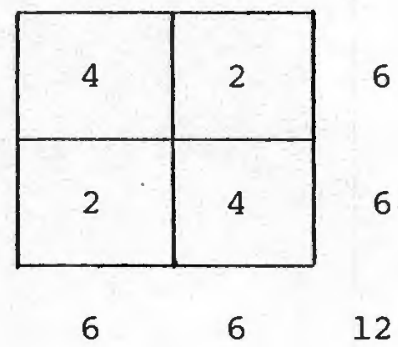

$p=.2435$

Time Period III

- Months Since Death

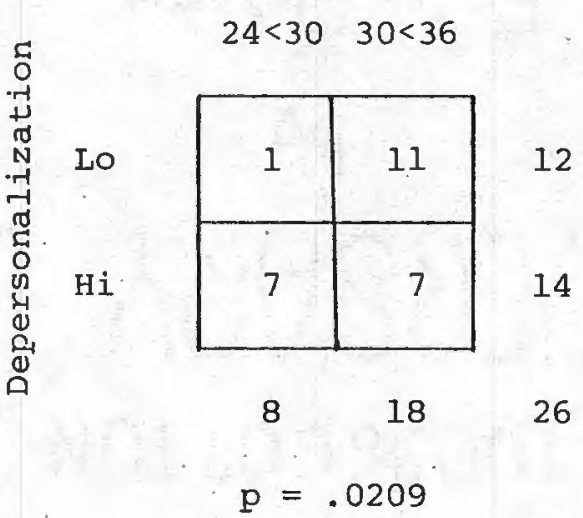


There was a significant association $(p=.0209)$ within Time Period III indicating that there was a reverse association in which parents whose child died longer ago within that time period reported less depersonalization and those whose child died a shorter length of time ago within that period reported more depersonalization. There were no significant associations in Time Periods I or II. However in Time Period I seventy-five percent of those whose child died longer ago within that period reported high levels of depersonalization (two times more than reported a low level of depersonalization) as compared to an equal split in low/high levels found within the first 6 months of that time period.

Prediction 4D: The longer the length of time since death, the lower will be the parental subscale score of Somatization on the Grief Experience Inventory

The range of scores for this subscale was 0-10 out of a possible 19. Table 14 shows the association between length of time since the death and Somatization scores.

TABLE 14

LENGTH OF TIME SINCE DEATH AND SOMATIZATION SCORES

Time Period I

Months Since Death

$0<6 \quad 6<12$

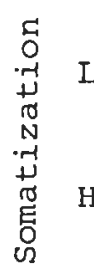

LO

$\mathrm{Hi}$

\begin{tabular}{|l|l|}
\hline 0 & 8 \\
\hline 4 & 4 \\
\hline
\end{tabular}

$4 \quad 12$

16
Time Period II Months Since Death

$12<18 \quad 18<24$

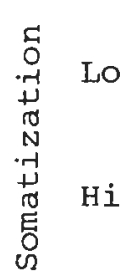

\begin{tabular}{|l|l|}
\hline 4 & 3 \\
\hline 2 & 3 \\
\hline
\end{tabular}

$$
\begin{array}{cr}
6 & 6 \\
p & =.3788
\end{array}
$$


TABLE 14--Continued

Time Period III

Months Since Death

$24<30 \quad 30<36$

\begin{tabular}{|c|c|c|}
\hline Lo & 2 & 10 \\
\hline \multirow[t]{2}{*}{$\mathrm{Hi}$} & 6 & 8 \\
\hline & 8 & 18 \\
\hline
\end{tabular}

A significant association $(p=.0385)$ was found in Time Pe-

riod I. This was a reverse association with parents whose child died earlier in the time period having reported high Somatization scores and those whose child had died later in the time period having reported lower scores $(662 / 3 \%)$. No significant associations were found in Time Periods II and III, however the same pattern found in Time Period I was suggested in Time Period III.

Prediction 4E: The longer the length of time since the death, the more discrepant will be the parental comparisons between pre-morbid coping

Present coping ratings were taken from the following item from the PEAF: "Compared to how I was coping in life prior to my child's illness, I feel that right now I am coping: (1) much worse; (2) a little worse; (3) at the same level; (4) a little better; (5) much better." The discrepancy between the pre-morbid and present coping styles was obtained by subtracting the present from the premorbid coping ratings. If it was a negative number this would indicate 
a positive change since the death. Zero would equal no change. A positive sum would indicate that a negative change had occurred in the person's coping style since the death of the child. Parents' discrepancy scores ranged from -4 to +3 . Table 15 revea 15 the association between length of time since the death and discrepancy between parental pre-morbid and present coping.

TABLE 15

LENGTH OF TIME SINCE DEATH AND DISCREPANCY BETWEEN PRE-MORBID AND PRESENT COPING

Time Period I

Months Since Death

$0<6 \quad 6<12$

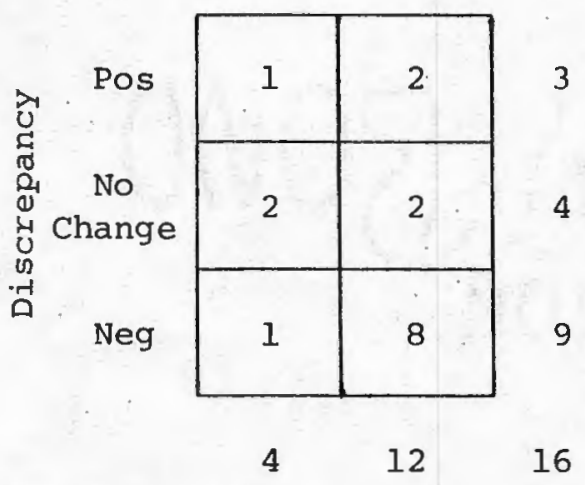

Time Period II

Months Since Death

$12<18 \quad 18<24$

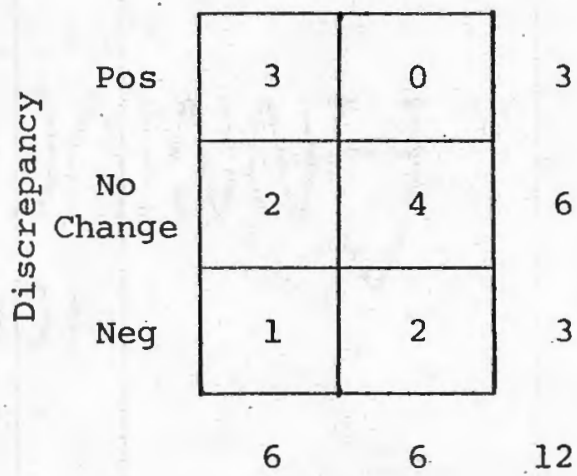

Time Period III

Months Since Death

$24<30 \quad 30<36$

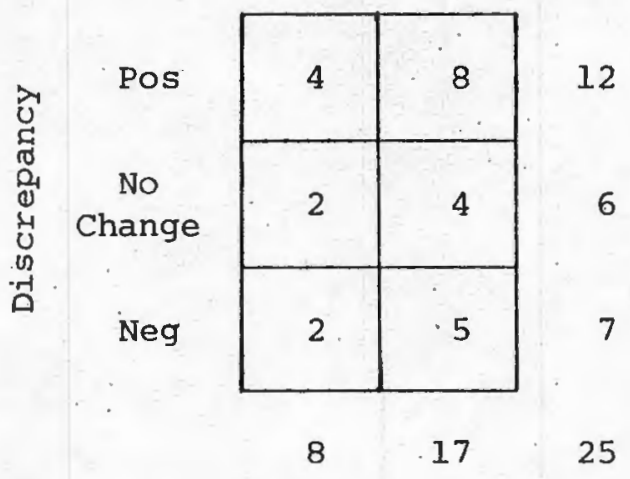


Neither chi-square analysis nor the exact probabilities method of analysis was applicable to these data. With regard to positive change, there appeared to be a pattern of increase in which the percentages of parents evidencing positive change increased each year. In the last half of Time Period I a clear majority of parents $(662 / 38)$ had evidenced negative change in their coping abilities since the terminal illness and death of their child. A similar change in the reverse direction was noted in the last half of Time Period III where fortyseven percent of the parents reported positive changes in their coping. Twice as many were likely to experience positive change as opposed to no change within that entire time period. In Time Period II there was a decided shift to neutral or poorer coping in the latter half of that period when contrasted to the earlier half.

Prediction 4F: The longer the length of time since the death, the lower will be the parental subscale score of Anger/ Hostility on the Grief Experience Inventory

Table 16 indicates the association between length of time since the death and Anger/Hostility scores.

TABLE 16

LENGTH OF TIME SINCE DEATH AND ANGER/HOSTILITY SCORES

Time Period I Months Since Death

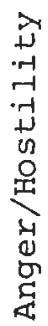

$0<6 \quad 6<12$

\begin{tabular}{|c|c|}
\hline 2 & 5 \\
\hline 2 & 7 \\
\hline 4 & 12 \\
\hline $\mathrm{p}$ & 956 \\
\hline
\end{tabular}

Time Period II Months Since Death

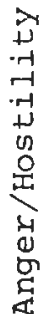
$\mathrm{Hi}$ \begin{tabular}{|c|c|}
$12<18$ & $18<24$ \\
\hline 3 & 3 \\
\hline 3 & 3 \\
\hline
\end{tabular} $6 \quad 12$ $\mathrm{p}=.4545$ 
TABLE 16--Continued

Time Period III

Months Since Death

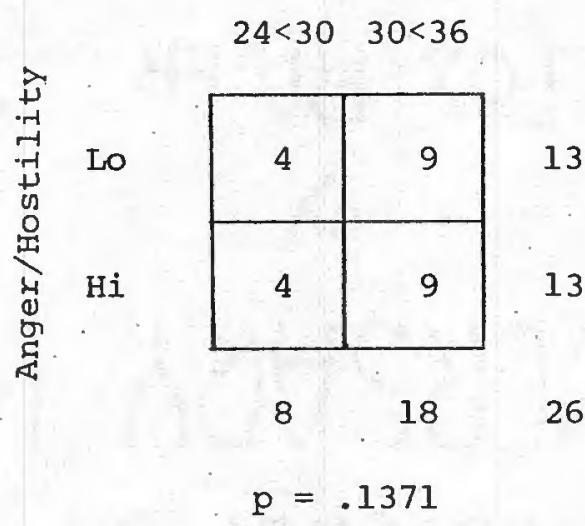

There were no significant associations found within any of the time periods. What is clear is that Anger/Hostility tended to be evenly distributed among all the time periods.

Prediction $4 \mathrm{G}$ : The longer the length of time since death, the lower will be the parental subscale score of Atypical Responses on the Grief Experience Inventory

Table 17 shows the association between length of time since the death and Atypical Responses scores.

TABLE 17

LENGTH OF TIME SINCE DEATH AND ATYPICAL RESPONSES SCORES

Time Period I

Months Since Death $\dot{0}<6 \quad 6<12$

Lo

$\mathrm{Hi}$

\begin{tabular}{|c|c|}
\hline 3 & 7 \\
\hline 1 & 5 \\
\hline 4 & 12 \\
\hline $\mathrm{p}=$ & 956 \\
\hline
\end{tabular}

Time Period II Months Since Death

0
0
0
0
0
0
0
0
0
01
-1
0
0
-1
0
01
01
a $12<18 \quad 18<24$

Lo .

$\mathrm{Hi}$

\begin{tabular}{|c|c|}
\hline 2 & 2 \\
\hline 4 & 4 \\
\hline
\end{tabular}
4 8

6 6 12 
TABLE 17--Continued

Time Period III

Months Since Death

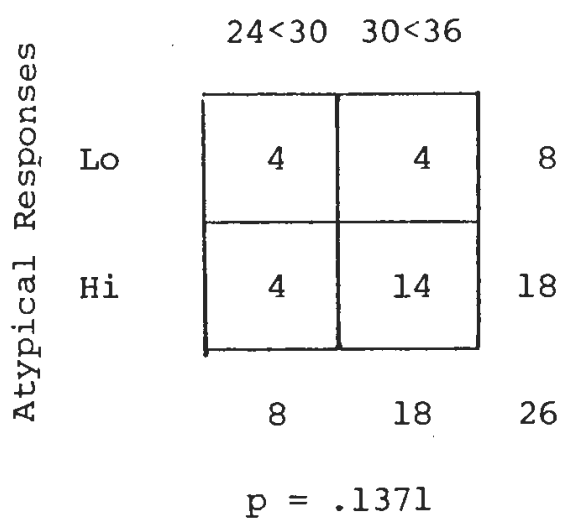

There were no significant associations found within any of the time periods. In Time Period I thirty-eight percent of the parents reported high Atypical Responses scores. In Time Period II sixty-six and two-thirds percent of the subjects received high scores on Atypical Responses. In Time Period III sixty-nine percent reported high Atypical Responses scores. In addition seventy-eight percent of the parents in the last half of that period scored high on Atypical Responses for the overall time period, revealing a marked increase in the number of high scoring parents when compared to the first six months of that time period. Therefore, when comparing the three time periods the percentage of parents with high Atypical Responses scores increased as the length of time from the death increased.

Prediction 4H: The longer the length of time since the death, the lower will be the parental subscale score of Rumination on the Grief Experience Inventory

The range of scores for this subscale was $0-9$ out of a possible 12. Table 14 illustrates the association between length of 
time since the death and Rumination scores.

TABLE 18

\section{LENGTH OF TIME SINCE DEATH \\ AND RUMINATION SCORES}

Time Period I

Months Since Death

$0<6 \quad 6<12$
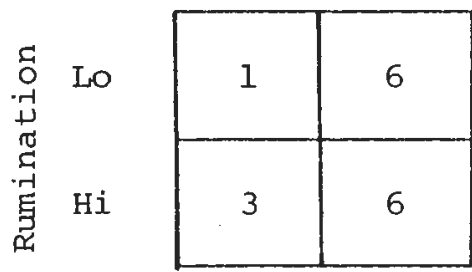

$4 \quad 12$

$p=.3231$
Time Period II

Months Since Death

$12<18 \quad 18<24$

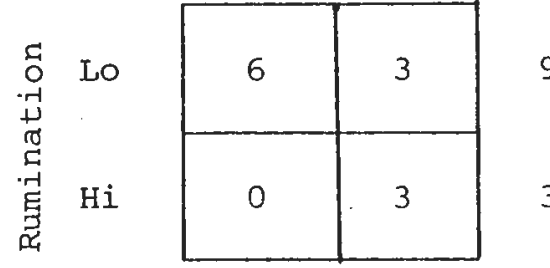

$\begin{array}{lll}6 & 6 & 12\end{array}$

$\mathrm{p}=.0909$

Time Period III

Months Since Death

$24<30 \quad 30<36$

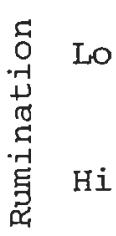

\begin{tabular}{|l|l|}
\hline 3 & 9 \\
\hline 5 & 9 \\
\hline
\end{tabular}

12

14

$8 \quad 18$

26

$\mathrm{p}=.2819$

There were no significant associations within any of the three time periods. Within Time Period II there was a strong suggestion that parents increased in Rumination as time passed. Whereas one hundred percent of the parents within the first half of that period scored low on Rumination, only fifty percent scored low who were in the second half of that time period. 
Prediction 4I: The longer the length of time since the death, the higher will be the parental ratings of subsequent adjustment

Table 19 shows the association between length of time since the death and parental ratings of subsequent adjustment.

TABLE 19

\section{LENGTH OF TIME SINCE DEATH AND RATINGS \\ OF SUBSEQUENT ADJUSTMENT}

Time Period I

Months Since Death

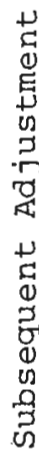

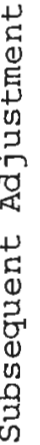

$\mathrm{Hi}$

\begin{tabular}{|c|c|}
\hline $0<6$ & $6<12$ \\
\hline 1 & 1 \\
\hline 3 & 11 \\
\hline 4 & 12 \\
\hline $\mathrm{p}=$ & 000 \\
\hline
\end{tabular}

Time Period II Months Since Death

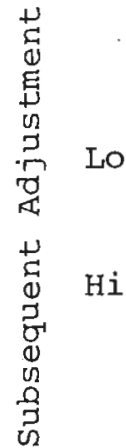
$12<18 \quad 18<24$

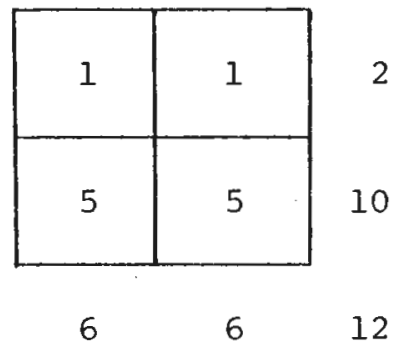

$p=.5455$

Time Period III

Months Since Death

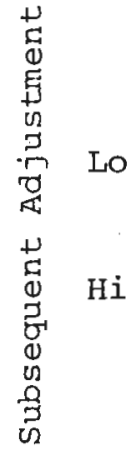

$24<30 \quad 30<36$

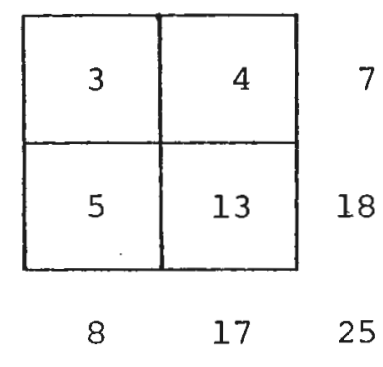

$\mathrm{p}=.2773$

There were no significant associations found within the three time periods. However, for the majority of parents across the entire 
sample rated themselves as highly subsequently adjusted (79\%). Of those who reported themselves as low subsequent adjusters, sixtyfour percent were parents who were in Time Period III and thus had lost their child longer ago.

Pattern analysis over time of GEI subscales, parental Discrepancy scores, and ratings of subsequent adjustment

Each GEI subscale and all parental ratings of subsequent adjustment, along with the Discrepancy scores derived from the differences between the parents' present and pre-morbid coping levels, were analyzed according to the patterns evidenced by mean changes over time. This was done in an effort to get an indication of the patterns of changes over time. Fig. 1 illustrates with graphs the mean scores for the parents on each variable for each of the three time periods.

Fig. 1. Mean GEI subscale, subsequent adjustment and Discrepancy scores for parents in three time periods. (T.P. = Time Period)

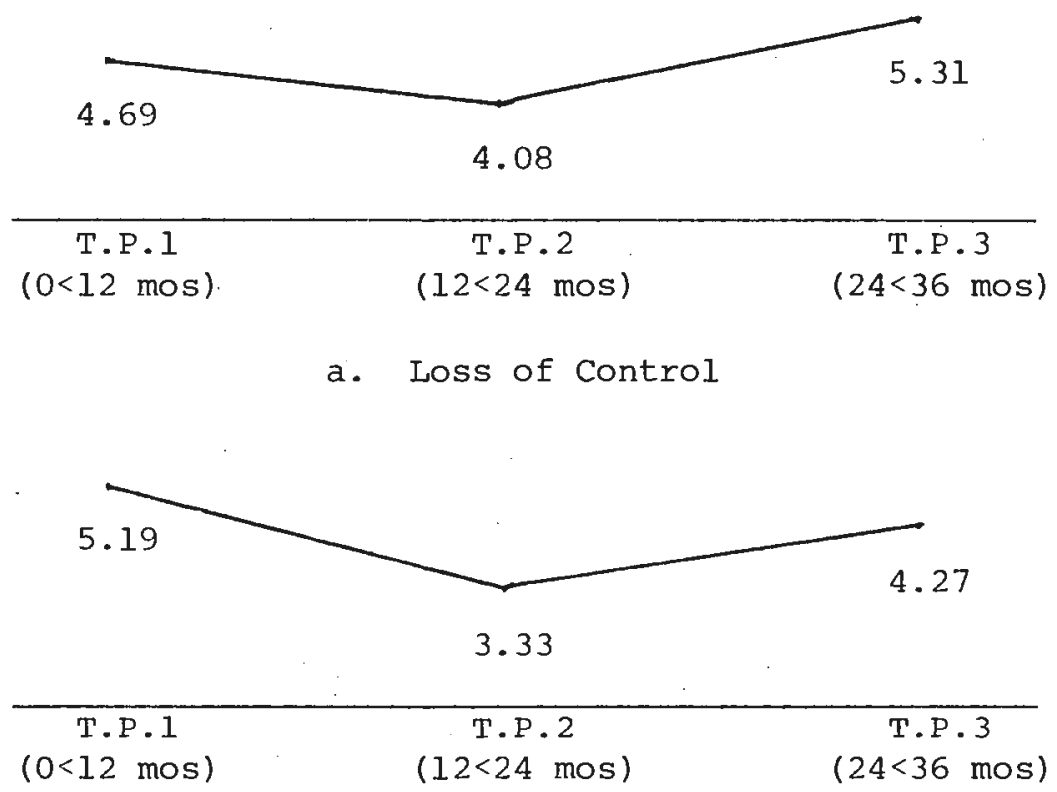

b. Despair 
Fig. 1--Continued

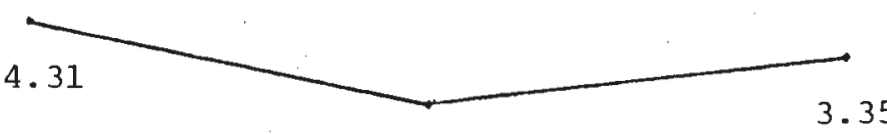

3.17

\begin{tabular}{ccc}
\hline T.P.1 & T.P. 2 & T.P.3 \\
$(0<12$ mos $)$ & $(12<24$ mos $)$ & $(24<36$ mos $)$
\end{tabular}

c. Depersonalization

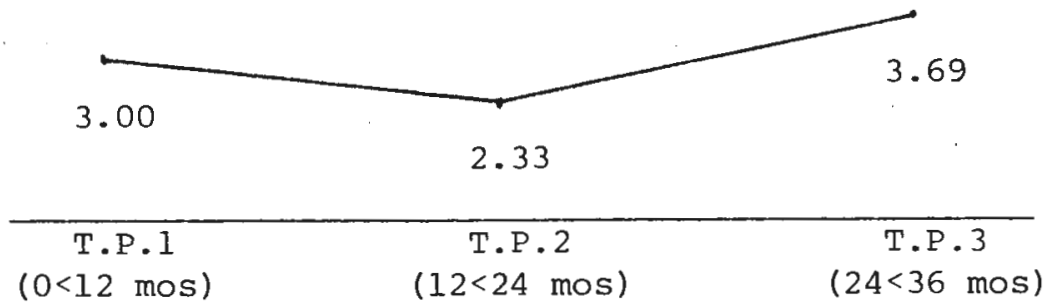

d. Somatization

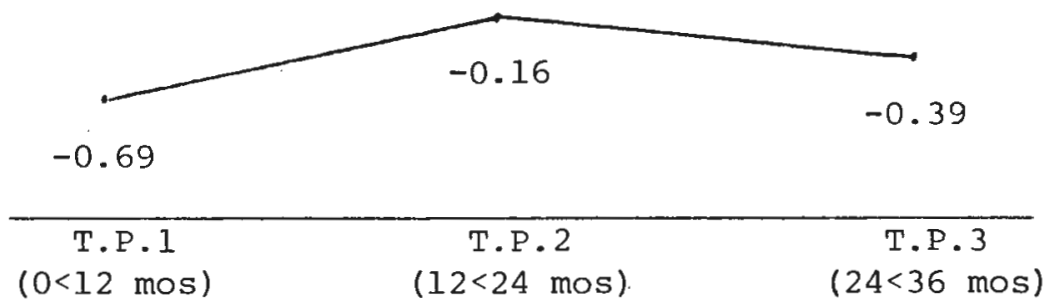

e. Discrepancy Between Pre-Morbid and Present Coping

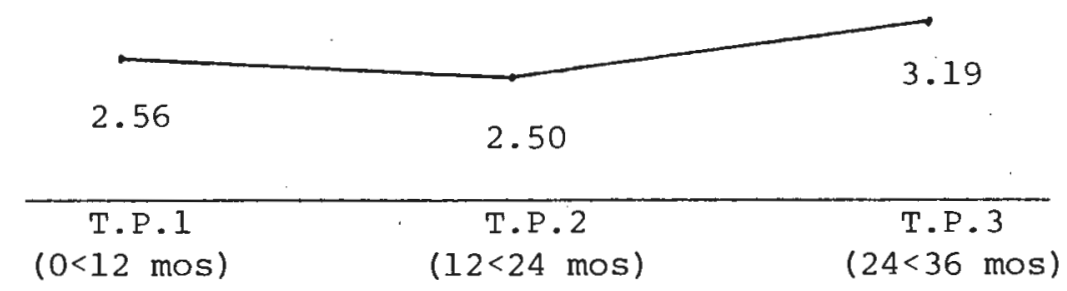

f. Anger/Hostility

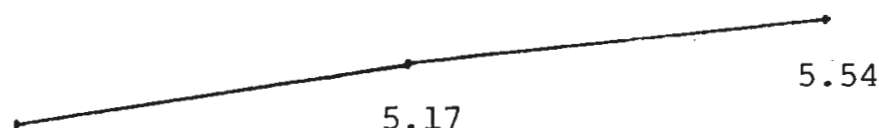

4.06

T.P.I

$(0<12$ mos)

$\begin{array}{cc}\text { T.P. } & \text { T.P. } 3 \\ (12<24 \text { mos }) & (24<36 \text { mos })\end{array}$

g. Atypical Responses 
Fig. 1--Continued

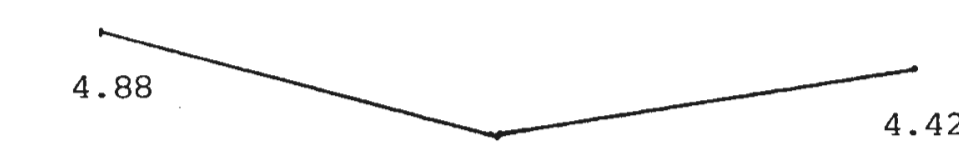

3.33

\begin{tabular}{ccc}
\hline T.P.1 & T.P.2 & T.P.3 \\
$(0<12$ mos $)$ & $(12<24$ mos $)$ & $(24<36$ mos $)$
\end{tabular}

h. Rumination

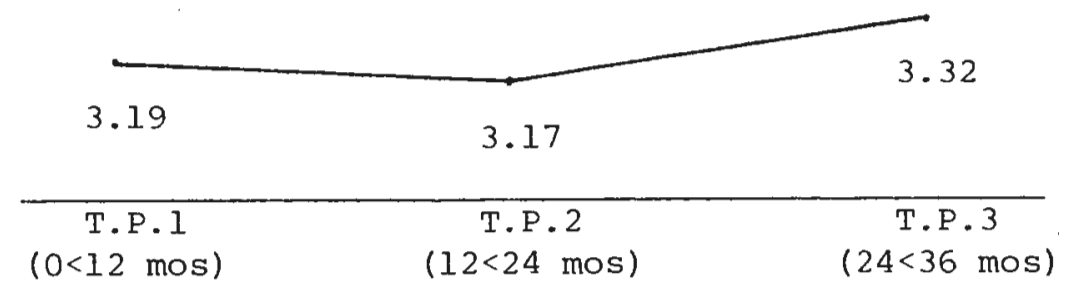

h. Subsequent Admustment

The graphs provide evidence that with the exception of Atypical Responses all the remaining eight variables distributed themselves over time in a similar fashion. There appeared to be a decrease in the intensity of parental experience (i.e., a move in the "positive" or adjusted direction) during the second year, (between Time Periods I and II) which was followed by an increase in intensity (i.e., a move in the negative direction) during the third year (between Time Periods II and III). For Discrepancy scores the pattern appeared inverted visually but the interpretation was still the same since an increase toward positive numbers signalled a negative change. That the overwhelming majority of variables tested (89\%) followed this pattern strongly suggests that something occurs by or within the third year which is correlated with a negative change for the parents.

The sole variable which is an exception to this pattern is Atypical Responses. There was no initial decrease in intensity evidenced within the second year and then reversed in the third. 
Instead; the parental experience of Atypical Responses continued to intensify each year as time went by.

Hypothesis 5: The Sex of Parents is Related to their Grief Experience

Prediction 5A: There will be a significant difference between the mean subscale scores of mothers and fathers on the Grief Experience Inventory

Table 20 indicates the means and $t$-values for each subscale.

TABLE 20

t-VALUES FOR DIFFERENCES BETWEEN MALES AND FEMALES AND MEANS FOR SUBSCALES OF THE GRIEF ·EXPERIENCE INVENTORY

\begin{tabular}{l|ccc} 
GEI Subscales & $\begin{array}{c}\text { Means for } \\
\text { Males }\end{array}$ & $\begin{array}{c}\text { Means for } \\
\text { Females }\end{array}$ & t-values \\
Anger/Hostility & 2.89 & 2.81 & 0.13 \\
Loss of Control & 4.56 & 5.11 & 1.14 \\
Rumination & 4.00 & 4.63 & 1.15 \\
Depersonalization & 3.30 & 3.89 & 0.95 \\
Despair & 3.48 & 5.19 & 1.73 \\
Somatization & 2.44 & 3.93 & $1.98 *$ \\
Atypical Responses & 5.00 & 5.04 & 0.063
\end{tabular}

*Significant at the $\mathrm{p}<.05$ level

A Student's t-test of significance revealed that the sole subscale to significantly differentiate between mothers and fathers was the Somatization subscale which indicated that mothers were significantly higher than fathers $(p<.05, d f=106)$. Mothers were higher on all other subscales with the exception of Anger/Hostility, however not to a statistically significant extent. 
Hypothesis 6: Parental Evaluation of the

Child's Treatment Experiences is

Related to Parental Grief

Experiences

The possible ratings of general overall parental satisfaction

of their child's treatment experiences were as follows: "( 1 ) dis-

satisfied; (2) partially satisfied; (3) mostly satisfied; (4) com-

pletely satisfied." Those rating (1) and (2) were categorized as being

low satisfied. Those rating (3) and (4) were categorized as high

satisfied.

Prediction 6A: The more positively

the parents evaluated their general

overall satisfaction with their

child's treatment experiences, the

lower will be their subscale score

of Anger/Hostility on the Grief

Experience Inventory

Table 21 shows the association between parents' general overall satisfaction with their child's treatment experience and their subscale scores on Anger/Hostility.

TABLE 21

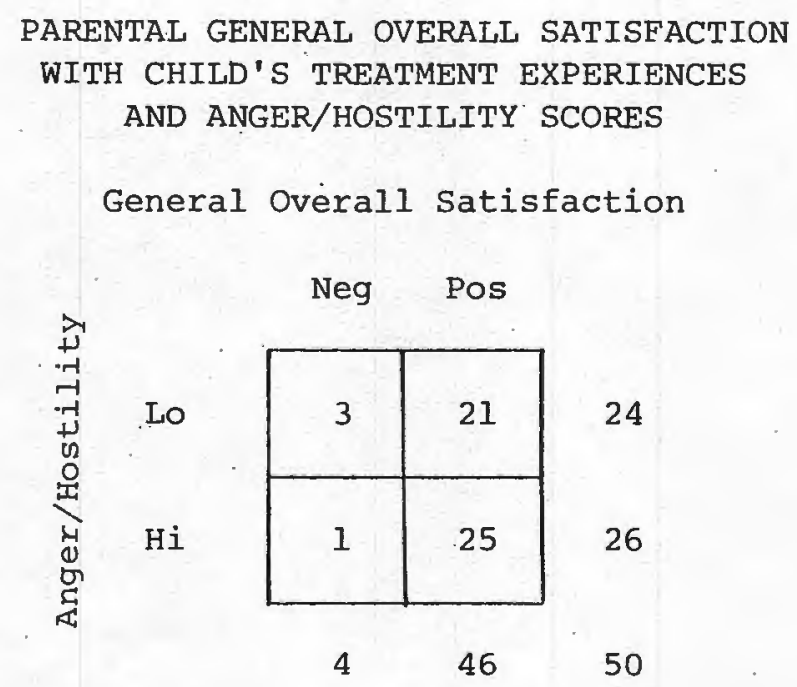


The exact probabilities method yielded $p=.2285$. There was no significant association and the prediction was not supported. In fact, fifty percent of the parents were concurrently high on Anger/ Hostility and Satisfaction with their child's treatment which is in the opposite direction of the prediction. Of those highly satisfied, fifty-four percent were high on Anger/Hostility. The overwhelming majority of parents (92\%) reported being generally satisfied with their child's treatment experiences.

Prediction 6B: The more positively the parents evaluated their general overall satisfaction with their child's treatment experiences, the lower will be their subscale scores of Rumination from the Grief Experience Inventory

Table 22 illustrates the association between parents' general overall satisfaction with their child's treatment experiences and their subscale scores on Rumination.

TABLE 22

PARENTAL GENERAL OVERALL SATISFACTION WITH CHILD'S TREATMENT EXPERIENCES

AND RUMINATION SCORES

General Overall Satisfaction

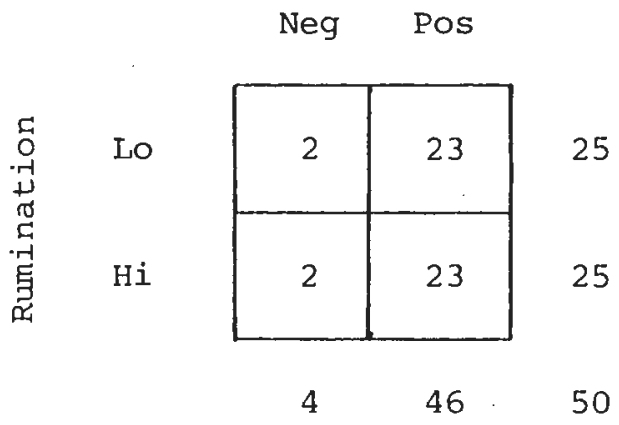

The exact probabilities method rendered $\mathrm{p}=.3908$. There was no significant association and the prediction was not supported. There 
was a definite indication that parents were highly satisfied with treatment $(92 \%)$. Parents were evenly split among low and high scores on Rumination in both the categories of negative and positive satisfaction with their child's treatment experiences.

Hypothesis 7: Anticipatory Grief is Related to Post-Death Grief Experience

Prediction 7A: There will be an association between the number of anticipatory grief behaviors engaged in by the parent prior to the death and their ratings of preparedness at the time of death

The ratings of preparedness were determined from the following question: "How prepared did you feel when your child died?: (1) not prepared at all; (2) a little prepared, but not enough; (3) adequately prepared for me; (4) totally prepared." Individuals who rated (1) or (2) were seen as low prepared and those who selected (3) or (4) were seen as high prepared. The anticipatory grief behaviors were summed for each parent and the totals were broken down by frequency and categorized. Table 23 illustrates the association between the numbers of anticipatory grief behaviors engaged in by parents and their ratings of preparedness at the time of the death.

TABLE 23

NUMBERS OF ANTICIPATORY GRIEF BEHAVIORS

AND RATINGS OF PREPAREDNESS AT DEATH

Preparedness

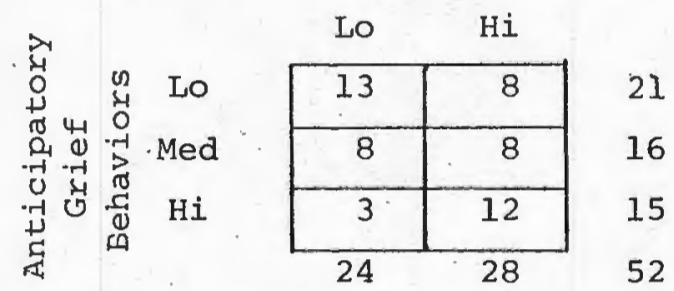


Chi-square analysis yielded a $x^{2}=6.3180(p<.05)$ and $c=.33$, $\mathrm{C}_{\max }=.71, \mathrm{C} / \mathrm{C}_{\max }=.33 / .71, \mathrm{df}=2$. The prediction was supported. Analysis of the table indicated that there was an association in the positive direction which revealed that the more parents had engaged in anticipatory grief behaviors, the more they were prepared for their child's death.

Prediction 7B: There will be an association between the number of the anticipatory grief behaviors engaged in by the parent prior to the death and their ratings of subsequent adjustment since the death

Table 24 shows the association between the number of anticipatory grief behaviors engaged in by the parents and their ratings of subsequent adjustment.

TABLE 24

NUMBER OF ANTICIPATORY GRIEF BEHAVIORS

AND RATINGS OF SUBSEQUENT ADJUSTMENT

Subsequent Adjustment

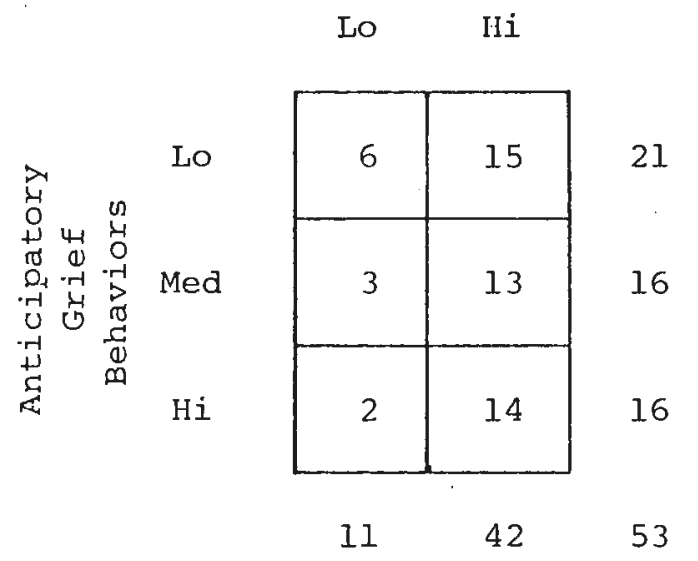

The data does not lend itself to either a chi-square or an exact probability analysis because of the low variance. It is clearly 
visible that the majority of parents (79\%) rated themselves as being high subsequent adjusters and that these high subsequent adjusters, in contrast to the low subsequent adjusters, were almost evenly distributed among the low, medium, and high categories of anticipatory grief behaviors. The majority of the low subsequent adjusters (55\%) had engaged in a low number of anticipatory grief behaviors with the rest distributed in declining fashion as the number of anticipatory grief behaviors increased.

Prediction 7C: There will be an association between the number of anticipatory grief behaviors engaged in by the parent prior to the death and the support they received during the terminal illness

Table 25 illustrates the association between the number of anticipatory grief behaviors engaged in by the parents and the support they reportedly received during the terminal illness of their child.

TABLE 25

\begin{abstract}
NUMBER OF ANTICIPATORY GRIEF BEHAVIORS AND SUPPORT RECEIVED DURING ILLNESS
\end{abstract}

Amount of Support

Lo Hi

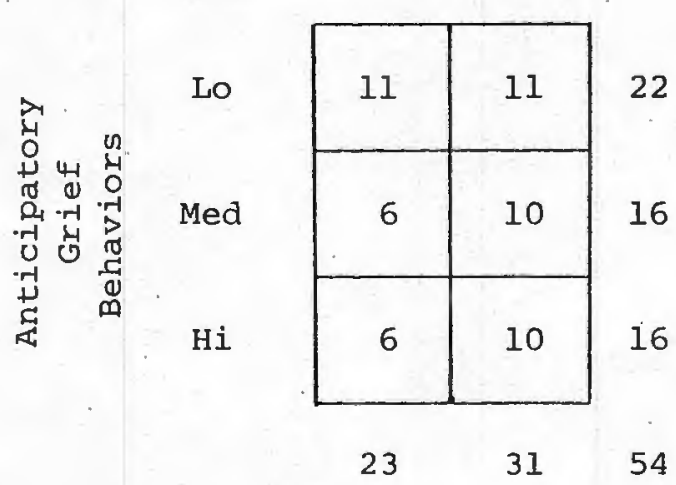


A chi-square analysis yielded a $x^{2}=.8340(p>.05)$. There was no significant association between the variables and the prediction was not supported. Parents who reported low support appeared to have engaged in fewer numbers of anticipatory grief behaviors.

Prediction 7D: The greater the amount of anticipatory grief behaviors, the less will be the subscale score of Atypical Responses from the Grief Experience Inventory

Table 26 shows the association between the numbers of anticipatory grief behaviors engaged in by the parent and their Atypical Responses subscale scores.

TABLE 26

NUMBER OF ANTICIPATORY GRIEF BEHAVIORS AND ATYPICAL RESPONSES SCORES

Atypical Responses

Lo Hi

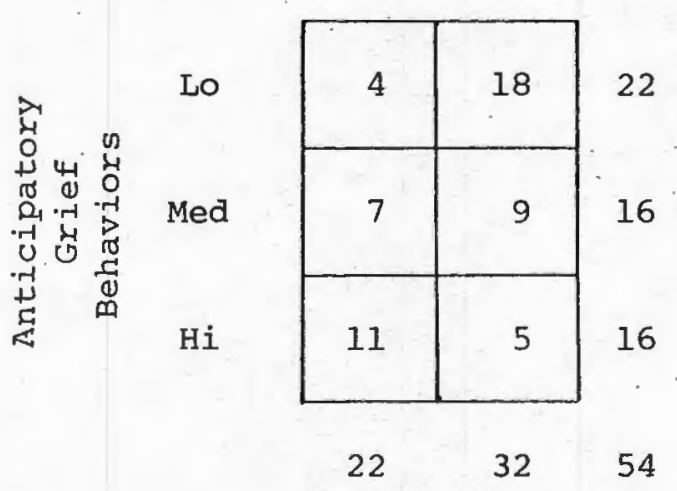

A chi-square analysis yielded $x^{2}=9.8873$ which was significant at the $\mathrm{p}<.01$ level. The prediction was supported. The data indicated that as the number of anticipatory grief behaviors increased, the number of Atypical Responses after the death decreased. 
prediction 7E: The greater the amount of anticipatory grief behaviors, the less will be the subscale score of Anger/Hostility from the Grief Experience Inventory

Table 27 shows the association between numbers of anticipatory grief behaviors engaged in by the parents and their Anger/Hostility subscale scores.

TABLE 27

NUMBER OF ANTICIPATORY GRIEF BEHAVIORS

AND ANGER/HOSTILITY SCORES

Anger/Hostility

Lo $\quad \mathrm{Hi}$

\begin{tabular}{|c|c|c|c|}
\hline \multirow{3}{*}{ 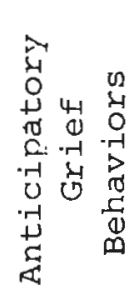 } & Lo & 11 & 11 \\
\hline & Med & 10 & 6 \\
\hline & $\mathrm{Hi}$ & 5 & 11 \\
\hline
\end{tabular}

A chi-square analysis yielded $x^{2}=3.18(p>.05)$. The prediction was not supported. In both low and high anticipatory grief groups, greater percentages of parents reported higher amounts of Anger/ Hostility, suggesting the notion of an optimum amount of anticipatory grief, i.e., the medium group. Additionally, subjects who were high anticipatory grievers had greater percentages of parents who scored high in Anger/Hostility.

Prediction 7F: The greater the amount of anticipatory grief behaviors, the less will be the subscale score of Loss of Control from the Grief Experience Inventory 
Table 28 indicates the association between the numbers of anticipatory grief behaviors engaged in by the parents and their Loss of Control subscale scores.

TABLE 28

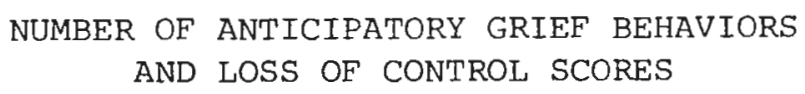

Loss of Control

LO $\mathrm{Hi}$

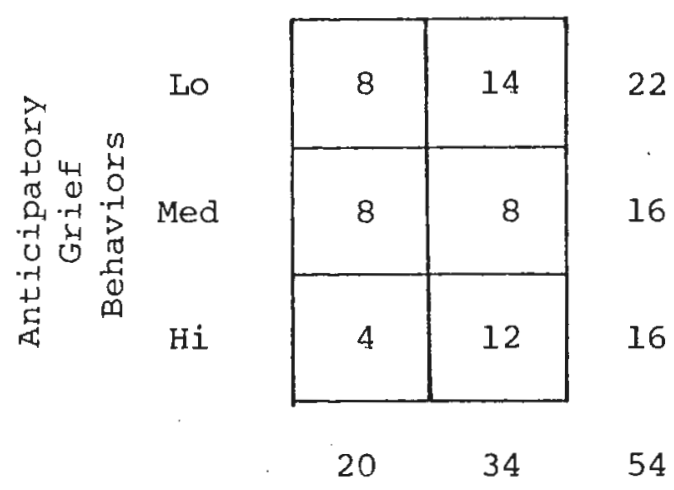

A chi-square analysis yielded $x^{2}=2.1506(p>05)$. The association was not significant and the prediction was not supported. The high anticipatory grief group included a larger proportion of parents with high Loss of Control subscale scores than was found in the other anticipatory grief groups. Again there is the implication that the medium range of anticipatory grief behaviors is an optimum one as it appears to be associated with less Loss of Control than either the low or high anticipatory grief groups.

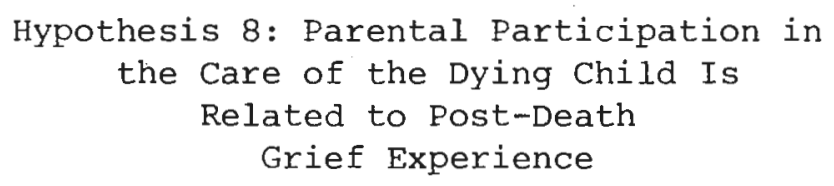

The following question from the PEAF was used to objectify 
the parents' behavioral involvement and participation in the care of the hospitalized child: "During your child's hospitalizations which of these behaviors, if any, did you participate in? Rooming-In; Visiting; Feeding/Dining with child; Clothing/Dressing child; Bathing; Helping hospital staff with procedures; Discussing illness with child." The participation behaviors scores were determined by summing the total number of behaviors the parents indicated they had participated in during their child's hospitalizations. These were divided by a median split into low and high categories. The range of numbers of behaviors participated in was $1-7$.

Prediction 8A: There will be an association between the amount of behaviors involving the care of the hospitalized child which the parents participated in and the parental ratings of subsequent adjustment

Table 29 shows the association between the number of behaviors in which parents participated in the care of their hospitalized child and the parents' ratings of subsequent adjustment.

\section{TABLE 29}

\section{NUMBER OF BEHAVIORS PARTICIPATED IN BY PARENTS DURING CHILD'S HOSPITALIZATIONS AND \\ PARENTS' RATINGS OF SUBSEQUENT ADJUSTMENT}

Subsequent Adjustment

Lo $\quad \mathrm{Hi}$

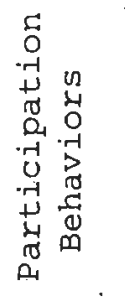

\begin{tabular}{|c|c|c|}
\hline Lo & 8 & 21 \\
\hline $\mathrm{Hi}$ & 3 & 21 \\
\hline
\end{tabular}



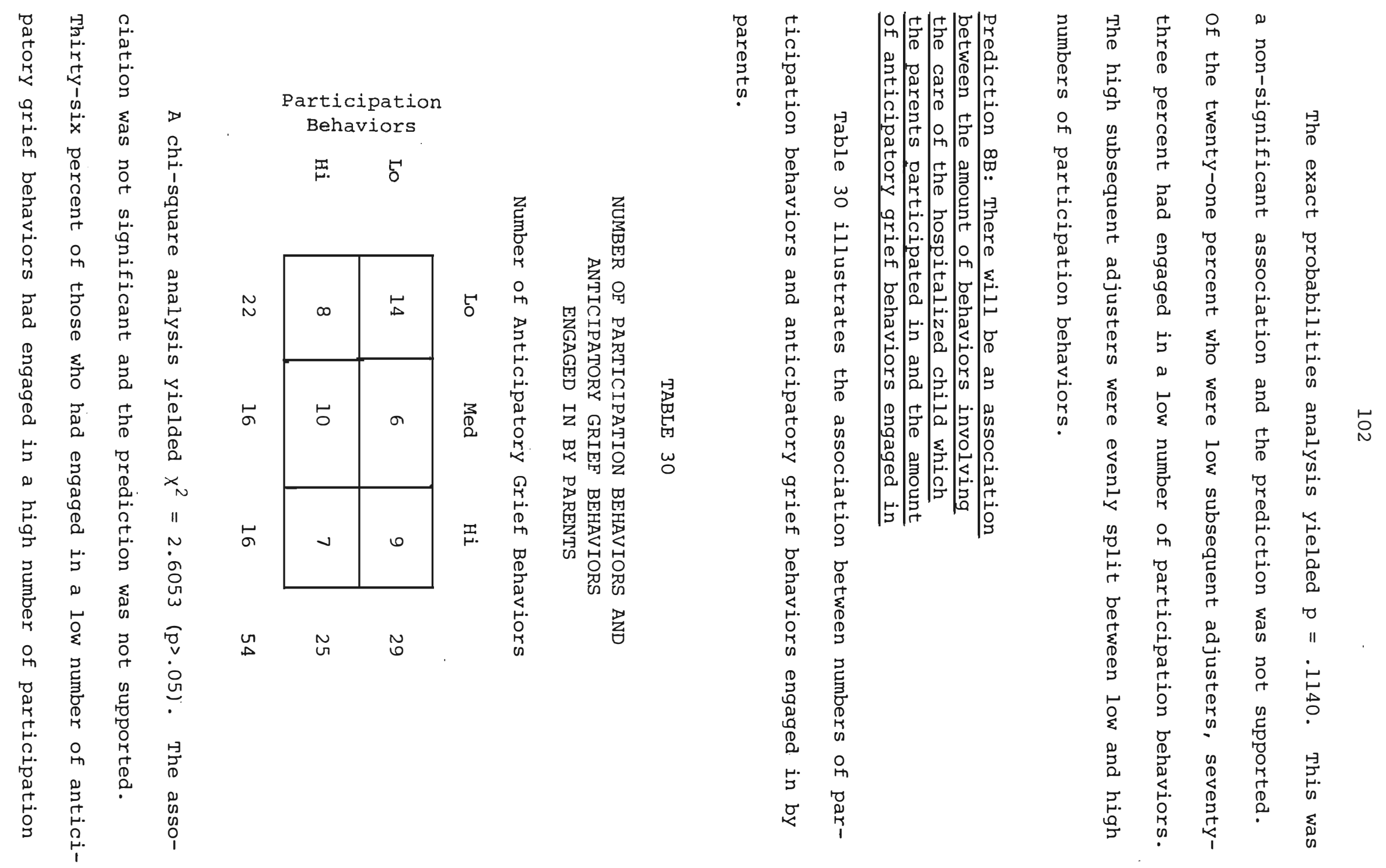
behaviors. This in in contrast to sixty-two percent for the medium anticipatory grief behaviors group and forty-four percent of the high anticipatory grief behaviors group. High numbers of participation behaviors seem to be most facilitated by a medium number of anticipatory grief behaviors. This appears to reflect an optimum amount of anticipatory grief behaviors above and below which parental participation declines.

Prediction 8C: There will be an association between the amount of behaviors involving the care of the hospitalized child which the parents participated in and the positive ratings of parental satisfaction with the child's treatment experiences (evaluation of child's treatment experiences)

Table 31 shows the association between the number of parental participation behaviors and the ratings of satisfaction with the child's treatment experiences.

TABLE 31

NUMBER OF PARTICIPATION BEHAVIORS AND RATING OF SATISFACTION WITH

CHILD'S TREATMENT

EXPERIENCES

Satisfaction with Child's Treatment Experiences

Lo $\quad \mathrm{Hi}$

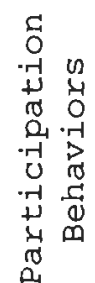

Lo

\begin{tabular}{|l|l|}
\hline 4 & 21 \\
\hline 0 & 25 \\
\hline
\end{tabular}
25 $\mathrm{Hi}$

$4 \quad 46 \quad 50$

An exact probabilities analysis yielded $\mathrm{p}=.0549$. The association was significant and the prediction was confirmed. Virtually 
all of those who reported low satisfaction with their child's treatment experiences had engaged in only a low number of participation behaviors. Those who were highly satisfied were more evenly split among low and high numbers of participation behaviors. This finding suggests a positive relationship with satisfaction tending to increase as the amount of participation increases. Most parents (92\%) appeared to be overwhelmingly satisfied with their child's treatment experiences.

Prediction 8D: There will be an association between the amount of behaviors involving the care of the hospitalized child which the parents participated in and the parent's ratings of satisfaction with their own involvement with their child

The ratings of satisfaction with the parents' own involvement with their child were determined from the following question on the PEAF: "Please rate your satisfaction with the amount of involvement you had with your child: (1) dissatisfied; (2) partially satisfied; (3) mostly satisfied; (4) completely satisfied." Those who rated either (1) or (2) were seen as low satisfied and those who rated (3) or (4) were seen as being high satisfied. Table 32 shows the association between the number of parental participation behaviors engaged in and the parents' ratings of satisfaction with their own involvement with the child.

TABLE 32

NUMBER OF PARTICIPATION BEHAVIORS AND

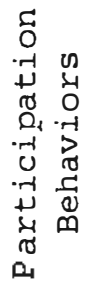
RATINGS OF SATISFACTION WITH

INVOLVEMENT WITH CHILD Satisfaction with Involvement

\begin{tabular}{|c|c|c|}
\hline \multirow{3}{*}{ IO } & Lo & $\mathrm{Hi}$ \\
\hline & 3 & 25 \\
\hline & 1 & 23 \\
\hline & 4 & 48 \\
\hline
\end{tabular}



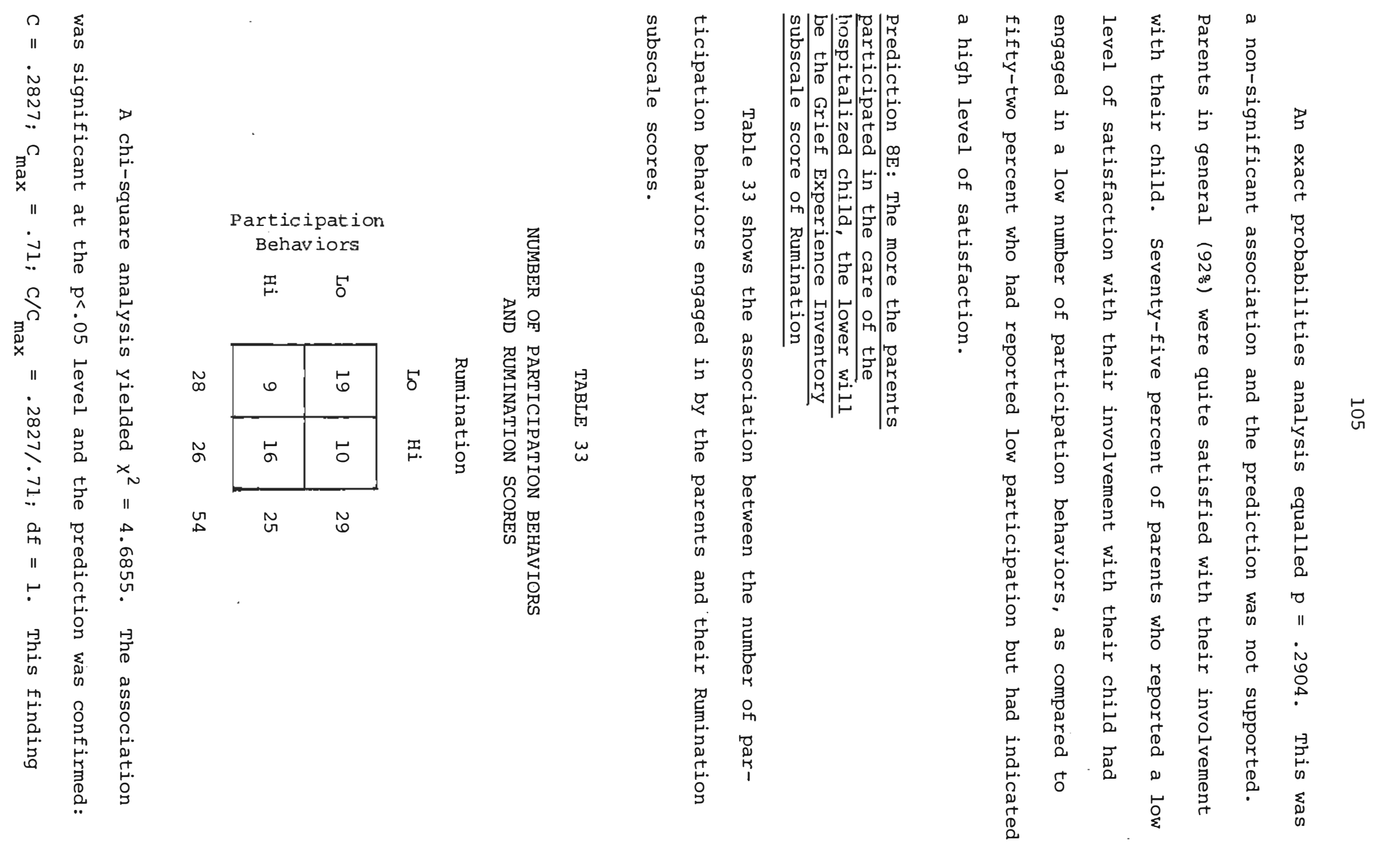
indicated that Rumination was associated with participation behaviors in a positive fashion with low numbers of participation behaviors associated with low Rumination scores, and high participation behaviors associated with high Rumination scores. Thus, as the number of participation behaviors increased so did Rumination. This finding is in the opposite direction of the prediction. 
CHAPTER V

\section{DISCUSSION}

The purpose of this investigation has been to critically examine retrospectively the experience and adaptation of parents during and subsequent to the terminal illness of their child afflicted with cancer. Previous research had been scarce, with inconsistent findings often based upon subjective clinical observation without valid, objective, or reliable measures. The research was mostly conducted prior to the recent advances in the treatment of cancer which has become more of a chronic, life-threatening illness demanding new treatment regimens and life expectancies, and resulting in altered familial lifestyles and experience. In this investigation fifty-four parents (twenty-seven married couples) were administered two objective instruments, the Grief Experience Inventory (Sanders et al. 1978; Appendix 1) and the Parental Experience Assessment Form (Rando 1979; Appendix 2), along with a Structured Interview; Appendix 3). The information provided current and retrospective information and parental perceptions about the parents' experiences during and after their child's terminal illness. Eight hypotheses generating thirty-one predictions were tested.

The majority of the information herein is based upon parental self-report data. Therefore, all conclusions drawn from this investigation are subject to the inherent assets and limitations of personal 
perspective. Procedures followed to minimize retrospective distortion were delineated in the Methodology chapter of this work and will not be repeated here.

Discussion of the results lends itself to a tripartite division: Personal Characteristics Influencing Parental Experience and Adaptation; Time Factors Influencing Parental Experience and Adaptation; and Parental Experience During the Illness. Each section will be examined with respect to the others and with discussion of implications.

\section{Personal Characteristics Influencing Parental Experience and Adaptation}

Personal characteristics of the parents were addressed in Hypotheses 2 (Previous Loss Influences Grief) and 5 (The Sex of Parents Is Related to Their Grief Experience).

In analyzing the impact of previous loss, this study found that high subsequent adjustment was associated almost twice as often with low loss as with high loss, in contrast to almost an equal split for low subsequent adjustment. This corresponds with findings in other literature indicating that loss experiences appear associated with poorer bereavement outcomes. The converse of this would imply that more positive outcomes would follow the relative absence of loss experiences. This stands in contradiction to the psychological theory proposed by Janis (1962) and others who would assert that a moderate amount of stress (in this case, anxiety from past losses). is therapeutic and that successful resolution of past losses would predict a more favorable outcome. Perhaps the key word is "successful." Nevertheless, ninety-five percent of the loss experiences 
reported by the parents were rated as having been successfully coped with, and the pattern was the same as that found by Parkes $(1975,1972)$ and Maddison (1968) when they reported that life crises prior to the death were associated with poorer outcome. Therefore, from this data; successfulness of coping with the loss appears irrelevant and the important determinant appears to be the amount of previous loss experienced which exerts a strong influence on the adjustment following the bereavement.

With regard to sexual differences the findings from this investigation reveal that there was only one GEI subscale on which there was a significant difference between fathers and mothers. This occurred on the Somatization subscale with the mothers significantly higher than the fathers. Interpretation of this finding must take into account the well-known tendency of females to admit to more somatic distress than males, and thus the reporting characteristics may have been influential. Nevertheless the finding is still significant and replicates many findings from previous literature. Also consistent with previous findings is the fact that with the exception of the Anger/Hostility subscale (on which fathers were .08 points higher in their mean as compared to mothers) mothers had higher mean scores than fathers on the GEI subscales. Therefore mothers appear to "experience" or at least admit to more intense reactions to bereavement than do fathers on the Grief Experience Inventory. Parenthetically, it is interesting to note that the sole subscale on which fathers were higher than mothers was Anger/Hostility. Out of all the emotions tapped by subscales of the GEI, Anger/Hostility is the one which would be most socially acceptable for males in our culture to admit to. 
Sexual response differences were also analyzed on the variables of anticipatory grief (as measured by the number of anticipatory grief behaviors reported), on the degree of parental participation during the child's illness (as operationalized by the amount of participation behaviors engaged in during the child's hospitalizations), and on parental reports of subsequent adjustment following the child's death. There was no statistically significant difference among mothers and fathers on the amount of anticipatory grief, although mothers reported more anticipatory grief behaviors than fathers. Neither was there any significant difference among parents with regard to their subsequent adjustment, however fathers clearly were higher in their adjustment than were mothers. There was a significant difference among parents with regard to the amount of their participation during their child's hospitalizations. Mothers were clearly more involved than were fathers.

These findings (which are derived from the data but not included directly in any of the main hypotheses) suggest several interesting thoughts. Previously researchers had postulated that the mother's increased participation facilitated her anticipatory grief and her higher subsequent adjustment (Hamovitch 1964). Also, many theorists have asserted the importance of anticipatory grief for the successful adaptation following the death (see literature review on Anticipatory Grief). These premises are not supported with the data from this investigation. Fathers were definitely inferior to mothers in the amount of participation behaviors engaged in, yet they were almost equal in their amount of anticipatory grief. This illustrates that participation need not be a sole or critical determinant 
of anticipatory grief and that there appears to be something which recompenses the fathers who have had lower levels of participation but report the same amount of anticipatory grief as mothers. An alternative possibility is that fathers may have a different optimum level of participation than do mothers. A socially-oriented explanation posits that fathers may consider their wives' participation to discharge their (the father's) responsibilities toward the child. The stereotypical social role of the mother which centers on her expressive function in the family, may give rise to this. This could explain why a relative deficit in participation behaviors (as compared to mothers) is not coincided with by lower anticipatory grief or subsequent adjustment on the part of the fathers, since they may feel their participation "duties" have been met by their wives' participation in addition to their own.

Fathers also reported higher levels of subsequent adjustment than did the mothers. This is consistent with the data reported from the Grief Experience Inventory in which mothers appeared to experience more intense reactions than did fathers. For fathers as a group, their lowered participation did not adversely affect their adjustment relative to their wives. Again this implies a restitutive mechanism which allows the fathers to equal and surpass mothers in their coping following the death, independently of being less involved behaviorally during the illness. The alternate explanation is that such behavioral indices of participation do not tap the "real" dimensions of participation and involvement. This may account for the almost equal anticipatory grieving of the parents despite dissimilar amount of behavioral participation. 
Another interpretation that is suggested by the present study is that contrary to the implications of previous theorists, the fathers are actually as involved in the process of anticipatory grief as are the mothers. Therefore, the social role of the male does not seem to preclude his emotional experience of anticipatory grief although it may affect his ability to participate behaviorally in his child's care. With regard to fathers, care must be taken not to insinuate emotional involvement or engagement in anticipatory grief from observable participation behaviors alone, since they appear not to be a reliable solitary predictor of the levels of such involvement.

In considering the present findings and implications of the parents' role and sex differences on the above variables, it is important to remember that a criterion for inclusion in the study was that parents still be married. This condition of still being married may imply certain selection characteristics of the parents which make generalizing information from this study to all parents (including those whose marriage fails) invalid. For example, perhaps the reason that a marriage was still intact was precisely because of a father's commitment to the family. His reactions during the illness may be different from that of the father who lacked such a commitment, which subsequently was reflected in a marital break-up and possibly would have been evident in a different type of experience for the father than is seen in this population. Further study of parents whose marriages failed. will be important to discern more completely to what degree the parents and experiences described here are representative of parents of terminally ill children in general: 
Time Factors Influencing Parental

Experience and Adaptation

There are two time dimensions which were examined in this investigation. The first time dimension is the Length of the Child's Illness (Hypothesis 3 ) and the second concerns the, Length of Time Since the Death (Hypothesis 4).

Results from this investigation, although not significant at a statistically acceptable level, did reveal three interesting points that bear on the impact of the duration of the illness.

First, the number of parents who were low on preparedness for their child's death was the highest for those groups with the least warning (length of illness less than six months) and with the most warning (length of illness greater than eighteen months). Those whose child died in the interim ranges (length of illnesses ranging from six to eighteen months) appeared to be the most prepared for the death. This finding supports both observations about the relationship between length of illness and bereavement: the one which states that a short illness is detrimental. (Natterson and Knudson 1960; Knudson and Natterson 1960; Chodoff et al. 1964; Binger et al. 1969; Silverman 1972; Glick, Weiss, and Parkes 1974; Parkes 1975; and Vachon 1976), and the school of thought asserting that prolonged illness is detrimental for the survivors (Gerber et al. 1975; Schwab et al. 1975; and Hamovitch 1964).

When analyzing which condition appears to be the worse for the parents in relation to their preparation time at the time of death, it is clear that it is most difficult for those whose children had the longest illness.

The second point relevant to these issues is that there appears 
to be evidence of a pattern suggesting that parents whose children had longer illnesses tended to have higher Atypical Responses subscale scores on the GEI. This implies more disturbed reactions on the part of these parents since the Atypical-Responses subscale measures responses which are statistically indicative of abnormality. Along with this is the suggestion of an increase in the intensity of Anger/Hostility as the length of the illness increases. For each successive time period there is an increase in the level of the parents' subscale scores of Anger/Hostility suggesting that the longer the illness continued, the angrier the parents were after the death.

These findings taken together suggest that there may be an optimum length of terminal illness as it is related to parental grief experience. With regard to the idea of an optimum length of illness as is related to parental grief experience, corroborating evidence is found in an analysis of the association between length of illness and parental subsequent adjustment. Of those parents whose child's illness lasted from six to eighteen months, ninety-three percent reported high subsequent adjustment. This is in contrast to eightyfour percent of those whose child had an illness of less than six months and sixty-five percent of those whose child's illness lasted longer than eighteen months, suggesting the ill effects of too long an illness and the optimum length of illness as from six to eighteen months. In its role as a determinant of parental preparation at the time of death the length can be neither too short nor too long. When it is too short parents appear to be unable to adequately prepare themselves. Apparently when an illness is longer than eighteen months 
the experience and stress associated with it exacerbates disturbed reactions following the death, increases the intensity of f'eelings of anger and hostility, and possibly acts to mitigate against adequate preparation when death finally comes following such a long course, one presumably filled with remissions as well as relapses. The possibility of parental denial of death arising since the child has survived so long with the disease may be important. An alternate possibility is that the long and arduous experience of such a lengthy illness saps the parents of their ability to cope as effectively as desired and thus their ability to be appropriately prepared at the time of death is compromised. The role of steadily increasing abnormal responses and intensifying anger and hostility may also preclude therapeutic readiness.

Further investigation of the grief experience of these sample parents needs to be conducted with the subjects divided according to the lengths of their children's illnesses and their ages at diagnosis and death in order to determine more accurately the impact of this variable.

There were numerous suggestions derived from the present investigation and its findings with respect to the influence of length of time since death and parental grief. All GEI subscales, as well as parental subsequent adjustment and discrepancy between pre-morbid and present coping, were analyzed within one of the three one-year intervals between the occurrence of the death and the interview. The range of time for the lengths of time since the death was from two months, ten days to two years, eleven months, twenty-seven days. Patterns exhibited across the entire three years included the steady increase in percentages of parents evidencing positive 
change as represented by the discrepancy scores of the parents between their pre-morbid and present coping levels. This seems to indicate that with the passage of time comes the increasing ability to cope at levels superior to those existent prior to the child's death. Several possible implications may be derived from this. First, that the experience of losing a child and surviving that loss indicates to the parents that they can cope with anything and that this recognition becomes more salient as time progresses and they continue to live on without their child. An alternative explanation is that the parents were so stunned who had recently lost a child that their discrepancy scores indicating negative or no change artificially lowered the positive discrepancy scores and that what is construed as an increase in positive coping may actually be a decrease in negative or neutral discrepancy coping. A third implication is that the apparent increase in positive discrepancies actually reflects an increasing level of denial on the part of the parents.

Support for this third implication (not to imply lack of support for the other two) comes from the increasing amount of denial that is reflected by the Denial subscale of the GEI. Although this subscale was not utilized in the testing of the hypotheses and their predictions (due to a currently unacceptable Alpha coefficient), the parental scores were analyzed independently. Over the three-year period represented in this study Denial rose consistently each year, increasing with distance from the death.

Another pattern that was clearly apparent during the threeyear spectrum investigated was that the percentages of parents 
experiencing low and high levels of Anger/Hostility on the GEI remained almost consistent throughout each of the six six-month periods. Thus, there appeared to be little change in the way that Anger/Hostility was distributed over time. The mean scores of each time period differed slightly but the percentages of parents experiencing them did not.

A third general pattern is expressed in a configural pattern to which all the GEI subscales except Atypical Responses and to which both parental subsequent adjustment and discrepancy scores conformed. This pattern is a " $V$ " configuration in which there is a decrease in the intensity of the experience in the second year of bereavement which is followed by an increase in intensity in the third year. (For the discrepancy scores an inverted " $\mathrm{V}$ " is perceived but the interpretation of the experience is still the same, with a move in the positive direction evident in the second year and then reversed in the third year.)

This pattern suggests that the third year of bereavement constitutes an experience which shifts the parents' responses from the positive to the negative direction. Exactly what the nature of this experience might be is unclear at the present time. There is data from several other GEI scales which may shed some light on the matter. In addition to Denial, several other GEI subscales were administered but not included in the hypotheses due to insufficient Alpha coefficients in the normative findings of the instrument. These are: Death Anxiety, Social Desirability, Social Isolation, and Guilt. The first two reflected a "V" configuration seen in the majority of the subscales. Social Isolation remained the same during the first 
two years prior to decreasing in the third year. Guilt declined steadily during the entire three years. Accompanying these is the Atypical Responses subscale, which had an adequate Alpha coefficient and was therefore utilized in the hypotheses and predictions of the present study. Scores on this scale, like that measuring Denial, rose steadily each year.

A possibility immediately apparent is that the rising denial allows for the decreasing guilt, as the normal parental defensive process reconstitutes after the severe blow dealt to it by the death of the child. Herein such a rise in denial would be considered adaptative, i.e., positive change. What appears to be less adaptative is the increasing tendency of the parents to endorse items (in Atypical Responses) which less than twenty-five percent of the GEI normative sample endorsed and hence, by empirical definition, reflects an increasing predisposition toward "abnormal" grief experience.

One possible explanation for the typical " $V$ " configuration may be that the increasing rise of Atypical Responses reflects an increase in intensity of bereavement experience and symptomatology which influences the other subscales toward intensification subsequent to their normal course of diminution in the second year after the death.

As mentioned previously, the rising GEI scale of Atypical Responses is paralleled by the similarly rising scale of Denial. This may reflect their both responding to a particular experience which would prompt them both to rise, i.e., an intensification of the grief process, or the Denial may elevate in response to the rise of Atypical Responses. Therefore, in the first case the rise in Denial may be construed to be more symptomatic, while in the second it may be viewed 
as more defensive. Although this may appear to be a question of semantics it is probably more than that since the continual rise of Atypical Responses, more so than Denial (at least at this point), begs explanation. Unfortunately, outside of the following interpretation, the reasons for this are unclear.

A phenomenon influencing the rise of both Denial and Atypical Responses may be the decrease of Social Isolation and the increase in Social Desirability in the third year. There may be something in the experience of resumed social contact that warrants an increase in Denial, especially as parents are increasingly exposed to the world on-going in spite of the loss of their child. If this "re-entry" is too painful it could prompt a temporary intensification of bereavement, resulting in the third year (at the precise time of decreased Social Isolation) in a swing in the negative direction of the majority of GEI subscales (hence the "V") and the exacerbation of Atypical Responses and Denial. Guilt is relieved by both the increase in Denial as well as not being a necessarily consequent emotion in the aforementioned conjectured situation.

Clearly continued research in this area is needed. To the author's knowledge this is the only empirical investigation of temporal effects on the bereavement symptomatology of parents who have lost children. The commonly held assumption that parental grief either diminishes in time or, at least continues unabated, is strongly challenged here with evidence suggesting an intensification of the bereavement experience in the third year subsequent to a decrease in the second. 
With respect to the influence of time on the variables of grief there were other findings. These occurred within the oneyear periods delineated and are discussed below.

of the subjects representing the first year of bereavement, seventy-five percent scored high on Depersonalization. This is consistent with prevailing theory that feelings of depersonalization are both high and normal after a death. A significant association was found which also corroborated the general concensus of thought. This was the association indicating that within the first year of bereavement Somatization decreases as time goes on. Also within the first year it is evident that the second six months saw an increase in Loss of Control and the numbers of parents who were coping poorer than prior to their child's illness (Discrepancy scores).

Within the second year of bereavement Loss of Control continued to be associated with time, this time to a statistically significant level, and there were more parents in the second six-month period with higher Loss of Control scores. Accompanying this was the tendency for Rumination to become more intense in the latter half of the year. In the third year of bereavement (the one in which there appears to be an experience prompting the intensification of grief responses relative to the second year) one finds sixty-four percent of the entire total of low subsequent adjusters from across the whole sample population. This clustering of low adjusters in this time period is a theoretically unexpected finding; however, it appears consistent with the data indicating high levels of Atypical Responses and relatively higher intensities on the majority of GEI scales evidenced at that time period. In this case, time appears to be associated 
with poorer adjustment and more intense bereavement. This strongly points out the need for continued research in this vein, not only to determine if the present findings can be corroborated, but to assess if there are further changes over time beyond that found here. Three other observations about this tine frame include: an increase in Atypical Responses over the year, the decrease in Somatization within the second six-month period, and the statistically significant association revealing a decrease in Depersonalization over the year. Regarding the increase in Atypical Responses, an impressive seventy-eight percent of the subjects in that year's last six months (which constituted sixty-nine percent of the population) scored in the high ranges of that scale, providing further evidence of the relationship between time and negative bereavement experience (as measured right here by lowered subsequent adjustment and higher Atypical Responses). There is a definite trend in the increase of numbers of parents with high Atypical Responses scores continuing as time progresses; with thirty-eight percent in the first year, sixty-seven percent in the second year, and sixty-nine percent in the third year. In summary of the relationship between time and bereavement experience, it is clear that time does not provide full relief from symptomatology or diminution of experience. In fact, the collected evidence argues for a worsening of the experience in the third year, independent beyond that indicating some lessening of grief during the second. Again, it must be repeated, that continued research in this area is definitely needed, especially in light of these findings which suggest the opposite of the common-sense notion and widely held belief that time "heals" grief: in fact, it may not, particularly 
with bereaved parents. Our expectations for parents in these situations may be entirely inappropriate and therefore needed therapeutic endeavors may be deficient or lacking.

\section{Parental Experience During the Illness}

Aspects of the parental experience during the illness were addressed in Hypothesis 7 (Anticipatory Grief Is Related to PostDeath Grief Experience); Hypothesis 8 (Parental Participation in the Care of the Dying Child Is Related to the Post-Death Grief Experience); Hypothesis 6 (Parental Evaluation of Their Child's Treatment Experiences Are Related to Parental Grief Experience); and Hypothesis 1 (The Amount of Support Received During the Terminal Illness Is Related. to the Post-Death Grief Experience).

For purposes of this investigation anticipatory grief was operationalized by eight elements. A parent's anticipatory grief score was determined by the numerical sum of the behaviors he/she had reported they engaged, in during their child's terminal illness. Two associations were found to be statistically significant. Anticipatory grief was associated with Preparedness at Death at the $p=.05$ level of confidence. This was a positive association with the level of Preparedness at Death increasing directly as anticipatory grief increases. This finding supports the contention that anticipatory grief leads to relatively more preparation than does the lack of it. It gives further credence to the notion that such a grief process prior to the death enables the parents to become more resigned, accepting, and prepared (Friedman et al. 1963; Chodoff et al. 1964; Friedman 1967; and wiener 1970; most notably among many). 
A stronger statistical level of significance (at the $p=.01$

level) describes the association between anticipatory grief and Atypical Responses, or abnormal grief. The more there is anticipatory grief, the less abnormal grief is present. This confirms most of the previously mentioned literature stating that the absence of anticipatory grief was associated with poorer adjustment, and by implication, that anticipatory grief is therapeutic and predisposes against pathological grief reactions.

Several other patterns imply the relative importance of anticipatory grief. Although not statistically significant there is a definite suggestion that support is related to the experience of anticipatory grief, for those parents who were low on support tended to have engaged in few anticipatory grief behaviors. This suggests that the engagement in anticipatory grief may be assisted by, or possibly requires, the support of other people.

Individuals who were low in their subsequent adjustment tended to have engaged in fewer anticipatory grief behaviors as is evident by the majority of parents falling within the low ranges of the behaviors. In contrast, those who reported high subsequent adjustment following the death had an almost equal chance of having engaged in either low, medium, or high amounts of anticipatory grief behaviors. This finding provides more evidence for the assertion that anticipatory grief facilitates grief work and that the absence of it predisposes one to worse bereavement outcomes. It follows theoretically and empirically the relationship between anticipatory grief and Atypical Responses.

A finding in the expected direction is that the majority of those who are low on anticipatory grief are concurrently low in 
participation behaviors during the child's illness. Interestingly, there is a reciprocal change in the majority of parents in the medium and high anticipatory grief groups. While the majority of parents in the medium grief group were high on participation behaviors, the majority in the high grief group were low on participation behaviors, a finding similar to the one for parents in the low anticipatory group. This may indicate that there is an optimum level of anticipatory grief which facilitates parental participation behavior (seen here in the medium anticipatory grief group). This would imply that too little or too much anticipatory grief is counterproductive. The reasoning for this being the case is easily apparent for the low anticipatory grief group. For that explaining the high grief group one could turn to the evidence that illnesses which are too long result in poorer adjustment (Gerber et al. 1975, and Schwab et al. 1975) and hypothesize that based on the same rationale too much anticipatory grief is disorganizing. Aldrich (1974) had raised this possibility with regard to post-death mourning.

It appears most likely, however, that the reason for this finding is based in much of the theory of anticipatory grief, i.e., that with anticipatory grief comes gradual detachment and interest in other children and activities. It does not seem that the fears of Travis (1976) or Levitz (1977) were realized, i.e., psychological or physical abandonment of the child, since forty-four percent of the parents were still high participators. This still is, nevertheless, a significant change from the parents in the medium anticipatory grief group of whom sixty-three percent were high in participation behaviors. This change may reflect the increasing detachment from the child as the 
amount of anticipatory grief increases.

These data suggest that there is an optimum level of anticipatory grief as it is related to participation with the child. Whether this would be true when taken from the perspective of the parent is unknown at this time. Still, questions arise such as "What are the important anticipatory grief behaviors to engage in?"; "Should some anticipatory grief be encouraged/discouraged depending on the anticipatory grief status of the parent?"; "What impact do the sex differences noted in the section on Personal Characteristics Influencing Parental Grief and Adaptation, in which fathers were significantly lower than others on participation behaviors but not on anticipatory grief, have with regard to the relationship between anticipatory grief and participation?" These questions and more will need further investigation in this area.

The notion of an optimum amount of anticipatory grief is given further support by the suggestions that anticipatory grief is related to the GEI scales of Anger/Hostility and Loss of Control in such a way that the medium anticipatory grief group exhibits the lowest intensities on both variables. In the low and high grief groups there are higher percentages of parents reporting high scores on both subscales. This is additional evidence that too much anticipatory grief is harmful (see Gerber et al. 1975 and Schwab et al. 1976) as is too little anticipatory grief (the conclusion of most of the studies cited on anticipatory grief).

An incidental finding is that there appears to be more parents with higher intensities of Loss of Control than with Anger/Hositility at all levels of anticipatory grief. This relatively lower Anger/ 
Hostility score is understandable given that its low intensity probably accounts in part for the high ratings of parental satisfaction. Basically, parents have less difficulty with Anger/Hostility than with other scales. The relatively high Loss of Control may be somehow related to the tendency for parents to increase in Atypical Responses and poorer subsequent adjustment. At the present time this relationship is unclear, if it exists at all. It is noteworthy, however, that the second most intense bereavement experience is in Loss of Control with the most intense being Atypical Responses when measured in the third year (the year which appears to be crucial for changing the direction of progress).

Hypothesis 8 addressed participation behaviors (Parental Participation in the Care of the Dying Child Is Related to the PostDeath Grief Experience).

For this study seven behaviors were used to operationalize the concept of participation. Of note is the fact that parents were asked to rate their participation during the hospitalizations of the child. This was done in an effort to approximate previous studies. The role of parental involvement when the child is at home is also a crucial one. It was felt, however, that participation during times of hospitalization would be highly correlated with at-home participation and also felt that if participation were to be measured at home there might be an absence of common denominators on which to evaluate the parents. Thus, for objectivity, the derivation of a participation index sprang from the experience common to all parents: hospitalization at Rainbow Babies and Childrens Hospital. 
There were two findings of statistical significance from the data reported herein. Rumination was found to be significantly associated with participation in a positive relationship, i.e., as the amount of participatory behavior increases, so too does the amount of Rumination. This finding is directly contrary to the prediction. It supports Hamovitch (1964), however. He noted that "full" participation predisposed the parents to be more volatile and so wrapped up in the care of the child that there was neglect of other responsibilities. This being "so wrapped up" with the child appears to continue after the death according to the present data. With low levels of participation there is lowered Rumination. What remains to be investigated are the delimitation points of "appropriate participation"; the differential impacts of the seven individual behaviors; and whether, if there can be determined an optimum amount of participation, this should be used as a guideline in modifying the participation of parents of terminally ill children. What is clear is that there very well may be such a thing as "too much of a good thing" with regard to participating in the care of the fatally ill child, especially as it relates to subsequent grief experience after the death. Analyses of the relationship of participation behaviors and the other GEI scores is also warranted to determine if this is valid for other facets of the grief experience or if this is an isolated phenomenon.

The second statistically significant finding (at the $p=.02$ level of significance) is the significant difference among mothers and fathers in their amounts of participation. Mothers were significantly higher in their participation scores. Discussion of this can be found in the section on Personal Characteristics Influencing 
Parental Experience and Adaptation. The reader is referred there for an analysis of the association between sex and participation behaviors. The parents' evaluations of their child's treatment experiences are associated with participation behaviors to a statistically significant extent $(p=.0549)$. Virtually all parents who reported a low level of satisfaction with the treatment experiences had engaged in a low amount of participation behaviors. Those who reported high levels of satisfaction were more evently split on both low and high amounts of participation behaviors, suggesting the trend that satisfaction with treatment increases as the number of participation behaviors increases. This supports the finding of Knudson and Natterson (1960) who wrote that parental participation decreased suspiciousness toward hospital staff members and facilitated the parents becoming friendly with the staff--the individuals who provided the treatment on which the parental ratings of satisfaction were based. Another explanation is that if parents are comfortable with the treatment (as indicated by their satisfaction) or are comfortable with the individuals providing the treatment, there may be more willingness to join in the treatment (participate) as a member of the treatment team. Conversely, parents' participation in the treatment may be just what it is that makes the treatment so satisfactory to begin with. In either event, the association between the variables of satisfaction with treatment and participation behaviors is a significant one. This is especially important in that parental participation is related to psychological adaptation (Richmond and Waisman 1955; Knudson and Natterson 1960; Burton 1974; and willis 1974) in reducing such emotions as guilt, denial, and anxiety and such adaptation may influence the perceptions 
of the child's treatment experiences, suggesting that participation itself has a direct influence upon the parental perceptions and evaluations.

There is an implication that participation behaviors have some kind of relationship with or effect upon subsequent adjustment. Although not statistically significant, seventy-three percent (nearly three-fourths) of the low adjusters were also low on participation, in contrast to the high adjusters who were evenly split between low and high participation. That low subsequent adjusters reflect a greater percentage of low participators than do high adjusters corroborates the findings of Richmond and Waisman (1955); Knudson and Natterson (1960); Burton (1974); and Willis (1974) who report that participation is related to psychological adaptation. Since positive adaptation is consistent with high subsequent adjustment, then it follows that a lack of such adaptation could preclude high subsequent adjustment. This data emphasizing the higher association of low participation with low subsequent adjustment as compared with high subsequent adjustment appears to lend support to the previous findings. Although high participation by itself does not guarantee high subsequent adjustment (as evidenced by the fact that there were twenty-seven percent of low adjusters who were high participators) and low participation is not exclusively related to low adjustment (since fifty percent of the high adjusters were low participators), the fact that low adjusters tended to include so many parents who were correspondingly low in participation implies that too few participation behaviors predisposes one more toward poorer subsequent adjustment than it does toward high subsequent adjustment. 
The relationship between anticipatory grief and participation behaviors has already been analyzed in the section discussing Anticipatory Grief. Suffice it to say at this point that there appears to be a relationship between the two suggesting that the optimum level of anticipatory grief is a "medium" level, and that this appears to facilitate the greatest percentage of high participation behaviors. A related indication is that the greatest number of low participators were found among those who were also low in anticipatory grief. The greatest number of high participators were found to score in the medium range of anticipatory grief. These findings are not surprising given that low participation is related to individuals obsessed with more external problems (Hamovitch 1964) which would most probably preclude adaptive anticipatory grief, and that a medium amount of anticipatory grief appears to be most therapeutic and therefore facilitative of participation or at least subject to the same process which allows expression of both. Of course, it must be remembered that in many instances participatory behaviors either are, or pave the ways for, experiences of anticipatory grief, and this would also serve to explain their association and similarities with respect to other variables.

In Hypothesis 6 (Parental Evaluation of Their Child's Treatment Experiences Are Related to Parental Grief Experience) the effect of the parents' evaluations were studied with respect to their Anger/ Hostility and Rumination scores on the Grief Experience Inventory. Previous writings had indicated the association of the level of parental satisfaction with the grief experience. 
In the present sample, ninety-two percent of the subjects rated themselves as highly satisfied, i.e., they had indicated that they were "mostly satisfied" or "completely satisfied" with their child's treatment experiences. This figure is quite impressive and had not been expected. It is clearly higher than others reported with the exception of the Hamovitch (1964) data.

When the parents' Anger/Hostility scores and their evaluation of their child's treatment experiences were analyzed, fifty percent of the population was high on both Anger/Hostility and satisfaction with treatment. This was contrary to the prediction that high satisfaction would be more closely associated with low Anger/Hostility scores. The pattern that was suggested was that those who were low satisfied were three times more likely to have low Anger/Hostility while those who were high satisfied were almost evenly split among low/high Anger/Hostility scores. This implies that there is an increase in Anger/Hostility as there is an increase in satisfaction. The reason for this is unclear from the data or from theory. Possibly analysis of this phenomenon according to time intervals after the death may offer some clarification.

The parents' satisfaction with treatment experiences was also examined in light of their Rumination scores from the GEI. In both categories of satisfaction (low and high) there was a perfectly even split of the parents into low/high ranges of Rumination. Thus, there appears to be no association between satisfaction and Rumination at all.

There appeared to be a significant association between satisfaction and the number of parental participation behaviors. For an 
in-depth discussion the reader is referred to the section on Participation Behaviors. Suffice it to say here that it appears that increasing levels of satisfaction are associated with increasing amounts of participation behaviors on the part of the parents. This speaks directly to the Hamovitch quote (1964, p. 119) which discusses the relationship between the parental need to feel they have done everything possible for the child (which would include participating in his/her care and this would be reflected in participation behaviors) and satisfaction with treatment experiences.

The final aspect of parental experience was addressed in Hypothesis 1 (The Amount of Support Received During the Terminal Illness Is Related to the Post-Death Grief Experience). Many writers had pointed to minimal or absent support as a determinant of poor outcome of bereavement (e.g., Maddison and Walker 1967, and Parkes 1975).

In the present study twenty discrete sources were rated by the parents according to the quality of support received. Those providing some measure of support were summed to generate a support score and were then analyzed with respect to the parents' subsequent adjustment, GEI Atypical Responses scores, and anticipatory grief scores. Since support is always a crucial influencing variable in any individual's response to a crisis, the predictions were in the direction that as the amount of support increased positive responses would be facilitated.

Although not at a statistically significant level, two of the three predictions generated data in the expected direction. There was a relative increase in the tendency for parents to have lower Atypical Responses scores (a positive sign) as they evidenced 
increasing amounts of support. It was also illustrated that parents with low support tended to have engaged in fewer numbers of anticipatory grief behaviors. This suggests that the experience of support facilitated the parents' coping during the illness and probably enabled them to undertake some difficult but necessary tasks (e.g., anticipatory grief).

Contrary to this there was an unexpected finding with regard to the association between support and subsequent adjustment after the death. The percentage of those with low subsequent adjustment increased as support increased, and the percentage of those with high subsequent adjustment decreased as support increased. Thus, as support increases subsequent adjustment decreases. The explanation for this is unclear from the data. One possibility is that the amount/type of support received during the illness is relatively unrelated to that which would be required after the death to facilitate parental subsequent adjustment. This could account for its (the amount of support) pattern of positive association with anticipatory grief prior to the death, since both take place within the same time period. It would not explain its pattern of association with Atypical Responses, however. It might prove interesting to further analyze this data with respect to the three one-year intervals since the death of the children, since the numbers of those with low subsequent adjustment were highest in Time Period III and may have confounded the present results. Aldrich's (1974) discussion on the possibility of a period of anticipation actually prolonging conventional grief since it precluded group factors which facilitated early working-through (e.g., the shared mourning and evidence of national sympathy subsequent to the Cocoanut Grove 
Fire) may be pertinent at this juncture. If his idea is even minimally correct it suggests by implication that in the case of parents of terminally ill children the illness may continue for so long that at the time of death (and afterwards) support is no longer forthcoming. Aldrich is concerned that this may result in difficulties in mourning but in this analysis the lack of support is most important in that it may not only impede mourning but also preclude desired subsequent adjustment. This would prompt the need for an analysis of the association between support and subsequent adjustment by the length of the illness, in addition to the time since the death. In any event, further investigation is warranted, as the present findings are in the opposite direction of the prediction.

\section{Limitations of the Study}

There are several limitations to this study. The first lies in the retrospective nature of this investigation. Ideally, a prospective study would provide the most valid and reliable data. Unfortunately, the experience of the parents while the child is dying often precludes the possibility of a well-controlled, objective investigation. Secondly, the nature of the subject population, in that a criterion for selection was that the parents were still married, eliminated those individuals whose experiences may have been so difficult as to place unbearable stress upon the relationship; who may have been psychologically unable to cope with the experience and whose inabilities are reflected in a broken marriage; and those who had to undergo the entire experience alone due to being a single parent prior to the illness. Without including such individuals the generalizability of these findings for people in those populations 
must be suspect at this point.

Thirdly, the nature of the Parental Experience Assessment Form lent itself to self-report bias. This is not perceived as a major limitation, however, since the self-perceptions of the parents were desired in this study and there is no other way around this problem. The form lent itself to a limited amount of ambiguity in not completely discriminating between answers of "not applicable" and "0." Although only positive responses were used in the calculations, such discriminations could afford a more complete picture of some of the individual parents. In addition, the question about rating previous loss experiences was ambiguous in that it was determined early in the interviewing that some subjects were rating losses not directly pertaining to themselves. Thus, a husband might have rated the operation that his wife had undergone instead of rating his own operations solely. Also, some subjects did not rate "graduation" when, in fact, they had had one. These reflect some of the misinterpretations that occurred; however, in general, such errors were minimal and were far outweighed by the wealth of data generated by the instrument. The reader is referred to the section on description of the subjects for further discussion of the potential limitations of the population sample and how these were addressed. Other related concerns are found in the methodology section.

\section{Emotional Reactions of the Investigator}

As the sole investigator, this author interviewed fifty-nine parents of deceased children from July 16, 1979, to August 26, 1979. This was the only activity of the author during this time period. 
Consequently, she was completely involved with the study and had little other distraction. In addition, the study was conducted in cleveland, and the author was without most of her main emotional supports who were back in Rhode Island. All of this contributed to a quite intense and emotional experience for this author.

The average time for each set of interviews was four hours. They occurred under varied conditions from the privacy of a library to the middle of a parlor where children constantly interrupted and mice scurried around. The majority of the interviews took place in the evening since that was the most convenient time for the parents to be interviewed together. It was not at all uncommon for this author to return home at one $0^{\prime}$ clock in the morning given the length of the interviews and the travel required. The author travelled two thousand, one hundred and eighty-one miles for interviews.

The above description is to indicate the physical hardships inherent in the study. They were insignificant, however, to the emotional ones. It was common to end up crying with a parent as they described the painful ordeal their child underwent and their excruciating loss since his/her death. Frequently they showed pictures of the dead child to the investigator. Once she had to look at pictures of a bald and bloated three-year old girl in a tiny pink casket. The resulting questions of "Why?" and the gutteral "It stinks!" came from-her privately as they had from the parents.

But, she, as the parents, had to have some meaning, and so this author continued the investigations and will continue to do so in the hope, as the parents articulated, that this knowledge will be helpful to those parents in future similar situations. 
CHAPTER VI

SUMMARY

The findings and suggestions of this investigation are summarized below with respect to the three main classes of variables influencing parental grief experience following the death of a child from cancer.

The personal characteristics of parents analyzed with respect to their grief experience were previous loss and sex differences. High subsequent adjustment was associated almost twice as often with low numbers of previous loss as with high numbers of previous loss, implying that previous loss tends to be associated with poorer bereavement outcomes (although not to a statistically significant extent). With regard to sex differences, mothers reported grief experiences and adjustments reflective of higher intensities of grief as compared to fathers on all variables except Anger/Hostility, which was reflected in a higher mean score for fathers. The only variables which statistically differentiated mothers and fathers were the variables of Somatization from the GEI and the number of participation behaviors the parent reported they had engaged in during the child's hospitalizations. On both variables mothers were higher than fathers. Duration of the illness and the length of time since the death were the two time variables studied in relation to parental grief. As the duration of the illness increased, there was an increase 
in the percentages of parents with higher Anger/Hostility and Atypical Responses scores. The medium range of lengths of illnesses (with the duration of the illness being from six to less than eighteen months) was associated with the highest amounts of parental preparation at death and subsequent adjustment following the death. Together these points suggest that, with regard to parents' grief, there is an optimum length of time for a child's illness to last, below and above which parental experience is worsened. Analysis of the impact of the length of time since the death reveals a configural pattern suggesting an intensification of the bereavement experience during the third year following a temporary improvement in the second year. This pattern held true for all variables tested with the exception of Atypical Responses which rose consistently. The collected evidence argues for a worsening of the bereavement experience in the third year following the loss and challenges the assumption that time provides full relief from symptomatology or diminution of experience.

There were four aspects of the parental experience during the child's terminal illness that were analyzed with respect to their grief experience. The first variable was that of anticipatory grief. Anticipatory grief was found to be associated with preparedness at death to a statistically significant level revealing that the more parents had engaged in anticipatory grief, the more they were prepared for their child's death. A second statistically significant finding confirmed theoretical expectation through the association of anticipatory grief and Atypical Responses. The more there had been anticipatory grief on the part of the parent, the less Atypical Responses (or abnormal grief experience) was reported. This supported 
previous Iiterature which had indicated that the absence of anticipatory grief is associated with poorer adjustment and, by implication, that it is therapeutic and predisposes against pathological grief reactions.

Other analyses of the variable suggested that engagement in anticipatory grief facilitated subsequent adjustment following the death of the child and that anticipatory grief itself was facilitated by or required support from other people. There appeared to be "optimum amounts" of anticipatory grief. A moderate range of anticipatory grief behaviors was associated with highest amounts of participation during the child's hospitalizations and with lowest amounts of Anger/ Hostility and Loss of Control, indicating the therapeutic effects of avoiding too little or too much anticipatory grief.

Participation during the child's hospitalizations was found to be statistically significant in association with the parents satisfaction with their child's treatment experiences. There was a positive association with satisfaction increasing as the parents participation increased. Such a positive association was also found with Rumination. Contrary to the prediction, Rumination increased as the amount of the parents participation increased. There was some indication that participation has some association with subsequent adjustment since low subsequent adjustment was associated with more individuals who had participated in fewer behaviors than was high subsequent adjustment. As noted previously, mothers were significantly higher than fathers on their mean participation index and a moderate amount of anticipatory grief appeared to facilitate maximum participation behavior. The third variable analyzed in this category was the parents' 
satisfaction with their child's treatment experiences. Ninety-two percent of the parents evaluated these experiences positively. An unexpected finding was that fifty percent of the parents were concurrently high on both satisfaction with treatment and Anger/Hostility. There is an implication that there is an increase in Anger/Hostility as satisfaction is increased. The reason for this is unclear from the data or from theory. The relationship between satisfaction with treatment and participation behavior during the child's hospitalizations has already been mentioned above and appears to be due to the facts that: such participation facilitates parents' interactions with the staff who provide the treatment on which the evaluation of satisfaction is based; parental participation in the treatment may be just what it is that makes the treatment so satisfying to begin with; that if parents are satisfied with treatment there will be more of a desire to participate in the care of the child; and that participation appears to be related to psychological adaptation and that such adaptation may influence the perceptions/satisfaction, suggesting that participation itself has a direct influence upon parental perceptions and evaluations. From the point of view of cognitive-dissonance theory, it is important to realize that there is a definite parental need to feel that they have done everything possible for their child and to perceive their experience in the best possible light retrospectively.

The final variable analyzed was that of support. Although not statistically significant, there was a suggestion that parents who had had less support engaged in fewer anticipatory grief behaviors. Additionally there was a relative increase in the frequency of parents having lower Atypical Responses scores (a positive sign) as they 
evidenced increasing amounts of support. These suggestions hnth supported the theory of the therapeutic nature of support. An unexpected finding was that the percentage of those with low subsequent adjustment increased as support increased, and the percentage of those with high subsequent adjustment decreased as support increased. Thus, as support increased, subsequent adjustment decreased. The explanation for this was unclear. Alternative explanations include the possibility that the amount/type of support received during the illness was unrelated to that which would be required after the death, i.e., the parental needs changed or that the duration of the terminal illness was so long that it precluded support at the time of death. In other words, over the course of a long-term illness the parents' sources of support may have dwindled or drifted away. This will need to be tested through analysis of the association between support and subsequent adjustment by the length of illness, in addition to the time since the death.

\section{Implications for Future Research}

Throughout this discussion specific issues have been cited as requiring future research. Basically, the entire area needs further study. Of crucial import is the further investigation of the present findings indicating that parental grief may exacerbate over time. If these findings are replicated, the need for a welldefined course of therapeutic intervention is mandated to assuage the intensification of bereavement which occurs sadly when most supports have been withdrawn. Those implications regarding the "optimum" levels of anticipatory grief and parental participation suggest the necessity of examining current practices which may 
encourage or discourage higher intensities in both these areas in order to facilitate the most therapeutic parental experience. Further investigation needs to be undertaken to determine the differential influences on parents of each sex as well as to gear appropriate therapeutic interventions towards each sex. If there are differences by sex in parental participation yet not in subsequent adjustment nor anticipatory grief the implications of these need to be made clearer. The finding that high previous loss may be indicative of possibly a poorer outcome needs continued investigation in order to understand its role as a determinant of outcome. And, the suggestion that illnesses that last longer than eighteen months are unfavorably related to outcome, as are those which are too short, demands verification in order to start to "red flag" those parents who are potentially in need of intervention due to the stress of the experience. 
APPENDIX I

GRIEF EXPERIENCE INVENTORY 
- Catherine M. Sanders, Paul A. Mauger, and Paschal N. Strong, Jr. -

\section{- INSTRUCTIONS}

This questionnaire is concerned with the experience of grief. The statements which are included represent various thoughts and feelings commonly expressed by people who have suffered the loss of a relative or close friend through death. Read each statement and then try to deterwine how well it describes you during your period of bereavenent. If you are stlll experiencing some of these thoughts or feelings, please respond in the same manner as you would a past experience. If the statement is true or mostly true as applied to you, blacken the space under true on your answer sheet. If the statemint is mostly false, blacken. the space under false on your answer sheet. If a statement does not apply to you leave it blank.

Please mark your answers on the sheet provided. In onarking your answers, be sure that the number of the statenent agrees with the number on the answer sheet. Write only on the answer sheet. Do not make any marks on the mimeographed booklet. 


\section{GRIEF EXPERIENCE INVENTORY}

1. imediately after the dath I felt exhaus ted.

2. I tend to be more I rritable with others.

3. I an strongly preoccupied with the juge of the deceased.

4. I frequently experience angry feelings.

5. It is not difficult to maintain soclal relationships with friends.

6. My arms and legs feel very heavy.

7. I em unusually arare of things raiated to death.

8. It seems to whe that more could have been done for the deceased.

9. I showed little emotion at -the funeral.

10. I felt a strong necessity for wintaining the worale of ohers after. the death.

11. I feel cut-off and isolated.

12. I rarely take aspirins.

13. feel reluctant to attend social gatherines.

14. I was unable to cry at the announceDent of the death.

15. I have feelings of guilt because I was spared and the deceased was taken.

16. I have a special need to be near others.

17. often experience csfusion.

18. † feel lost and helpless.

19. I am comforted by believing that the deceased is in heaven.

20. I have had frequent headaches since the death.
21. It was diffleult to part with the clothing and personal articles of the decased.

22. It.was necessary to take sleeping :pllis after the death.

23. The yearming for the deceased is so intense that I sometlmes feel physical pain In my chest.

24. I ery easily.

25. I have taken tranquilizers since the death.

26. I experienced a dryness of the moth and throat.

27. I feel restless.

28. Upon first leaming of the death had a dazed feeling.

29. Concentrating upon things is diffleult.

30. I have feellings of apathy.

31. I experienced a feeling when the death occurred thet "something died within me".

32. Aches and pains seldom bother we.

33. I find 1 an often irritated with others.

34. I could not ery until after the funeral.

35. I feel that I may in some way have contributed to the death.

36. I find myself performing certain acts which are similar to ones performed by the deceased.

37. - 1 made the funeral arrangements.

38. I lack the energy to enjoy physical exercise.

39. I rarely feel enthusiastic about anything.

40. I feel that grief has aged me. 


\section{APPENDIX 1--Continued}

41. I have never dreamed of the deceased as stlll being ailve.

42. I find ayself frequent ly asking "why did the death have to happen in this way?"

43. I sometimes have difficulty bellering the death has actually oceurred.

4h. I feel a strong desire to complete certain unfinished tasks the dacieased had begun.

45. I have often dreaned of times when the deceased was living.

46. I often Irrltable.

47. I have dreamed of the decansed as beling dead.

-48. I feel extremely anxlous and unsertled.

49. I feel tenseness in my neck and shoulders.

50. Sonetimes 1 have a strong deslre to seream.

51. I an so busy that i hardly have titue to moum.

52. I feel anger toward 6od.

53. I have the urge to curl up in a small ball when I have attacks of erying.

54. I feel the need to be alone great doal.

55. i rarely think of gny awn death.

56. I find it diffieult to ery.

57. Looking at photographs of the doceased is too painful. .

58. Life has lost its meaning for tre.

59. I have no difficulty with digestion.

60. I have had brief morents when I actually felt anger at having been left.

61. I have had no trouble sleeping since the death.

62. I have a hearty appetite.

63. I feel healthy.
64. It conforts we to taik with others who have had a similar loss.

65. I yearn for the deceased.

66. I seidone feel depressed.

67. I have the feeling that 1 am watching myself go through the motions of living.

68. Life seams enty and barren.

69. There are times when I have the feelling that the deceased is present.

70. I often take sedatives.

71. I heve frequent mood changes.

72. The ections of some people make me resentful.

73. My feelings are not easfly hurt.

1 74. I losing weight.

75. Small problems seem overwhelning.

76. I sometimes feel guilty at being able to enjoy myself.

77. I frequently have di arriea.

78. I often wish that I could hove been to die Instead.

79. I have lost my appetite.

80. I sometimes taik with the picture of the deceased.

81. I am not intereszed in sexual activities.

82. At times I wish I were dead.

83. It is hard to maintain my rellglous faith in light of all the pain and suffering caused by the death.

84. I seem to have lost my energy.

85. I dread viewing a body, at the funeral home

86. I find myself ideailizing the deceased.

87. I have problems with constipation.

88. I frequently take long walks by anself.

801 avsid mecting oid friends. 
.946 ! 28

zou znq hep suz 6u!dnp dools ues I

-746!U ग47 t० ग1Pp!W ग47 U!

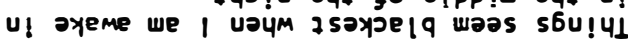

-5746!U z sow IIOM dools ।

- dools of yoeq zo6 zouues pue

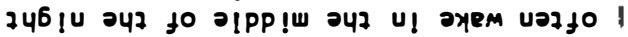

\section{- Ajsom dono dools osol |}

-sunoy jejonos jof oxpme o!l

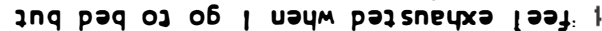

-746!U ग47 f० z sow aypme we ।

-uossod o!zs!jeas e zou we |

-shep osouz osow 6u!y ws we ।

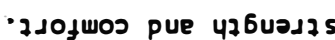

douu! to sasnos e 5 ! 47 !et sno!b!los NW

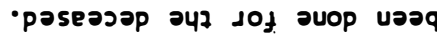

oneY PInOS zeपz IIE P!P I JeYZ loof I

- w 07 osolo swoכs $\Lambda_{1}$ lwef $\lambda_{W}$

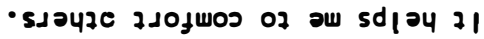

- पzeכp כ47 כjofoq poseosop

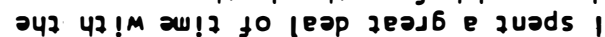

. 47600 गUд ग70700

в47 Mou כs

. uo!zenzis jejoos e u! oseo

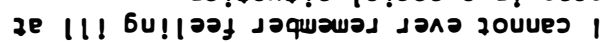

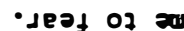

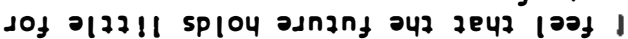

- Addey hilensn zou we I

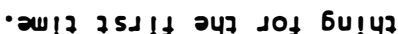

-2wos po!dz I uoym |nfssoכons oq $p$ InOm

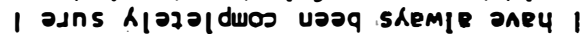

- soduaz kil osol danau I

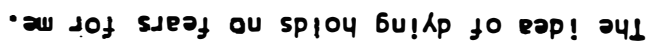

- sem seoponu to z46nouz ग4z ze soppnys I

•sdn-यכग्ये

دOf J0z50p ग47 of 6u!O6 pu!̣ zOU Op ।

- دosues wodf 6u!kp to p!efe zou we । •५รl -ทย I

- 521

- EZl

.611

811 •ヤl $\bullet \varepsilon$ II

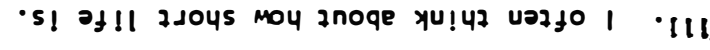

-sjedount

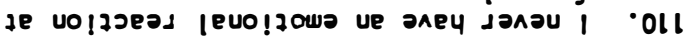

-6u!^ग!د6 5 ! O4M

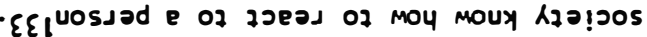
S,Aepoz U! ग/dood ru! ra zOU op $1 \cdot 601$

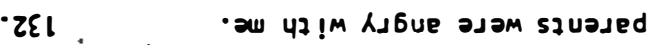

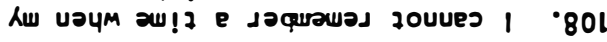

- पдеәp znoqe भाEz

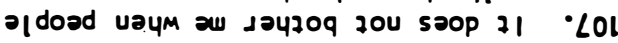

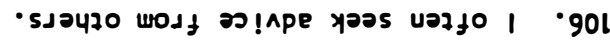

- uosjad 6uina!jo

e of hes of zeym mour shemp । • SOl

:L1 - ow of 6uill

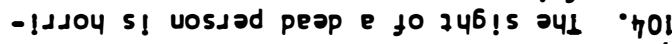

- 921 - suosjad mag e hluo 47!m osolo we 1 • EOl

- osni!ef to jeof ou oney I •zOl

- hip jdes os hq

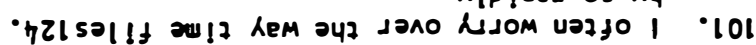

Gu!hp s! oum ouozwos 6u!z!s!^ Kserun looj zou plnam I 001

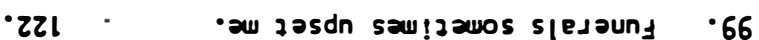

- oseosip jnfuied

- Irl e 6u!aney znoqe po!juom donou oney |

$\cdot 86$

-puge New

- 021 saOzuo wOplos yzeop fo z46nO4z כ41

$\cdot 26$

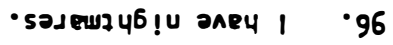
11 av of 6u!nuddey गq zou $P$ Inos $s$ ! $4 \perp_{11}$ 'z46nouz।

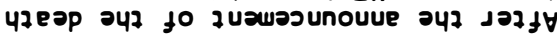
$\bullet$ ५6 प7е०р эपว

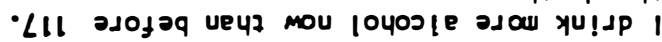
$-16$

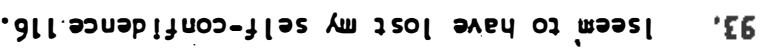

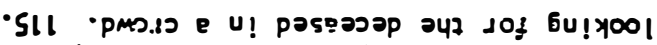

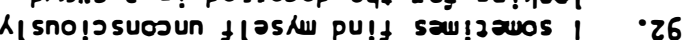
$\bullet 16$ $.07 \times 18707$

¿Il of ouoswos jof poou le!jods e aney | 06 
APPENDIX 2

PARENTAL EXPERIENCE ASSESSMENT FORM 
(C) Copyright 1979

T. A. Rando, M.A.

PLEASE INDICATE THE QUALITY AND FREQUENCT OF SUPPORT THAT YOU REGETVED DURING YOOR CHILD'S TERMINAI ILINESS. (Please do not leave any blanks)

Rating of Quality of Support

0 . no support

1. not he lpful, actually harmful

2. not helpful, but didn't hurt

3. belped atte

4. a igntficant help

5. coulda't have managed without it

\section{Rating of. Freguency}

1. never

2. once in a while

3. Erequent $1 y$

4. most of the time

5. 11 of the time
SOURCE

\section{EATI}

spouse

parent-mother

-father

- 1blinga-sisters

(list their ages beside

ratings of quality)

-brothers

(list tbelr ages beside

ratings of quality)

grandparents-waternal

-pacernal

your other ch1ldren

other relatives (In general)

In-Iaws

FRIENDS (in general)

\section{ORGANIZATIONS}

church/syagogue

employment

commintty ageacy

club/organization

RATE QUAIITI

RAIE FREOUERTI
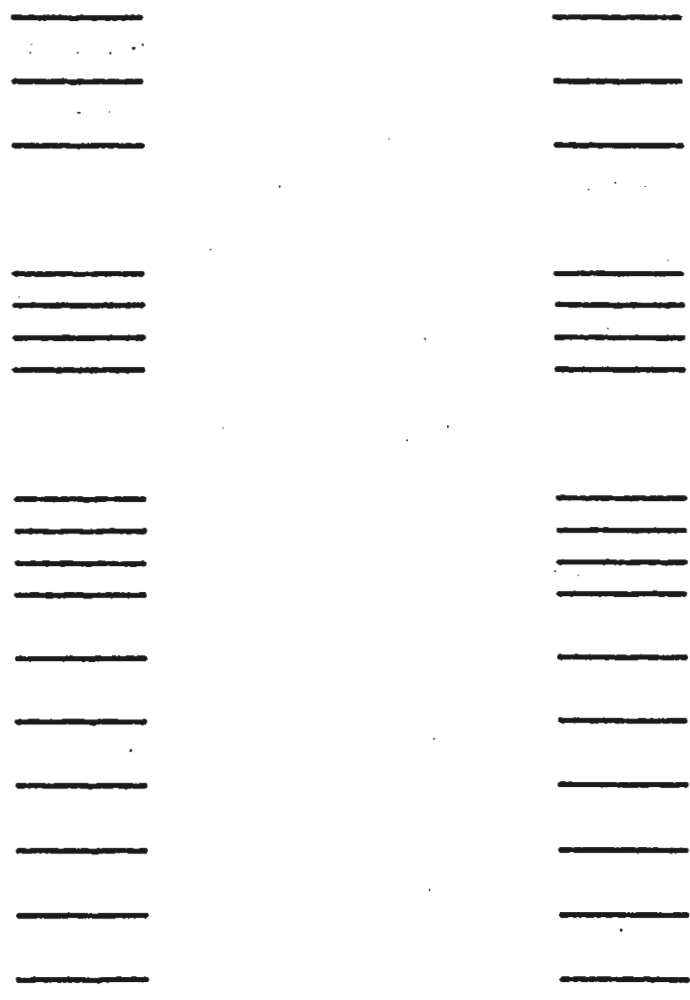


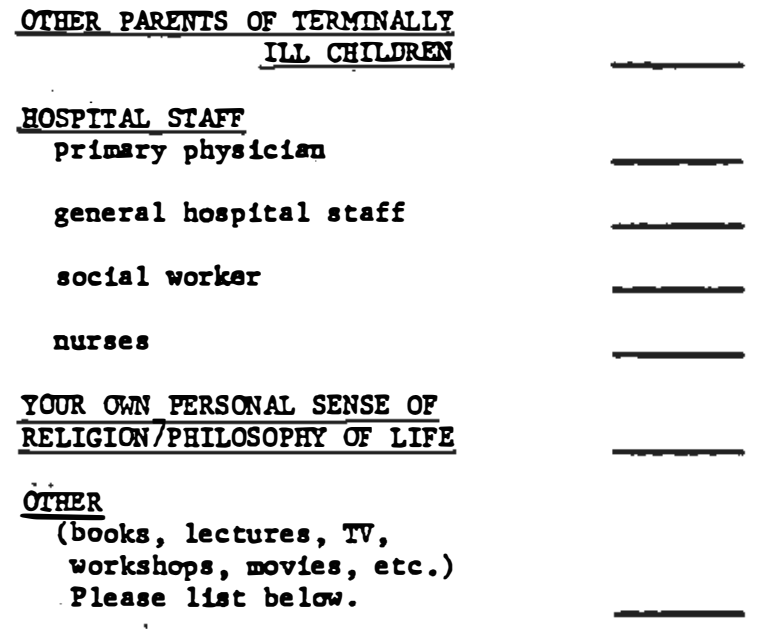

Who/wbat provided greatest support?

PLPASE INDICATE ANY OF TER FOLLOWING EXPERINNCES YOO MAT BAVE BAD BY RATING THEM ACCORDING TO THE DEGREE YOO FEEL YOO COPED WITH THEM AND BON THET COLPARED WILE IHE AMOUNT OP STRESS OF YOOR CEIID'S TERMMNAL ILINESS AND DEATE.

Ratiog of Coplog

1. didn't cope at all

2. coped ooly minlmally

3. coped falrly well

4. coped very we 11

EXPERIENCE

Death (list who)

Divorce

Marital Separat100

Abort100

M1scarriage

Serlous Illness (list what)

Persooal Infury

Operat100

Change in Jobs

Job Loss

Ret1rement

Graduat100

Loved One Leaving Home

Break-Up of Loved Relat1ooshlp

Move/Re locat100

Terminat100 of Psychotherapy

Other

(please list any other 1088 experlences and rate them also)
Compar1son With Ch1ld's Iliness

1. much less stress than chilcts illness

2. I1ttle less stress than dild's illness

3. same amoumt of stress as dillos iliness

4. a l1ttle more stressthan dild's illess

5. much more stress than child's illness

RATING OF COPING

COMPARISON OF AMOUN OF STRESS

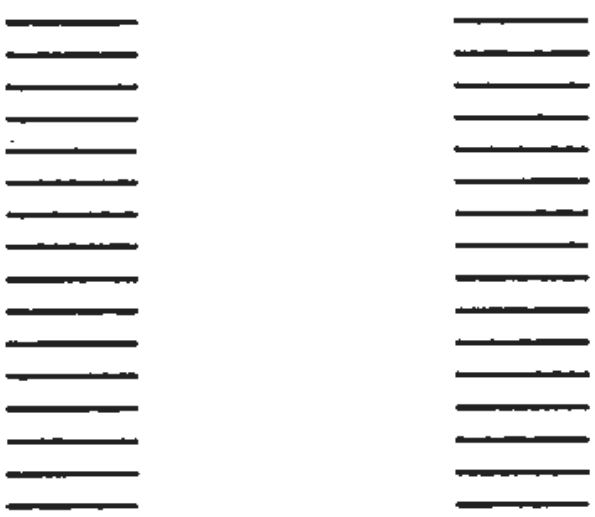


DOR ING YOUR CHID'S HOSPITALIZATIONS WBICB OF THESE BEBAVIORS, IF ANT, DID YOO PARTICIPATE IN? (Rate frequency per each week of hospital stay)

\section{BEHAVIOR}

Rooming-In

Visteing

Feeding/Dining with child

Clothigg/Dressing child

Bathing child

Helping hospltal staff with procedures

Discussing 11lgess with child

Others (please list and rate)

PLEASE CIRCLE THE EXTENT OF YOUR INTOLVEMANI WITH THE HOSPITAL STAFT AROUND YOUR CEIID'S CARE.

1. not involved

2. only minimally involved

3. Involved to a significant extent

4. completely lovolved

PLEASE CIRCLE THE EXIENT OF YOUR INVOLVEMENT WITH YOUR CHIID WHILE HE/SHE WAS HOSPITATIZED.

1. not involved

2. only minlmally lapolved

3. Involved to a significant extent

4. completely involved

PLEASE RATE YOUR SAIISFACTION WITH IHE AMOUNT OF IIVOLVEMENT YOO HAD WITH YOOR CHILD.

1. dissatisfied

2. partially satisfled

3. mostly satisfted

4. completely satiofied

Did your child have an Important last wiah? Ies No

If Yes, what was it?

Were you able to grant it?
PARTICIPATION

1. did particlpate

FREQUENCF

Rate per each

7 day perlod

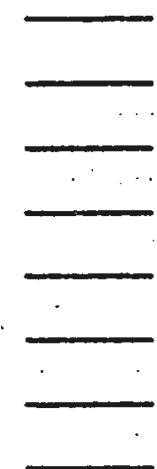

0. dId not participate 
PIEASE RATE YOUR OVERALI SATISFACTION WITE THE BEALTH CARE AND TREATMENT YOUR CEITD RECEIVED FROM IEE FOLLOWING PEORLE.

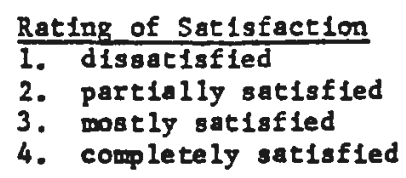

SOURCE

SATISFACTION WITH CARE AND TREATMETTI

Fanily Physician

Hospltal Physiclens

Bospltal Nurses (in-patient)

Bospltal Socfal Workera

Clintc Physiclans

Clinic Hurses

Techictans

Cancer Center Staff

Others (please 11st)

General Overall Care

PRIOR.TQ TOUR CEILD'S DEATH DID YOO EVER:

(Clrcle)

IES

so

Discuss with family the possibllity that your child would die?

Discuss with someone outside of your family the possibility that your child would die?

IES

no

Think what the future would be without your ch1ld?

Plan the type of death gou wanted for your chlld?

YES

no

TES

No

Acknowledge the fact that your child wes going to die?

YES

STO

Grieve in anticipation of the loss of your child?

YES

INO

Start to partially disengage yourself emotionally frow your ch1ld?

IEES

NO

Make funeral preparationa?
No

IES No

Bave you ever sought professlonal treatment to help you cope with your child's Illness or death? YES NO 
HOW PREPARED DID YOD FEEL WHEN YOUR CHIID DIED?

1. not prepared at all

2. a I1ttle prepared, but not enough

3. adequate is prepared for we

4. totally prepared

BEFORE MT CHILD'S IIINESS I MANAGED TO COPE WITH IIFE:

1. not weil at all, with wajor difficulty

2. not too badly, but with a number of problems

3. adequate $1 \mathrm{y}$, without too many problems

4. very we11, without very many problems at all

5. excellentig, without any problems

COMPARED TO BOW I WAS COPING IN IIFE PRIOR TO MP CHID'S IIUNESS, I FEEL THAT RIGHI NOW I AM COPING:

1. wuch worse

2. a I1ttle worse

3. at the same level

4. Iltele betcer

5. much better

I FEEI THAT I HAVE COPED WITH MT CEETI'S DEATH:

1. not well at a11, with mefor difficulty

2. not too badly, but with a mumber of problems

3. adequate $1 y$, without too many problems

4. very we11, wtthout very many problems at all

5. excellentig, witbout any problems

FOR ME, TEE MOST DIFFICULT THING ABOUT MY CHIT'S IIIATESS AND DEATH WAS (IS):

TEE THONG(S) I DID THAT HETLPED ME COPE THE MOST WAS (WERE):

IF I HAVE PROBLEMS RELATED TO MY CHILD'S ILINESS AND DEATH THEY SEEM TO BE IN THE AREA(S) OF: 
APPENDIX 3

STRUCTURED INTERVIEW TOPICS 


\section{Structured Interview Topics}

The structured interview is designed to elicit information around these general questions pertaining to the major areas to be covered.

1. Pre-Diagnosis: What led up to your child's being diagnosed?

2. Diagnosis: Please describe the details surrounding your being told that your child was ill.

3. Post-Diagnosis: Please describe your reactions in the early days and weeks following the diagnosis.

4. Course of Illness: Flease describe the physical course of your child's illness. How did you cope throughout the illness? What was family life like?

5. Terminal Phase and Death Event: Please describe what happeried to you and your child during the terminal phase of the iliness. Flease describe what happended to you and your family when your child died.

6. The Child as Patient: Please describe how your child dealt with his/her illness.

7. Relationship with Srouse: How was your relationship with your spouse during the course of your child's illness as compared to before?

8. Relationship with Other Children (if applicable): How was your relationship with your other children during the illness as compared to before?

9. Friends and Relatives: Describe the roles that friends and relatives played for you during the illness.

10. Relationships with Physicians and Nurses: Please describe the types of relationships you had with four child's physicians and nurses.

11. Religion and Fhilosophy of Life: Please describe any ways in which a religior or personal philosophy of life was helpful to you.

12. Funeral: Please describe whether a funeral service occurred and what it was like for you.

13. Rebuildinr of Life: Flease describe what has happened to you in the time since your child has died.

14. In Petrospect...: In retrospect: When was the most difficult? when you required the most support?; What recommendations would you make to staff? friends? other parents?; What are the most important things one needs to kriow/do for parents? 
APPENDIX 4

PARENTAL CONSENT FORM FOR PARTICIPATION

IN INVESTIGATION 
UR:YERSITY HOSPITALS OF CLEVELAMID PATIENT COHSENT FOR INVESTIGATIONAL STUDIES :5

Tire 0F PRJUECT: Grief and Adaptation in Parents those Children Have Died from Leukeala

lescription of Studies:

As you have discussed with your doctor, the jajor purpose of this study is to Investigate how parents cope during and after the terminal illness of thefrchild. We hope to gain information about the nature of parental grief which will enable us to better understand and support parents.

We will be asking you to $\$ 111$ out a questionalre about how you have managed since your child has died. This will take approxinately one half hour and may be filled out privately at your convenience in your own home. Then we vill personally intervieu you individually about your experiences during your chlld's 11lness: This should take approximately one hour. This intervieu can take place in your own hore at a time convenient to you.

We recognize that there wil be times during this interview that you may feel sad talking about your experiences. At the same time, we believe that this information will ultimately be helpful for the dying child and his/her siblings. As It will provide Inforwation that may be helpful to other families.

Although we hope that you will continue until the end of the study, you are free to withdraw your participation at any time should the investigation be too uncomfortable or time consuming for you. You may also feel free to ask

$-=$ any questions you may have at any point during the study and to decline to

- answer questions that you feel are too stressful or personal.

The Information that you provide will be recorded and added to that recelved from other parents. We will not identify you or your child's name. All Lnformation will remain confidential to our personnel. In the event of publication or reporting, you end your family will not be 1 dentified by name.

hes described to me whet is going to be done, how ft is ng to be done. the risks, hazards and benefits involved, and will be available for stions at I understand that my decision to participate or not to participas: this stuJy will not alter my usual health care. In the use of information generated frose studies, my identity will remain anonymous. I am aware that I may withdraw from this idy $2 t$ eny time. I furtier understand that in the event of physical injury or illness .urring to re resulting from the research procedures. University Hospitals nill not wide frae metical care or campensetion for lost wages.. The undersigned volunteers to ticipete in this projezt to be conducted at least in part ai the University Hospitals cieveland.

isrieture Age Date

arent or Guzrdien Signz:ure

iinasses by गิ4 (If subject is a minor) Date 
APPENDIX 5

ORIGINAL VERSION OF PARENTAI EXPERIENCE ASSESSMENT FORM 
(c) Copyright 1979

T. A. Rando, M.A.

\section{PARENTAL EXPERIENCE ASSESSMFNT FORMP}

\section{(original veraion)}

FLEASE INDICATE TIE SOURCE, QUALITY, HIND FREQUENCY CF SUPPORT YOU RECEIVDD DURIIC YOUR CHILD'S TERHIIML ILINESS.

\section{Ratirg of Quality}

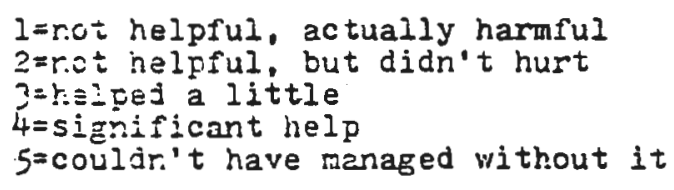

SOURCE

FANIILY

spouse

parent-mother

- father

siblings-sister

-brother

grandparents

other relatives

\section{FRIENDS}

ORGAIIIZATIOI:S

chureh

employment

community azency

club/organization

HOSFITAL STAFF

QTHES FARENTS OF

TERTIAILY IIL CHILDREN

REIIGIOI:/PHIICSOFHY OF LISE

0nL:Es

isory, lectures,

wot:sinops, Fy,

rovies, etc.)

lY LEE list belo\%.

\section{RAIE QUAIITY}
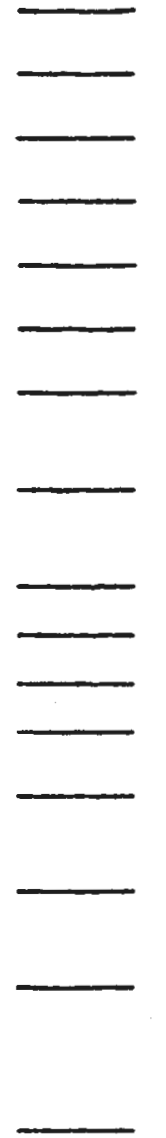

\section{Pating of Frequency}

$I=$ never

$2=$ once in a while

$3=$ frequently

$4=$ most of the time

$s=a l l$ of the time

RATE FREQUENCY
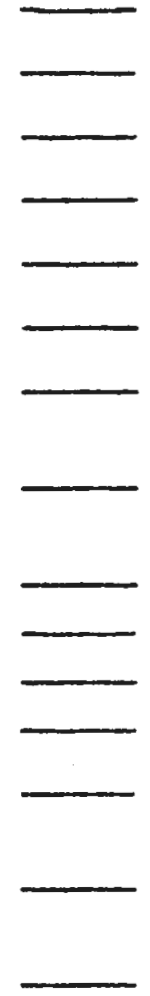

Iho/ wingt trooiced greatest support? 
FIEASE INDICATE ANY OF THE FOLLOHING EXPERIENCES YOU L.AY HAVE HAD BY RATING THEN ACCORDINC TO THE DEGREE YOU FEEL THAT YOU COPED WITI THES AND HOH THEY COMPARED TO THE AliOUNT OF STRESS OF YOUR CHIDOS TERITTHL IIINESS AI:D DEATH.

\section{Ratin= of Coping}

1. didn't cope at all

2. coped only minimally

3. coped fairly vell

4. coped very well

\section{Comparison with Child's Iliness}

1. much less stress

2. little less stress

3. same amount of stress

4. a little more stress

5. much more stress

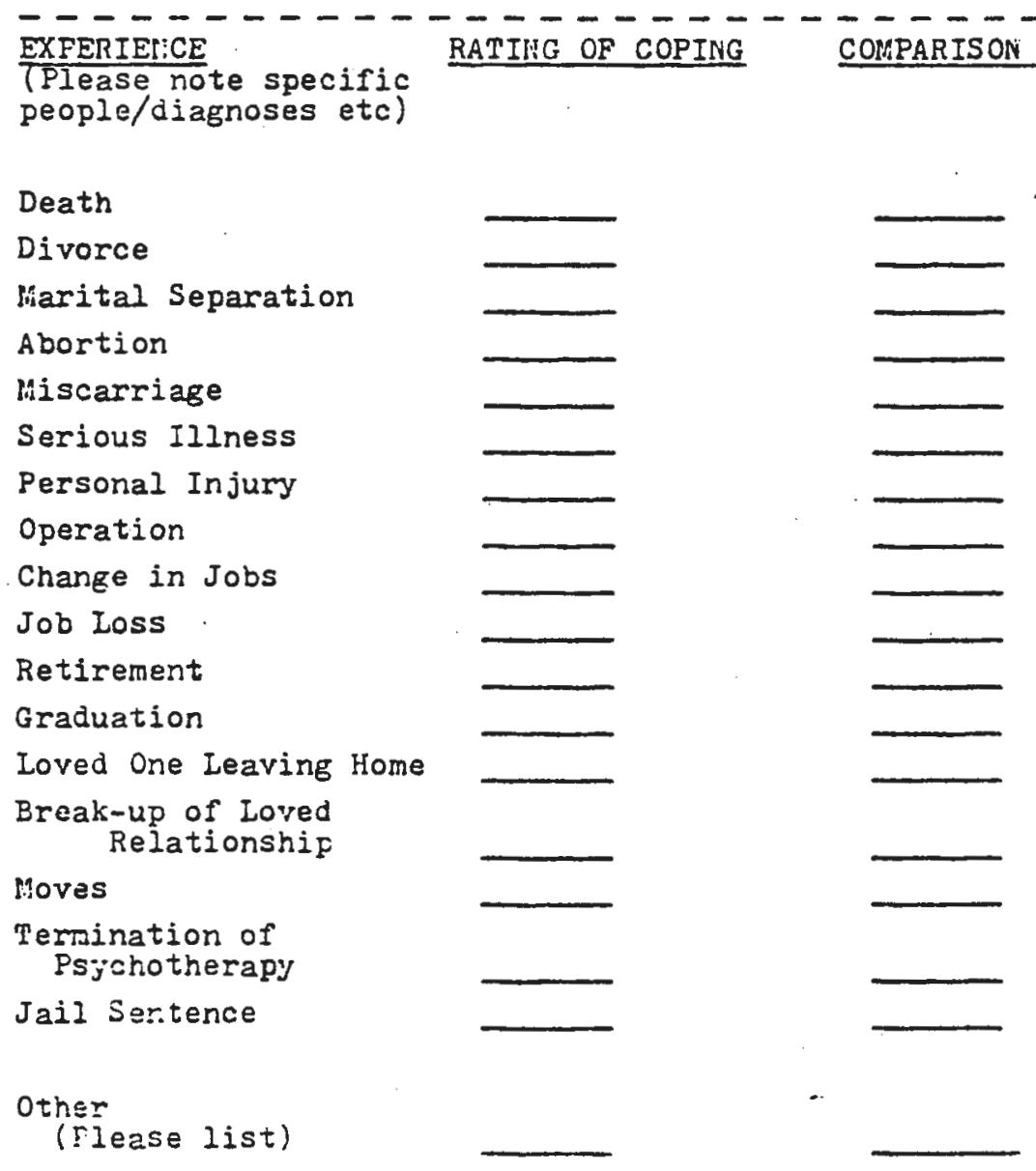


APPENDIX 5--Continued

DURING YOUR CHILD'S HOSPITALIZATIONS KHICH BEHAVIORS, IF AIYY, DID YOU FARTICIPATE IN? Rate Frequency per each week of stay in hospital.

BEAAYIOR

Rooming-In

Visiting

Feeding/Dining with child

Clothing/Dressing

Bathing

Ilelping with Procedures

Discussing IIlness

with child

Others

(Please list)

\section{PARTICIPATION}

o. did not participate

1. did participate
EREQUENCY

Rate frequency in each? day period.

Did your child have an important last wish?

If yes, what was it?

Was it able to be granted by you?

PLEASE RATE THE EXTENT OF YOUR INVOLVEMENT WITH YOUR CHILD WHILE HE/SHE WAS HOSFITALIZED UNDER THE DOCTORS CARE.

1. not involved

2. onl $y$ rinimally involved

3. involved to a significant extent

4. completely involved

PLE $\AA_{S} S E$ RATE YOUR SATISFACTION WITH THE AMOUNT OF YOUR I:IVOLVEMENT

i. dissatisfied

2. partially satisfied

3. mostly satisfied

i. corpletely satisfied 
PLEASE RATE YOUR OVERALI SATISFACTION: HITH THE HEALTH CARE YOUR CHIID RECEIVED FRO!: THE FOLLO!IIIG PEOPLE.

Rating of Satisfaction

i. disatisfied

2. partially satisfied

3. mostly satisfied

4. completely satisfied

SOURCE

Family Physician

Hospital Physicians

Hospital Rurses

Clinic Physicians

Clinic Nurses

Technicians

Others

(Flease list)

General Overall Care
RATING OF SATISFACTION VIITH CARE

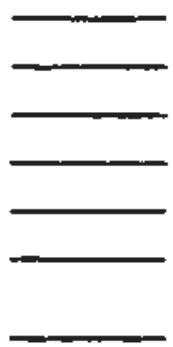


BEFORE ITY CHILD'S ILLNESS I MANAGED TO COPE WITH LIFE

3. not well at all, but with major difficulty

2. not too badly, but with a number of problems

3. adequately, without too many problems

4. very well, without very many problems at all

5. excellently, without any problems

CORPARED TO HOW I WAS COPING IN LIFE PRIOR TO MY CHILD'S ILINESS I FEEL THAT RICHT NONI I AM COPING

1. much worso

2. a little worse

3. at the same level

4. a little better

5. much better

I FEEL THAT I HAVE COPED WITH MY CHILD'S DEATH

1. not well at all, but with major difficulty

2. rot too badly, but with a number of problems

3. adequately, without too meny problems

4. very well, without very many problems at all

5. excellently, without any problems

IF I HAVE PROBIENS THEY SEEM TO BE IN THE AREA(S) OF

드 UE, THE HOST DIFFICULT THING ABOUT HY CHILD'S ILLNESS ANID

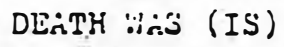

THE THI:E(S) I DID THAT IIELPED RIE COPE THE HOST UAS (WERE) 


\section{SELECTED BIBLIOGRAPHY}

Alby, M., \& Alby, J. Le mèdecin face a la mort de l'enfant (The doctor faces the death of the child). Mèdecine de l'Homme, 1970, 30 , $30-34$

Aldrich, C. K. Some dynamics of anticipatory grief. In B. Schoenberg, A. C. Carr, A. H. Kutscher, D. Peretz, \& I. Goldberg (Eds.), Anticipatory grief. New York: Columbia University Press, 1974, pp. 3-9.

Benfield, D. G., Leib, S. A., \& Reuter, J. Grief response of parents after referral of the critically ill newborn to a regional center. The New England Journal of Medicine, 1976, 294, 975978.

Benfield, D. G., Leib, S. A., \& Vollman, J. Grief response of parents to neonatal death and parent participation in deciding care. Pediatrics, 1978, 62(2), 171-177.

Binger, C. M., Ablin, A. R., Feuerstein, R. C., Kushner, J. H., Zoger, S., \& Mikkelsen, C. Childhood leukemia: Emotional impact on patient and family. New England Journal of Medicine, 1969, $280(8), 414-418$.

Bowlby, J. Separation: Anxiety and anger. New York: Basic Books, Inc., 1973.

Bozeman, M. F., Orbach, C. E., \& Sutherland, A. M. Psychological impact of cancer and its treatment. III. The adaptation of 
mothers to the threatened loss of their children through leukemia. Part I. Cancer, 1955, 8, 1-19.

Burton, L. Tolerating the intolerable--the problems facing parents and children following diagnosis. In L. Burton (Ed.), Care of the child facing death. London: Routledge \& Kegan Paul, 1974 (a), pp. 16-38.

- The family coping with a heavy treatment regime. In L.

Burton (Ed.), Care of the child facing death. London: Routledge \& Kegan Paul, $1974(\mathrm{~b}), \mathrm{pp} .74-84$.

Cain, A. C., \& Cain, B. S. On replacing a child. Journal of the American Academy of Child Psychiatrists, 1964, 3, 443-456.

Cannell, C., \& Kahn, R. Interviewing. In S. Lindzey \& E. Aronson (Eds.), The Handbook of Social Psychology. 2nd ed., (Vol. 2), Reading, Massachusetts: Addison-Wesley, 1968, pp. 526-595.

Chodoff, P., Friedman, S. B., \& Hamburg, D. A. Stress, defenses and coping behavior: Observations in parents of children with malignant disease. American Journal of Psychiatry, 1964, $\underline{120}, 743-749$.

Clayton, P. J., Desmarais, L., \& Winokur, G. A study of normal bereavement. American Journal of Psychiatry, 1968, 125, 64-74.

Clayton, P. J., Halikas, J. A., Maurice, W. L., \& Robbins, E. Anticipatory grief and widowhood. British Journal of Psychiatry, $1973,122,47-51$.

Easson, w. M. The dying child. Springfield, Illinois: Charles C. Thomas Publishers, 1970.

Freud, S. Mourning and melancholia (1917). Standard Edition of the Complete Psychological Works of Sigmund Freud (Vol. 14). 
London: Hogarth Press, 1957, pp. 237-258.

- Inhibitions, symptoms, and anxiety (1926). Standard Edition

of the Complete Psychological Works of Sigmund Freud (Vol. 20).

London: Hogarth Press, 1959, pp. 77-178.

Frey, D. Science and the single case in counseling research. Personnel and Guidance Journal, 1978, 56, 263-268.

Friedman, S. B. Care of the family of the child with cancer. Pediatrics, $1967,40,498-504$.

Friedman, S. B., Chodoff, P., Mason, J. W., \& Hamburg, D. A. Behavioral observations on parents anticipating the death of a child. Pediatrics, 1963, 32, 610-625.

Fulton, R., \& Fulton J. A psychosocial aspect of terminal care: Anticipatory grief. Omega, 1971, 2, 91-99.

Furman, E. Comment on J. Kennell and M. Klaus "Caring for the parents of an infant who dies." In M. Klaus \& J. Kennell (Eds.), Maternal-infant bonding, St. Louis: C. V. Mosby Co., 1976, pp. 233-235.

Futterman, E. H., Hoffman, I., \& Sabshin, M. Parental anticipatory mourning. In B. Schoenberg, A. C. Carr, D. Peretz, \& A. H. Kutscher (Eds.), Psychosocial aspects of terminal care. New York: Columbia University Press, 1972, pp. 243-272.

Geis, D. P. Mothers' perceptions of care given their dying children. American Journal of Nursing, 1965, 65(Feb.), 105-107.

Gerber, I., Rusalem, R., Hannon, N., Battin, D., \& Arkin, A. Anticipatory grief and aged widows and widowers. Journal of Gerontology, 1975, 30(2), 225-229. 
Glaser, B., \& Strauss, A. The social loss of dying patients. American Journal of Nursing, 1964, 63, 119-121.

Glick, I. O., Weiss, R. S., \& Parkes, C. M. The first year of bereavement. New York: John Wiley \& Sons, 1974.

Goldberg, S. B. Family tasks and reactions in the crisis of death. Social Casework, 1973, July, 398-405.

Goldman, L. Toward more meaningful research. Personnel and Guidance Journal, 1977, 55, 363-368.

Gorer, G. Death, grief, and mourning. London: Cresset Press, 1965. Hamovitch, M. The parent and the fatally ill child. Los Angeles: Delmar, 1964.

Heller, D. B., \& Schneider, C. D. Interpersonal methods for coping with stress: Helping families of dying children. Omega, $1978, \underline{8}(4), 319-331$.

Herter, F. In J. A. Knight \& F. Herter (authors), Anticipatory grief. In A. H. Kutscher (Ed.), Death and bereavement. Springfield, Illinois: Charles C. Thomas, Publishers, 1969, pp. 196-201. Jackson, E. N. Comment in N. Linzer (Ed.), Understanding bereavement and grief. New York: Yeshiva University Press, 1977, pp. 187190.

Janis, I. L. Psychological effects of warnings. In G. W. Baker \& D. W. Chapman (Eds.), Man and society in disaster. New York: Basic Books, 1962 .

Kalish, R. A. The effects of death upon the family. In L. Pearson (Ed.), Death and dying. Cleveland: Press of Case Western Reserve University, 1969. 
- Dying and preparing for death: A view of families. In

H. Feifel (Ed.), New meanings of death. New York: McGrawHill, 1977, pp. 216-232.

Kalish, R. A., \& Reynolds, D. K. Death and ethnicity: A psychocultural investigation. Los Angeles: University of Southern California Press, 1976.

Kennell, J. H. \& Klaus, M. H. Caring for parents of an infant who dies. In J. H. Kennell \& M. H. Klaus (Eds.), Maternalinfant bonding. St. Louis: C. V. Mosby Co., 1976, pp. 209-239.

Kennell, J. H., slyter, H., \& Klaus, M. H. The mourning response of parents to the death of a newborn infant. The New England Journal of Medicine, $1970,283(7), 344-349$.

Kliman, A. S. Comment in Section on "The Parents," in N. Linzer (Ed.), Understanding bereavement and grief. New York: Yeshiva University Press, 1977, pp. 191-192.

Knudson, A. G., \& Natterson, J. M. Participation of parents in the hospital care of fatally ill children. Pediatrics, 1960, $26,482-490$

Lang, P: A., \& Oppenheimer, J. R. The influence of social work when parents are faced with the fatal illness of a child. Social Casework, 1968, 49(3), 161-166.

Levitz, I. N. Comment in Section on "The Parents," in N. Linzer (Ed.), Understanding bereavement and grief. New York: Yeshiva University Press, 1977, pp, 179-186.

Lindemänn, E. Symptomatology and management of acute grief. American Journal of Psychiatry, 1944, 101, 141-148. 
Maddison, D. C. The relevance of conjugal bereavement for preventative psychiatry. British Journal of Medical Psychology, $1968, \underline{41}, 223-233$.

Maddison, D. C., \& Viola, A. The health of widows in the year following bereavement. Journal of Psychosomatic Research, 1968, 12, 297-306.

Maddison, D. C. \& Walker, W. L. Factors affecting the outcome of conjugal bereavement. British Journal of Psychiatry, 1967, $113,1057$.

Marris, P. Widows and their families. London: Routledge \& Kegan Paul, 1958 .

McCollum, A. T., \& Schwartz, A. H. Social work and the mourning parent. Social Work, 1972, 17(1), 25-36.

Morrissey, J. R. Children's adaptation to fatal illness. Social Work, $1963,8,81-88$.

Natterson, J. M., \& Knudson, A. G. Observations concerning fear of death in fatally ill children and their mothers. Psychosomatic Medicine, 1960, 22, 456-465.

Nolfi, M. W. Families in grief; The question of casework intervention. Social Work, $1967, \underline{12(4), 40-46 .}$

Orbach, C. E., Sutherland, A. M., \& Bozeman, M. F. Psychological impact of cancer and its treatment. III. The adaptation of mothers to the theatened loss of their children through leukemia. Part II. Cancer, 1955, 8, 20-33.

Parkes, C. M. The first year of bereavement. Psychiatry, 1970, 33, $444-467$. - Bereavement: Studies of grief in adult life. New York:

International Universities Press, Inc., 1972. 
- Determinants of outcome following bereavement. Omega, $1975, \underline{6}(4), 303-323$.

Peretz, D. Reaction to loss. In B. Schoenberg, A. C. Carr, D. Peretz, \& A. H. Kutscher (Eds.), Loss and grief: Psychological management in medical practice. New York: Columbia University Press, 1970, pp. 20-35.

Prugh, D. G., Staub, E. M., Sands, H. H., Kirschbaum, R. M., \& Lenihan, E. A. A study of the emotional reactions of children and families to hospitalization and illness. American Journal of Orthopsychiatry, 1953, 23, 70-106.

Rando, T. A. Parental Experience Assessment Form, U.S.A. Copyright, 1979.

Rees, W. D., \& Lutkins, S. G. Mortality of bereavement. British Medical Journal, 1967, 4, 13-16.

Richmond, J. B., \& Waisman, H. A. Psychological aspects of management of children with malignant diseases. American Journal of Diseases in Children, 1955, 89, 42-47.

Rosenbaum, M. Emotional aspects of wartime separation. Family, 1944, $24,337-341$.

Sanders, C. M. Typologies and symptoms of adult bereavement. Unpublished doctoral dissertation, University of South Florida, 1977.

Sanders, C. M., Mauger, P. A., \& Strong, P. N. The Grief Experience Inventory, U.S.A. Copyright, 1978.

Schiff, H. S. The bereaved parent. New York: Crown Publishers, Inc., 1977. 
Schwab, J. J., Chalmers, J. M., Conroy, S. J., Farris, P. B., \& Markush, R. E. Studies in grief: A preliminary report. In B. Schoenberg, I. Gerber, A. Wiener, A. H. Kutscher, D. Peretz, \& A. C. Carr (Eds.), Bereavement: Its psychosocial aspects. New York: Columbia University Press, 1975, pp. 82-87.

Schneidman, E. S. The college student and death. In H. Feifel (Ed.), New meanings of death. New York: McGraw-Hill, 1977, pp. $68-86$.

Schwartz, A. M. Comment in Section on "The Parents," in N. Linzer (Ed.), Understanding bereavement and grief. New York: Yeshiva University Press, 1977, pp. 193-196.

Silverman, P. R. The impossibility of anticipatory grief. Paper presented at the Foundation of Thanatology, New York, 1972. Solnit, A. J., \& Green, M. Psychological considerations in the management of deaths on pediatric hospital services. I. The doctor and the child's family. Pediatrics, 1959, 24, 106-112.

Spinetta, J. J., Swarner, J. A., Kard, T. L., \& Sheposh, J. P. Effective parental coping following the death of a child from cancer. Manuscript submitted for publication, 1978.

Stehbens, J. A., \& Lascari, A. D. Psychological follow-up of families with childhood leukemia. Journal of Clinical Psychology, $1974,30(3), 394-397$.

Stephens, S. Bereavement and the rebuilding of family life. In L. Burton (Ed.), Care of the child facing death. London: Routledge \& Kegan Paul, 1974, pp. 207-217. 
Sue, D. Single case approaches. (Editorial). Personnel and Guidance Journal, 1978, 56, 260.

Thoreson, C. Making better science, intensively. Personnel and Guidance Journal, 1978, 56, 279-282.

Townes, B. D., \& Wold, D. A. Childhood leukemia. In E. Mansell Pattison (Ed.), The experience of dying. Englewood Cliffs, New Jersey, Prentice Hall, Inc., 1979, pp. 138-143.

Townes, B. D., Wold, D. A., \& Holmes, T. H. Parental adjustment to childhood leukemia. Journal of Psychosomatic Research, 1974, $18,9-14$

Travis, G. The experience of chronic illness in childhood. California: Stanford University Press, 1976.

Vachon, M. L. S. Grief and bereavement following the death of a spouse. Canadian Psychiatric Association Journal, 1976, $\underline{21}, 35-44$.

Vachon, M. L. S., Formo, A., Freedman, K., Lyall, W. A., Rogers, J., \& Freeman, S. J. Stress reactions to bereavement. Essence, $1976, I(1), 23-33$.

Volkart, E. H., \& Michael,S. T. Bereavement and mental health. In A. J. Leighton, J. A. Clausen, \& R. N. Wilson (Eds.), Explorations in social psychiatry. New York: Basic Books, 1957, pp. 281-304.

Wallace, J. Comment on "Family Functioning." In "Care of the child with cancer." Pediatrics, 1967, 40, 515-517.

Wiener, J. M. Reaction of the family to the fatal illness of the child. In B. Schoenberg, A. C. Carr, D. Peretz, \& A. H. Kutscher (Eds.), Loss and grief: Psychological management 
in medical practice. New York: Columbia University Press, 1970, pp. 87-101.

Willis, D. J. The families of terminally ill children: Symptomatology and management. Journal of Clinical Child Psychology, 1974, $\underline{3}(2), 32-33$.

Wolff, C. T., Friedman, S. B., Hafer, M. A., \& Mason, J. W. Relationship between psychological defenses and mean urinary 17-hydroxycorticosteroid excretion rates: I. A predictive study of parents of fatally ill children. Psychosomatic Medicine, 1964, 26, 576-591. 